\title{
Job Search, Emotional Well-Being, and Job Finding in a Period of Mass Unemployment: Evidence from High-Frequency Longitudinal Data
}

ABSTRACT This paper presents findings from a survey of 6,025 unemployed workers who were interviewed every week for up to 24 weeks in the fall of 2009 and winter of 2010. We find that the amount of time devoted to job search declines sharply over the spell of unemployment; we do not observe a rise in job search or job finding around the time that extended unemployment insurance (UI) benefits expire. The workers in our survey express much dissatisfaction and unhappiness with their lives, and their unhappiness rises the longer they are unemployed. The unemployed appear to be particularly sad during episodes of job search, and they report feeling more sad during job search the longer they are unemployed. We also find that in the aftermath of the Great Recession the exit rate from unemployment was low at all durations and declined gradually over the spell of unemployment. Both the amount of time devoted to job search and the reservation wage help predict early exit from UI.

F or the first time since the early 1980s, mass unemployment is a problem in the United States. The unemployment rate reached 10.1 percent in October 2009, more than double its rate a year and a half earlier. In addition, in early 2011 nearly half of the unemployed had been out of work for 27 weeks or longer, and the mean duration of an ongoing spell of unemployment was around 9 months. Extended unemployment carries with it the risk that many of those out of work will lose relevant skills and become discouraged from looking for work, raising the specter of hysteresis 
and permanently higher joblessness. This paper provides evidence on the job search process, the effectiveness of job search activities, the emotional well-being of the unemployed, and the likelihood of finding a job and leaving unemployment insurance, using new survey data collected in the fall of 2009 and winter of 2010 from a large sample of unemployed workers. We devote particular attention to measuring how job search activity and emotional well-being evolve over the course of unemployment for a given set of individuals, to assess whether the unemployed become discouraged.

Research has long found that the exit rate from unemployment falls over the spell of unemployment (see, for example, Kaitz 1970). However, it is difficult to infer whether this declining hazard rate is due to changes in the behavior of the unemployed over time (for example, because discouragement leads to less job search and thus a lower exit rate) or to changes in the composition of the sample of unemployed workers (that is, heterogeneity bias, because those who search most intensively are more likely to find a job sooner). ${ }^{1}$ In addition, research for the United States has found that part of the reason for the observed declining hazard rate is that some workers are recalled to previous jobs (Katz and Meyer 1990).

Our study is distinguished from past work by the use of high-frequency longitudinal data on search activity. We designed and implemented a largescale weekly survey of unemployment insurance (UI) benefit recipients in New Jersey. More than 6,000 unemployed workers participated in the survey for up to 12 weeks, and the long-term unemployed (those unemployed 60 weeks or longer at the start of the survey) were surveyed for an additional 12 weeks. A total of 39,201 weekly interviews were completed. We also have restricted access to administrative data from the UI system, which is important given that our survey had a high rate of nonresponse. New Jersey's unemployment rate closely mirrored the national average in 2009 and 2010 (figure 1); thus, the results shed light on job search behavior in the worst labor market environment in decades. Nationwide, the number of workers claiming state and federal UI benefits at the start of our survey in October 2009 was nearly two-thirds as large as the total number of unemployed workers estimated by the Bureau of Labor Statistics (BLS). Thus, the behavior of UI recipients represents that of a large share of the unemployed population.

1. See Devine and Kiefer (1991) and Van den Berg and van Ours (1994) for a summary of the literature that attempts, using data on unemployment spells, to distinguish between heterogeneity bias and changes in behavior as causes of the declining exit rate. 
Figure 1. Unemployment Rate, Seasonally Adjusted, New Jersey and United States, 2008-10

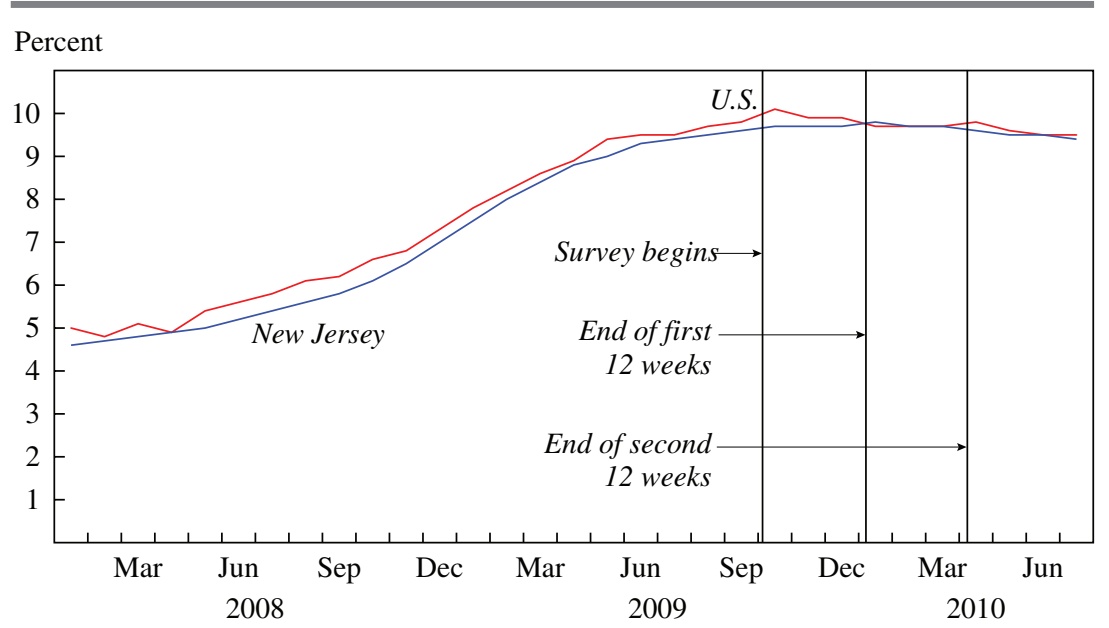

Source: Authors' tabulations of Bureau of Labor Statistics data.

We focus on individuals' job search activity over the spell of unemployment. We also examine the relationship between job search and the likelihood of receiving a job offer and exiting UI, and subjective well-being over the spell of unemployment. ${ }^{2}$ Our main conclusions are the following: first, job search declines steeply over the spell of unemployment for a given set of individuals; second, after a period of rapidly rising unemployment, workers who lost their jobs at different times have strikingly different characteristics, and comparisons across cohorts of workers who lost their jobs at different times are prone to bias (another source of heterogeneity bias); third, unemployed workers express much dissatisfaction with their lives, and their self-reported mood worsens the longer they are unemployed, whereas life satisfaction stays relatively constant; fourth, the unemployed appear to be particularly sad during the hours they spend actually searching for a job, and they find job search more emotionally onerous, if anything, as the duration of unemployment increases; fifth, in the wake of the Great Recession the exit rate from unemployment was low at all durations of unemployment and declined gradually over the spell of unemployment;

2. Given that Elsby, Hobijn, and Şahin (2010) find the outflow rate from unemployment to be the most important determinant of future reductions in the unemployment rate, an investigation of the relationship between job search and job finding is particularly timely. 
sixth, the choice of job search activities and the amount of search time do not bear a straightforward relationship with the likelihood of receiving a job offer, but job search time and the reported reservation wage do predict early exit from UI, although unmeasured characteristics of workers could distort the estimated relationships; finally, we find little evidence that exhaustion of extended UI benefits is associated with an increase in job search activity or in job offers.

The next section describes the data used in our study and assesses the effect of survey nonresponse. Section II summarizes relevant features of UI as it was in effect in New Jersey during the fall of 2009 and the spring of 2010. Section III examines the pattern of job search behavior over the spell of unemployment. Section IV considers the subjective well-being of the unemployed, devoting particular attention to psychological well-being during periods of job search. Section V considers the relationship between job search activity and the incidence of job offers and early exit from UI benefit receipt. Section VI concludes.

\section{Description of the Survey}

In early October 2009 the Princeton University Survey Research Center (PSRC) obtained a complete list of the roughly 360,000 individuals receiving UI benefits in New Jersey as of September 28, 2009. The data were subjected to a stratified random sampling procedure to obtain a sample of 63,813 UI recipients. The strata consisted of duration-of-unemployment intervals interacted with the availability of an e-mail address. Long-term unemployed workers and those with e-mail addresses on file were oversampled. The sampled individuals were invited to participate in an online survey for a period of 12 weeks, with weekly interviews on their job search activities, time use, reservation wages, job offers, food consumption, and other variables. Participants were paid $\$ 20$ to $\$ 40$ for participating in the survey. Weekly interviews of the long-term unemployed in the sample took place for an additional 12 weeks, for a total of 24 weeks.

The questionnaire consisted of two parts: an entry survey, administered in the first week, with demographic, income, and wealth questions, and a shorter follow-up survey, administered in the first and each subsequent week, that focused on job search activities, the reservation wage, and receipt of job offers. ${ }^{3}$ The appendix describes the survey and the questionnaire in detail.

3. The survey questionnaire can be downloaded at www.princeton.edu/ psrc/NJWS/ ENTRY.pdf and www.princeton.edu/ psrc/NJWS/WEEKLY.pdf. 
One concern is that the response rate was low. Only 10 percent of the sampled individuals who were contacted participated in the entry wave of the survey, and respondents in the entry survey participated in only about 40 percent of the weekly follow-up surveys after the first week. Fortunately, the administrative data file contains a rich set of demographic variables that we could use to create sample weights to adjust for nonresponse, and the characteristics of respondents could be compared with the universe along a number of relevant dimensions, including preunemployment earnings. ${ }^{4}$ In addition, we were able to match information on the duration of benefit receipt as of April 2010 for the entire sample frame; thus, we can compare the UI exit rate for the sample frame with that for the respondents.

Table 1 summarizes the characteristics of the universe of New Jersey UI recipients, the sample frame, and the respondents. In addition, the last two columns report estimates that adjust for strata weights and nonresponse weights. Compared with the universe, the (unweighted) respondents were more likely to be college graduates (41 percent versus 19 percent) and female (52 percent versus 45 percent) and to have had higher annual earnings in the base period $(\$ 48,994$ versus $\$ 35,335)$. The weighted sample and the universe are very similar in terms of demographic characteristics, however, which is not entirely surprising given that demographic variables were used to create nonresponse weights. Weighted-average earnings in the base year, typically defined as the first four of the five quarters before the UI claim, at $\$ 37,960$ are reasonably close to average base-year earnings in the universe, which is more reassuring because earnings were not used to create weights. In addition, the industry composition of the weighted respondents is similar to that of the universe, although construction workers are somewhat underrepresented among the respondents. Finally, weeks of UI benefits paid are slightly lower for the weighted respondents than for the universe, but similar to those in the weighted stratified sample frame. As a whole, the weighted survey participants and the universe appear to be similar along many dimensions despite the low response rate.

Additional evidence suggesting that the low response rate did not significantly skew the sample is provided in figure 2 , which shows the Kaplan-Meier nonparametric UI exit rate by duration of unemployment as measured by weeks of UI benefits paid. The hazard rates are reported

4. Sample weights were derived by estimating a logit model for participation in the survey each week, and predictors were the demographic variables listed in the bottom panel of table 1. It was necessary to weight the sample frame to reflect the universe as well because of oversampling of certain strata. See the appendix for more details on the construction of both sets of weights. 


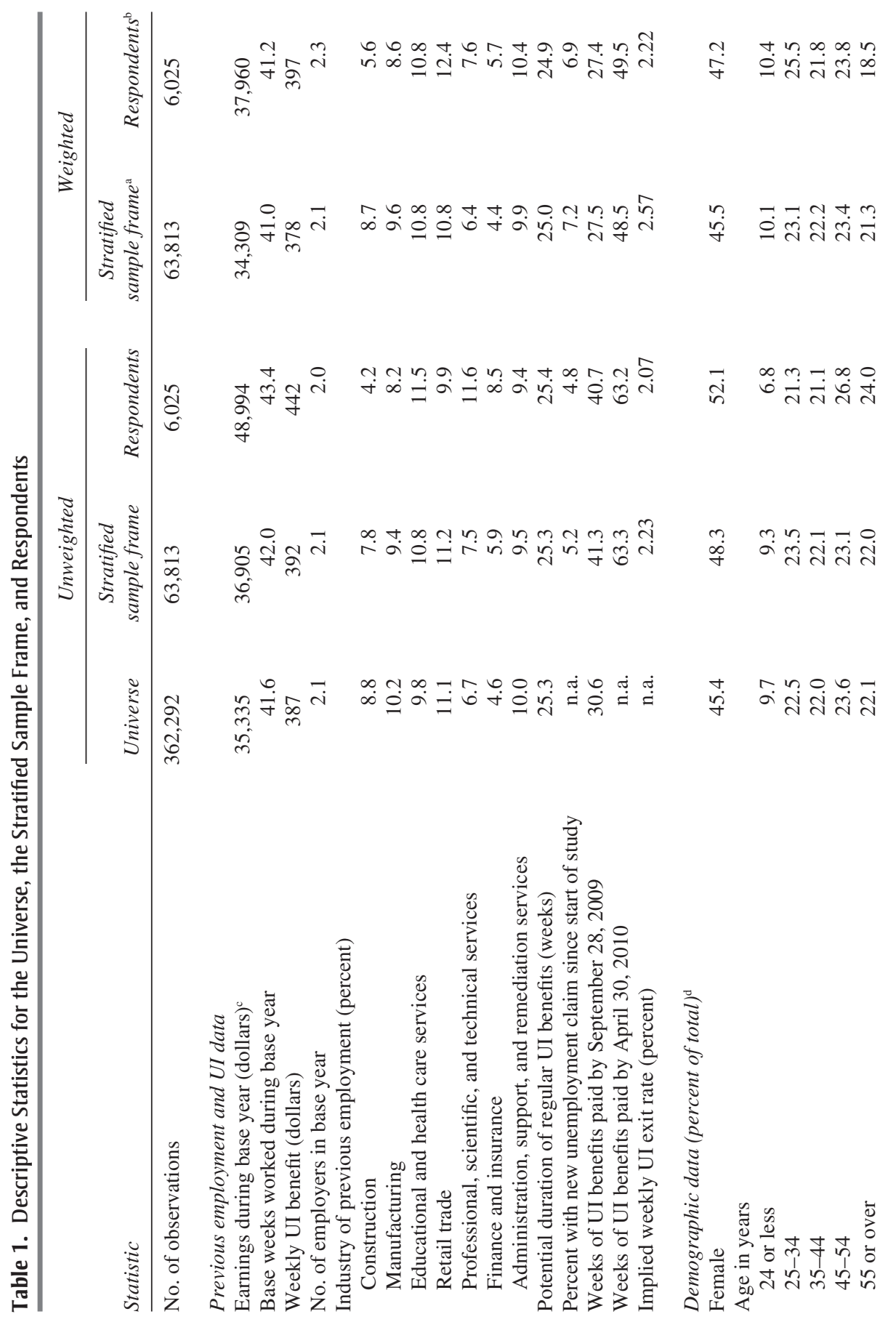




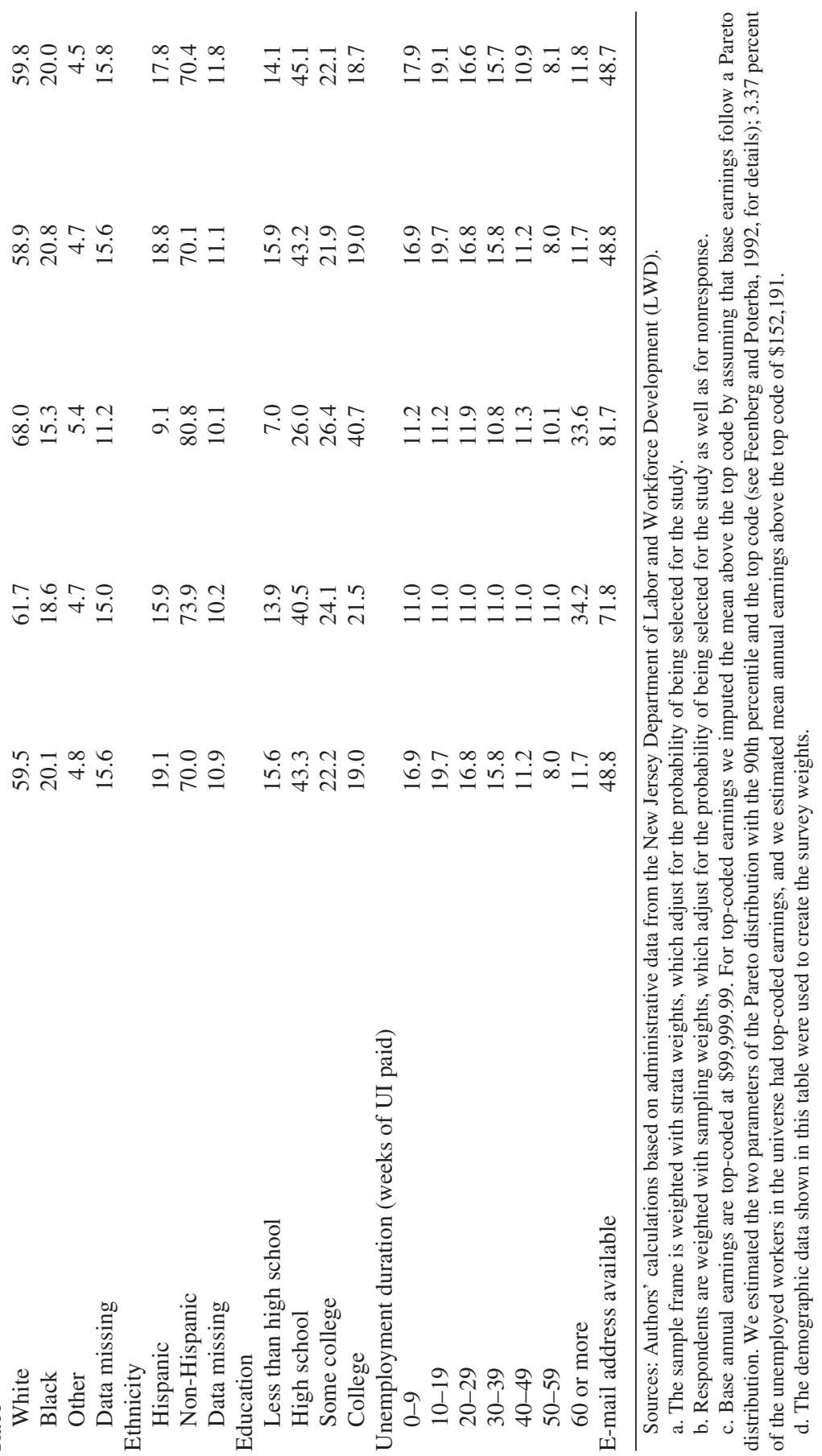


Figure 2. Kaplan-Meier UI Weekly Exit Rate, by Unemployment Duration ${ }^{\mathrm{a}}$

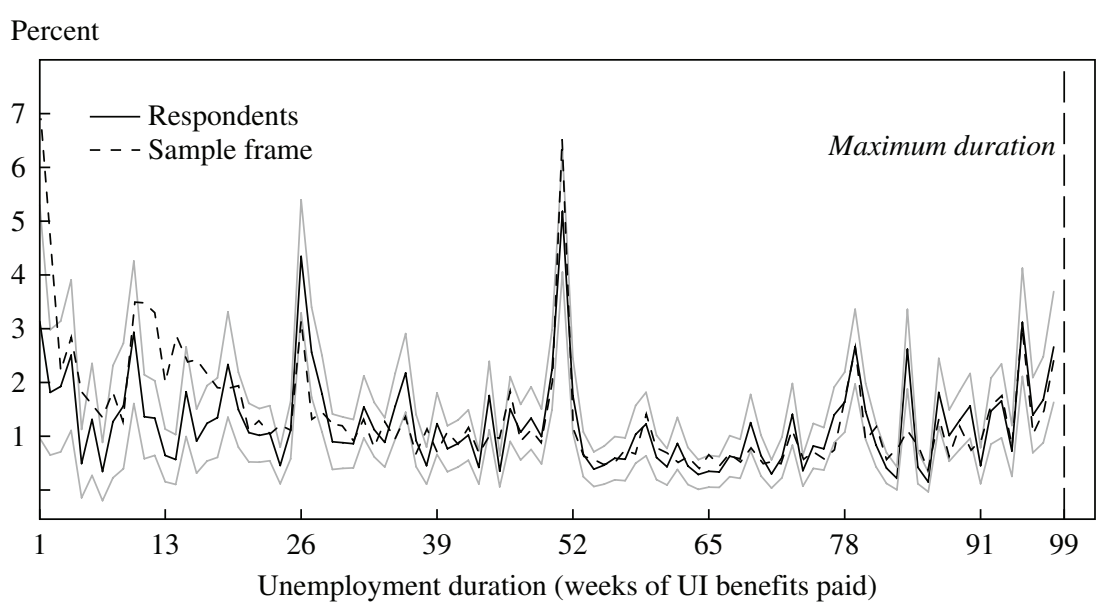

Source: Authors' calculations based on administrative data from LWD.

a. Hazards are weighted with survey weights for respondents and with strata weights for the sample frame. Shaded lines indicate 95 percent confidence bands for respondents' hazard rate. Confidence bands for the sample frame are not shown because the standard errors are usually small (around 0.001), but they are higher for less than 20 weeks of UI benefit duration.

separately for the stratified sample frame and for respondents (both weighted). The hazard rate at duration $t$ is defined as the fraction of UI spells ongoing at the start of week $t$ that ended during week $t$. A spell could end because a worker found a job or because the worker was no longer eligible for benefits. Spells were considered censored if the date of the last UI payment was in the week of April 30, 2010 (the date we received the updated administrative data on weeks of UI benefits paid) or later. ${ }^{5}$ Figure 2 shows that the weekly

5. One minor complication is that the universe consists of all individuals who were unemployed at the end of September 2009 and thus includes some unemployed workers who filed UI claims as early as May 2006, but those who filed claims in May 2006 or later and then exited UI before the end of September 2009 are not included in our universe file. Typically, studies that analyze UI exit rates (such as Moffitt 1985 and Meyer 1990) draw their sample from the newly unemployed (the inflow), not the stock of unemployed, and thus do not encounter this sample truncation problem. The issue can be easily addressed by using only information on UI spell duration from the start of the study and thereafter. In other words, individual UI spells were included in the number of ongoing spells only for durations equal to or greater than the duration at the beginning of the study. For example, if an unemployed worker had 60 weeks of UI benefits paid at the start of the study, he or she was not included in the number of ongoing spells in weeks 1 through 59, but only in week 60 and onward. Including this person in the number of ongoing spells before week 60 , in the absence of data on unemployed workers who filed claims at the same time but exited unemployment before week 60, would severely downwardly bias the hazard at lower durations. 
exit rate for the respondents closely tracks that of the sample frame, which is within the 95 percent confidence interval of the exit rate for the respondents at almost all durations. A notable exception, however, occurs in the first couple of weeks, when the hazard rate for the sample frame is around twice that for the respondents. This disparity probably arises because some workers found employment shortly after they filed their UI claim and thus were unlikely to respond to our survey. ${ }^{6}$ Over most durations, however, the hazard rates are similar.

Figure 2 displays the typical pattern of a declining hazard rate at the beginning of a spell of unemployment and a flatter rate thereafter. The hazard rate profile is flatter than has been found in other studies (such as Katz and Meyer 1990), however. In addition, the weekly UI exit rate is lower than has been found in previous work. For example, Katz and Meyer (1990), using data for Missouri in 1979-81, report UI exit rates that start at around 10 percent and vary from 4 to 8 percent per week in most subsequent weeks, whereas the hazard rate in figure 2 begins at around 7 percent and quickly falls below 2 percent in most weeks. These differences probably reflect the weak job market in late 2009 and the low incidence of recall to one's previous job. $^{\text {? }}$

Figure 2 also shows notable spikes in the hazard rate at week 26 and week 51. The reason for the spike at week 26 is that the eligibility requirements for extended UI benefits are slightly more stringent than the requirements for regular benefits, which for most workers last 26 weeks. ${ }^{8}$ Therefore, a small number of recipients exhausted benefits at week 26 . The spike at week 51 arises because workers are tested for continued eligibility for extended benefits at the end of each benefit year ( 52 weeks after the UI

6. There was a 2- to 3-week gap between the date on which the data were extracted and the date on which invitations to participate in the survey were sent out.

7. Katz and Meyer (1990) find a lower hazard rate that does not vary with unemployment duration for those who are not recalled to their previous job.

8. The earnings requirement for regular UI benefits in New Jersey in 2009 was 20 base weeks of work (earning a minimum of $\$ 143$ each week) or total earnings of at least 1,000 times the state minimum wage ( $\$ 7.25$ per hour in New Jersey as of July 2009) in the base year. The earnings requirement for extended benefits (both the federal and the state program) is again 20 base weeks of work (earning a minimum of $\$ 143$ each week) or 40 times the individual's weekly benefit amount on his or her UI claim. This implies that unemployed workers who qualified for regular benefits because of total earnings in excess of $\$ 7,300$ but had less than 20 base weeks worked may not qualify for extended benefits if the weekly benefit amount on their regular UI claim was high. For example, for a worker with earnings of $\$ 7,300$, the weekly benefit amount on the regular claim had to be lower than $\$ 182.50$ to meet the extended benefit earnings requirement. 
claim was filed). ${ }^{9}$ We do not see a spike in the job finding rate at either 26 or 51 weeks in our survey data, and so the spikes most likely result from these program requirements. Regardless of the reason for the spikes, the weighted sample appears to have similar prospects of leaving UI as the broader sample frame that we sought to interview, suggesting that nonresponse was fairly random with respect to job market prospects.

\section{Unemployment Insurance in New Jersey in 2009-10}

New Jersey has one of the more generous UI systems in the United States. The benefit amount in 2009 was 60 percent of previous earnings up to a maximum weekly benefit of $\$ 584 .{ }^{10}$ The maximum duration of regular UI benefits varies between 1 and 26 weeks, depending on how many weeks the claimant worked in the base year. Most unemployed workers in New Jersey qualify for the maximum duration: in our data, 87 percent qualified for 26 weeks of regular benefits, and only 3 percent qualified for fewer than 20 weeks.

In New Jersey, UI recipients are allowed to work at part-time jobs while receiving benefits. Earnings from part-time jobs are deducted from the benefit amount, with an earnings disregard of 20 percent of the weekly benefit. This implies that UI recipients who work part time can keep weekly earnings of up to 20 percent of the weekly benefit amount; any earnings in excess of that are deducted from the weekly benefit. Thus, those who earn more than 120 percent of their weekly benefit do not qualify for benefits in that week. A worker who works part time during a period of unemployment may draw benefits for a longer period than the maximum duration for an otherwise comparable beneficiary who does not work at all. The reason

9. One of the requirements for eligibility for extended UI benefits is that the worker not be eligible for a new claim of regular UI benefits. A small number of individuals qualify for a new regular UI claim because earnings from the initial base year usually exclude the quarter just before the start of the UI spell, but earnings in that quarter and part-time earnings during the initial unemployment spell contribute toward eligibility for a new regular claim. The spike at 51 weeks probably occurs because the benefit rate drops substantially when unemployed workers qualify for a new regular claim (because of lower earnings in the new base year), and thus individuals may not find it worthwhile to file a new regular UI claim and instead allow their benefits to expire.

10. Unemployed workers can also qualify for a dependents' allowance for up to three dependents (children under the age of 19, children under the age of 22 if in school full-time, and a spouse). The allowance is 7 percent of the weekly benefit for the first dependent and 4 percent each for the second and the third dependent. However, the maximum weekly benefit is not adjusted for dependents. 
is that the state specifies a maximum dollar amount that can be received for a given UI claim (the maximum benefit amount), and those who work part time can receive benefits for a longer period of time because their weekly benefit amount is reduced.

The duration of UI benefits is affected by federal extensions as well as by state policy. In June 2008 the federal government established the Emergency Unemployment Compensation (EUC) program, which entitled UI recipients in all states to an additional 13 weeks of extended benefits, and in November 2008 EUC was extended to 33 weeks in high-unemployment states, of which New Jersey was one. The American Recovery and Reinvestment Act, enacted in February 2009, extended the expiration date of EUC to December 31, 2009, and raised weekly benefits by $\$ 25$. In addition to the federal extension, New Jersey activated the state Extended Benefits (EB) program on March 15, 2009, which initially provided for an additional 13 weeks of UI benefits, and then for 20 weeks on May 3, 2009.

At the time interviewing for our survey commenced on October 13, 2009, UI recipients in New Jersey were eligible for up to 79 weeks of benefits, counting regular benefits, EUC, and EB. ${ }^{11}$ On November 6, 2009, the federal government increased EUC benefits by an additional 20 weeks, increasing the maximum duration in New Jersey from 79 to 99 weeks. The increase to 99 weeks probably came as a surprise to many workers. This extension was retroactive in the sense that workers who had exhausted the 79 weeks of benefits for which they were eligible before the extension to 99 weeks became eligible for another 20 weeks of benefits. The extension was effective in New Jersey as of November 8, 2009.

We refer to the 640 individuals in our sample who had exhausted benefits before November 8 and then qualified for the 20 -week extension as having "lapsed benefit receipt" in the interim period when they were not receiving benefits. (Some 1,264 weekly surveys were completed during periods when benefits had lapsed.) We refer to the 224 individuals in our sample who reached 99 weeks of paid benefits and then were no longer eligible for benefits as having "exhausted benefits" after week 99. (Some 346 weekly interviews were completed by individuals after they had exhausted benefits.) We estimate the effect of the availability of an additional 20 weeks of EUC

11. Note that the weekly benefit amount on EUC as well as on the EB program was the same as for regular benefits, and the maximum potential duration was less than 79 weeks if a worker qualified for less than 26 weeks of regular benefits. The potential duration of extended benefits is nearly proportional to the potential duration of regular UI benefits. The exact formulas can be found at lwd.state.nj.us/labor/ui/content/ui_benefit_extensions.html. 
in our sample by including a dummy variable indicating weeks after the extension took effect on November 8, 2009.

\section{Job Search over the Spell of Unemployment}

In a standard job search model with stationarity (for example, that of Mortensen 1977), the amount of time and effort that job seekers devote to searching for a job should be constant or rising over the spell of unemployment, as benefits are exhausted and assets are run down. We provide the first test of this prediction with longitudinal data. We have two measures of job search: information from a time diary for the day preceding the interview, and responses to questions about time spent on various search activities in the preceding week.

According to the time diary data, the average worker spent 70 minutes a day searching for a job on weekdays and 65 minutes a day over all days. (See the appendix for a detailed description of data coding procedures.) This is close to the average amount of time that unemployed workers who appear eligible for UI benefits reported searching for a job in the 2009 American Time Use Survey (ATUS).

The responses to the weekly recall questions on job search activitieswhich asked for the amount of time spent on 11 categories of search activities in the last week-imply that workers spend significantly more time searching for a job than the time diary data indicate. The average reported amount of time spent searching was 11.5 hours per week, or 100 minutes per day. ${ }^{12}$ It is unclear whether the week-long recall questions lead respondents to exaggerate their search time or whether listing the specific activities results in more accurate recall. As a consequence, we analyze both measures.

The top and bottom panels of figure 3 display average search time from the diary survey and the weekly recall questions, respectively, broken down by cohort, where cohorts are defined by the duration of unemployment at the start of our survey. (Individuals are dropped from the sample once they accept a job offer.) Both graphs show the same pattern: search time declines over the duration of the unemployment spell for each cohort. It is curious, however, that the search time profiles are approximately parallel lines and, with the exception of the very long term unemployed, that average search time at the end of one cohort's data does not overlap with the

12. For comparison, Katz and Meyer (1990) find that the average UI recipient who did not expect to be recalled to his or her previous job in Pennsylvania and Missouri in 1979-81 searched for an average of 12 hours per week, and the average worker who expected to be recalled searched for an average of 5.7 hours per week. 
Figure 3. Average Time Spent on Job Search, by Unemployment Duration and by Cohort

Minutes per day

Yesterday (time diary)

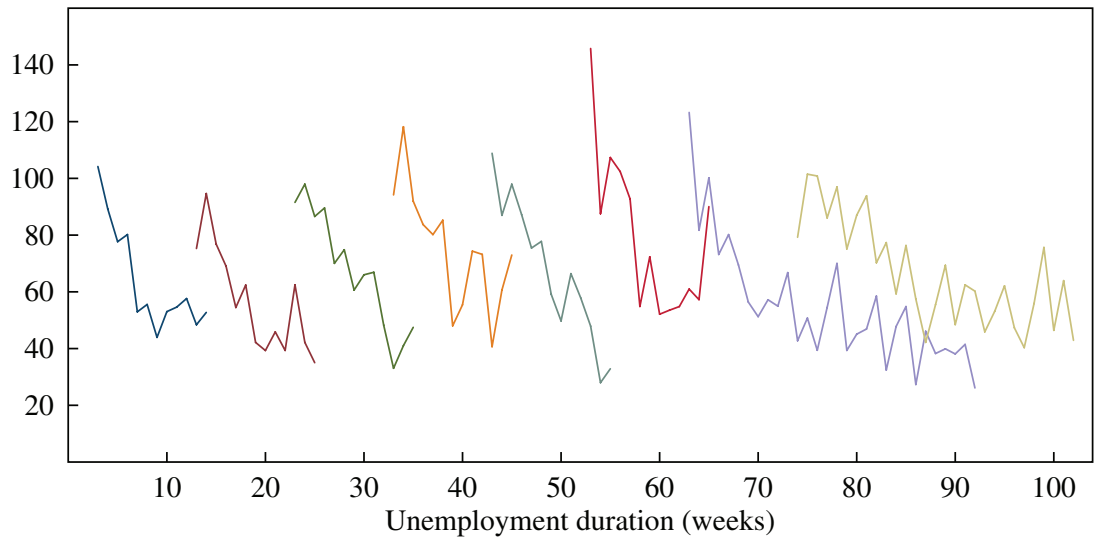

Last 7 days (weekly recall)

Minutes per day

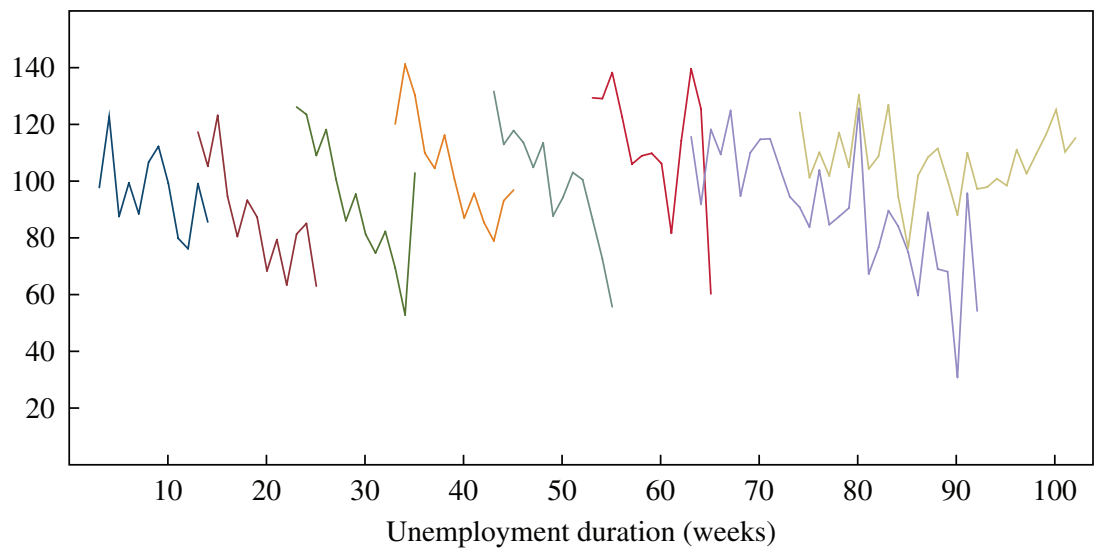

Source: Authors' calculations based on the survey data and on administrative data from LWD.

beginning of the next cohort's. We return to this feature of the data at the end of this section.

Table 2 presents regression estimates where the dependent variable is time spent searching for a job per day, as measured by the time diary (top panel) or the weekly recall questions (bottom panel). The key explanatory variable is duration of UI benefit receipt; other explanatory variables vary across regressions and include age, education, sex, race, ethnicity, 


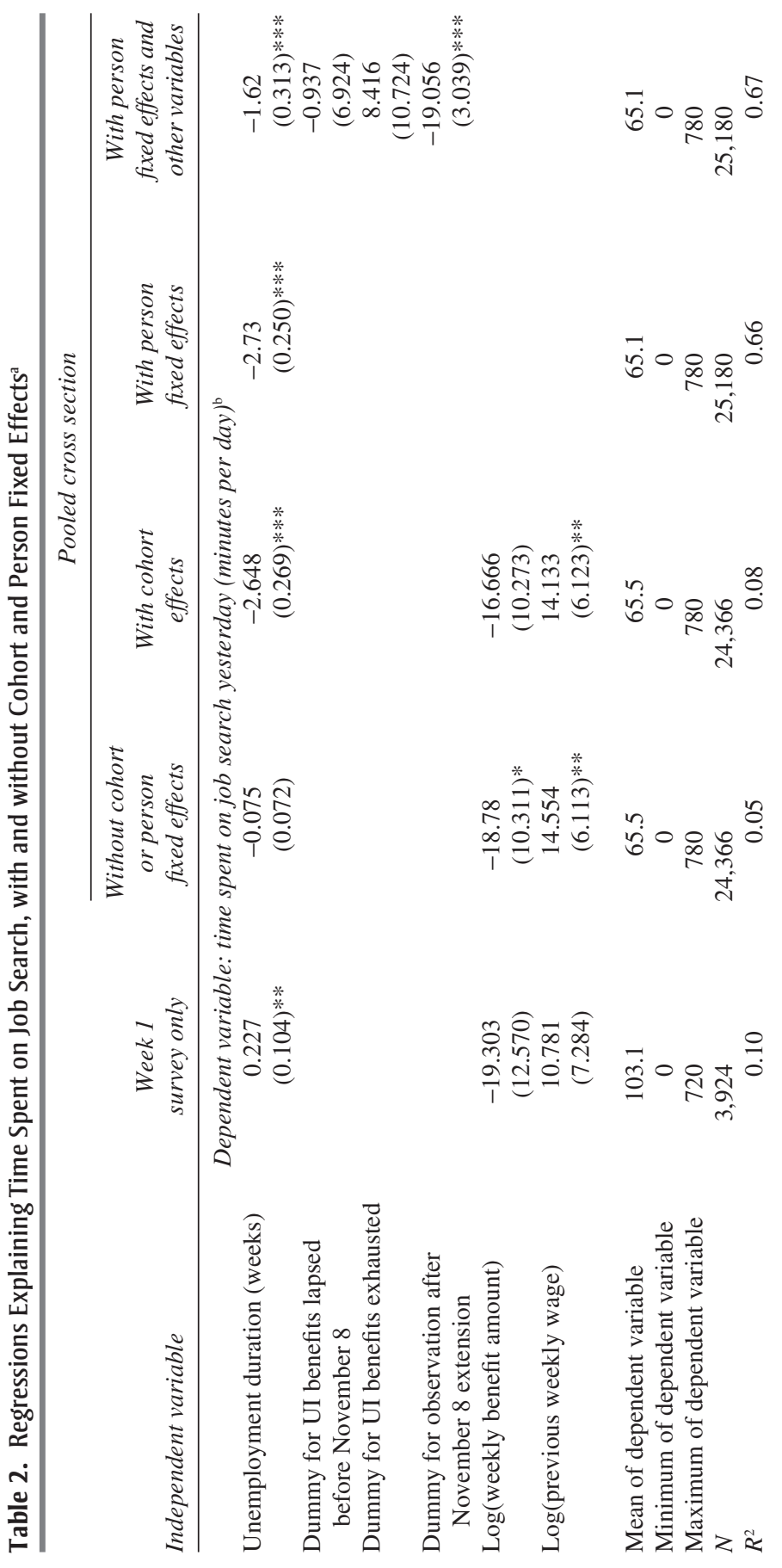




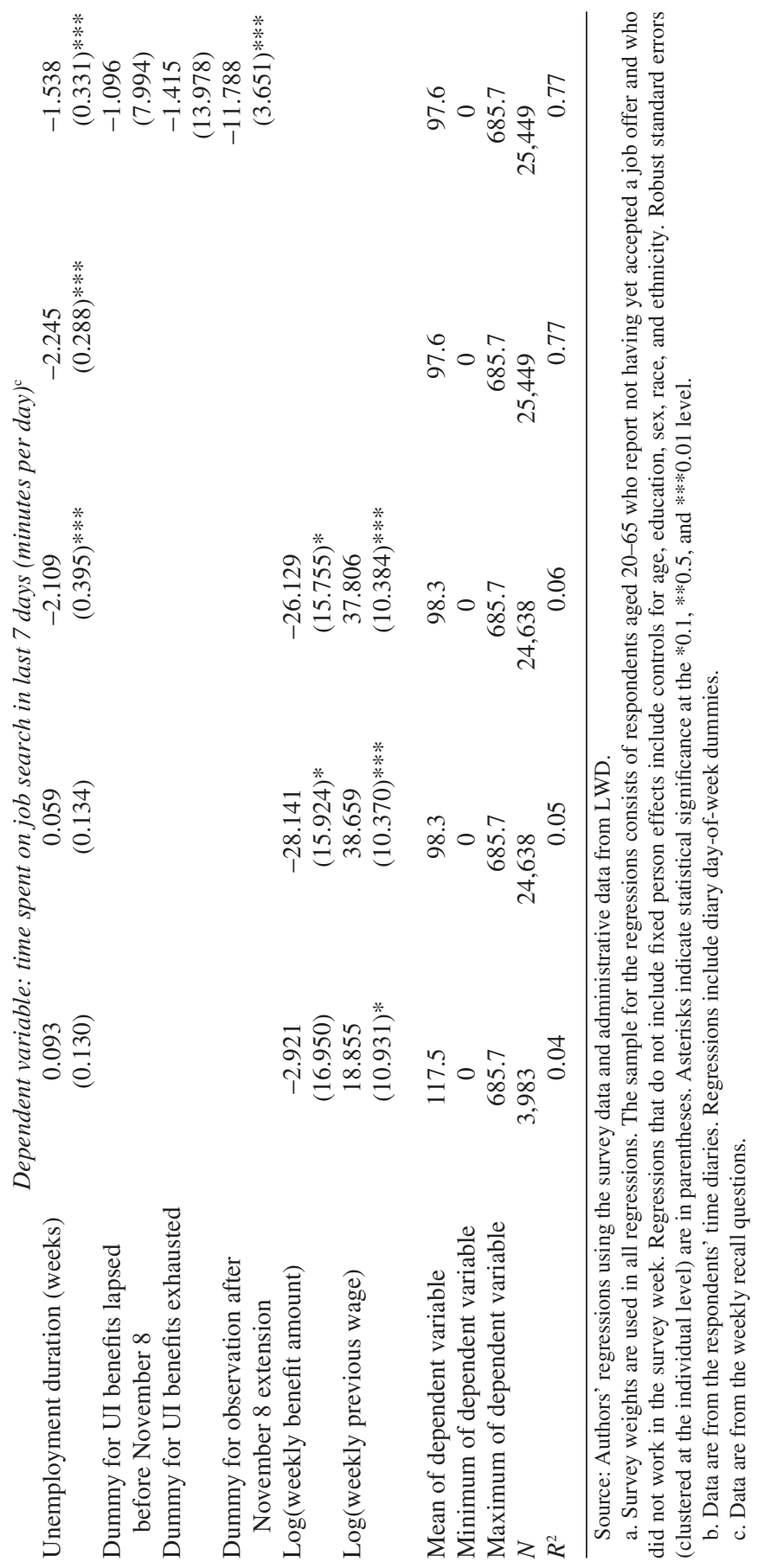


the weekly benefit amount (in logarithms), and the previous weekly wage (in logarithms). The first column is estimated using only the entry-week survey, so there is just one observation per respondent. These estimates correspond to those in the cross-sectional literature that compares search time across workers with different durations of unemployment (for example, Barron and Mellow 1979, Krueger and Mueller 2010). The remaining columns are estimated with the pooled sample of all respondents' weekly responses. The third column adds cohort dummies (that is, dummies for each of the strata indicating initial duration of unemployment). The fourth and fifth columns control for unrestricted person fixed effects, so that the only source of variability in the duration variable is within-person changes in unemployment duration.

The table highlights the importance of analyzing longitudinal data. Duration of unemployment has a positive association with search time in the first-week-only model using either measure (and the relationship is significant using the time diary data, in the top panel), whereas it has a negative, statistically significant, and sizable association in the fixed effects models, which exploit the longitudinal data. It is clear from figure 3 that a line fit across the cohorts would have a different slope than the typical line fit within each cohort; the regressions bear this out. A comparison of the third and fourth columns of table 2 indicates that, within cohorts, there is hardly any evidence of heterogeneity bias, in that the decline in search activity over the spell of unemployment is about the same for all individuals who lost their job around the same time, whether or not we remove individual fixed effects. Thus, the decline in search activity appears to be a result of a change in behavior over the spell of unemployment, rather than a change in the composition of the sample.

The sharp decline in search time over the spell of unemployment is noteworthy. In the fourth column of the top panel of table 2, for example, daily search time falls by 30 minutes over a 12 -week period, about a third of the average search time for those with new spells of unemployment. This pace of decline could not be sustained for very long without hitting the zero bound. From figure 3, however, it is apparent that the gradient becomes flatter at long durations of unemployment.

Using the time diary data, we also looked at which activities increase while search time decreases over a spell of unemployment (results available from the authors on request). Interestingly, the only activity that significantly increases with duration of unemployment is sleep. Even more precisely, sleep in the morning hours tends to rise. An analysis of the time diaries indicates that half of job search activity takes place between 7 a.m. and 1 p.m. 
Figure 4. Participation in Job Search Yesterday and Time Spent on Job Search Yesterday Conditional on Nonzero Search, by Unemployment Duration and by Cohort ${ }^{\mathrm{a}}$

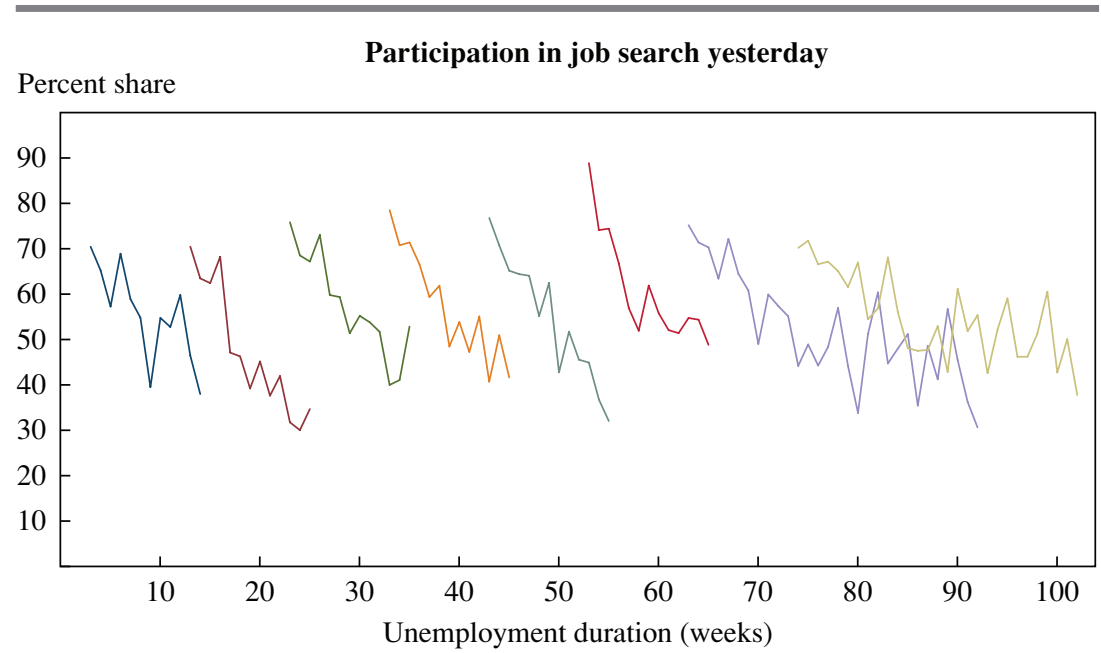

Time spent on job search (conditional on nonzero search)

Minutes per day

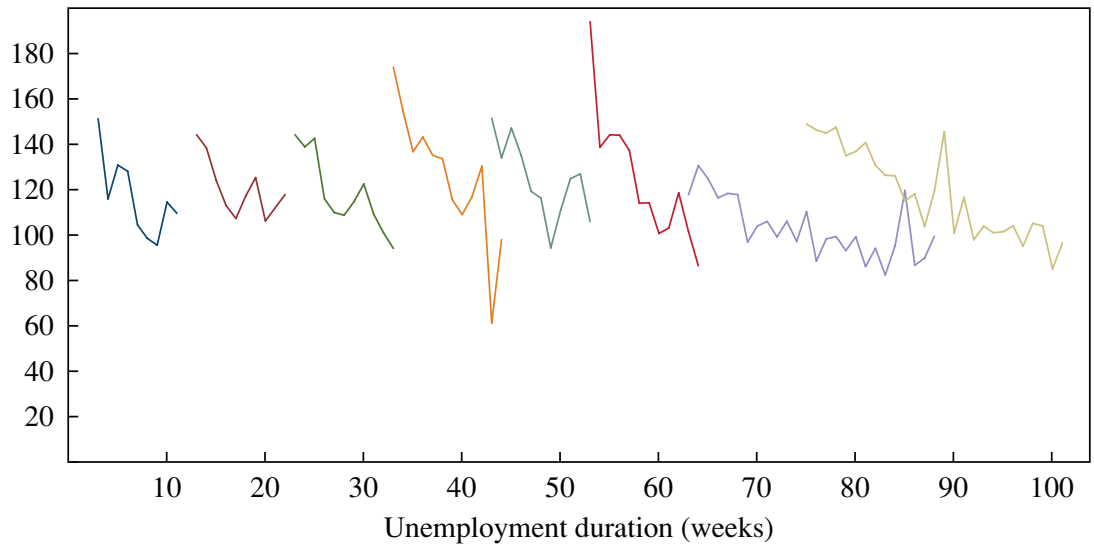

Source: Authors' calculations based on the survey data and on administrative data from LWD. a. Both panels remove person fixed effects.

We looked separately at participation in any job search at all on the reference day and the amount of time spent searching conditional on some time spent searching. Both of these decline with the duration of unemployment, as shown in figure 4 (to account for individual heterogeneity, the figure removes person fixed effects from the estimates). Moreover, this finding holds in both the time diary data (shown in the figure) and the weekly recall data. 
The model reported in the last column of table 2 includes three additional dummy variables relating to UI benefit receipt: the first two indicate weeks when an individual's UI benefits lapsed or were exhausted, and the third indicates observations after November 8, 2009, the date when the maximum duration of benefit receipt was extended from 79 to 99 weeks. Adding these variables reduces the magnitude of the coefficient on unemployment duration by about a third, but it is still negative and highly statistically significant. Moreover, when we estimate the model in the fourth column of table 2 separately using data before or after the November 8 extension (results not shown), we find that search time declines with unemployment duration in both samples. Thus, the decline in search activity over the spell of unemployment seems to be robust to efforts to take account of the extension of benefits in early November.

We do not find statistically significant evidence of a change in search time, by either measure, during periods in which benefits lapsed or were exhausted. The post-November 8 EUC extension variable is highly statistically significant, although the effect of the extension is difficult to interpret, as it could reflect nonlinear effects of duration. The effect of this variable is larger and more robust to changes in the functional form of unemployment duration in the diary data on job search. When we add the square of the duration of unemployment to the model in the last column (results not shown), for example, the coefficient on the post-November 8 dummy variable using the time diary data decreases to -14.5 minutes but is still highly significant, with a $t$ statistic of 4.2 , whereas it falls more steeply from -11.8 minutes to -5.7 minutes and is no longer significant $(t=1.5)$ with the weekly recall data. Thus, estimates of the effect of the extension on job search time are dependent on the functional form of unemployment duration and the measure of job search time.

To examine the pattern of search time around the exhaustion of benefits more closely, figure 5 arrays the search data by the number of weeks before or after the exhaustion of UI benefits, again removing person fixed effects. Contrary to the prediction of Mortensen's (1977) search model, there is no visible increase in search activity in the weeks leading up to the exhaustion of benefits in either the daily or the weekly search data. Instead, in both figures the downward drift in search time continues around the time that benefits are exhausted.

Turning to the other variables in table 2 , we find that the log of the benefit amount and of the previous wage have their expected signs. The benefitsearch elasticity at the mean search time over all observations is around -0.3 with either measure of search time. This is substantially smaller than the 
Figure 5. Time Spent on Job Search, by Weeks before or after UI Benefit Exhaustion ${ }^{\mathrm{a}}$

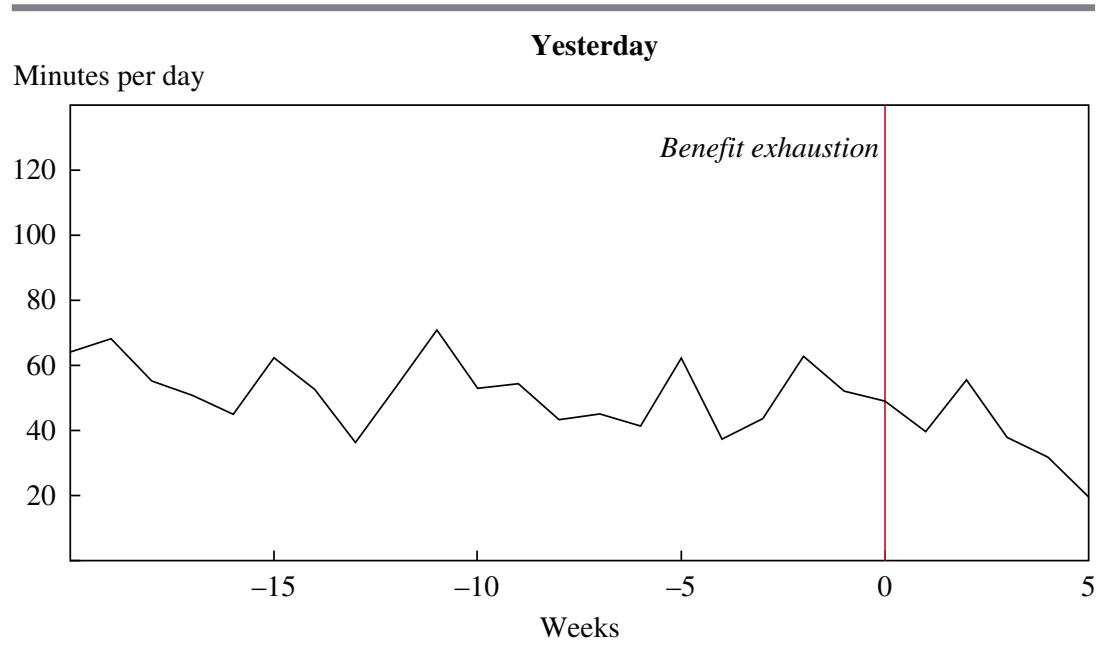

Last 7 days

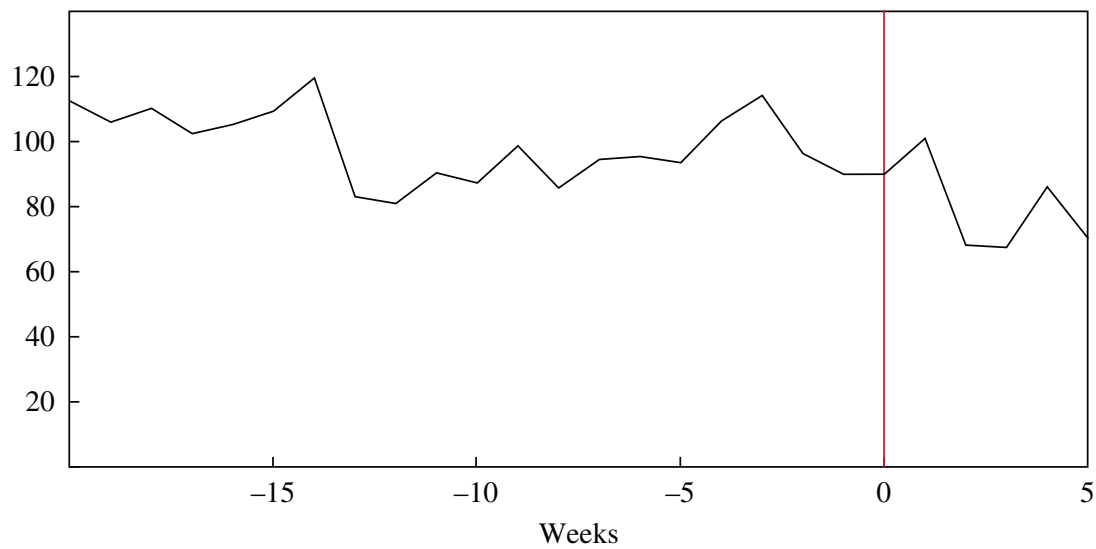

Source: Authors' calculations based on the survey data and on administrative data from LWD. a. Both panels remove person fixed effects.

corresponding elasticity in Krueger and Mueller (2010), perhaps because of the higher unemployment rate in the period under study in this paper or the different source of benefit variability. The wage elasticity ranges from 0.2 to 0.4 in the model in the second column. The identification of the wage and benefit elasticities, however, depends on nonlinearities in the benefit formula, so these estimates should not be taken too literally. 
Figure 6. Time Spent on Job Search by Search Method ${ }^{a}$

\section{First interview}

Contacted public employment agency (2\%)

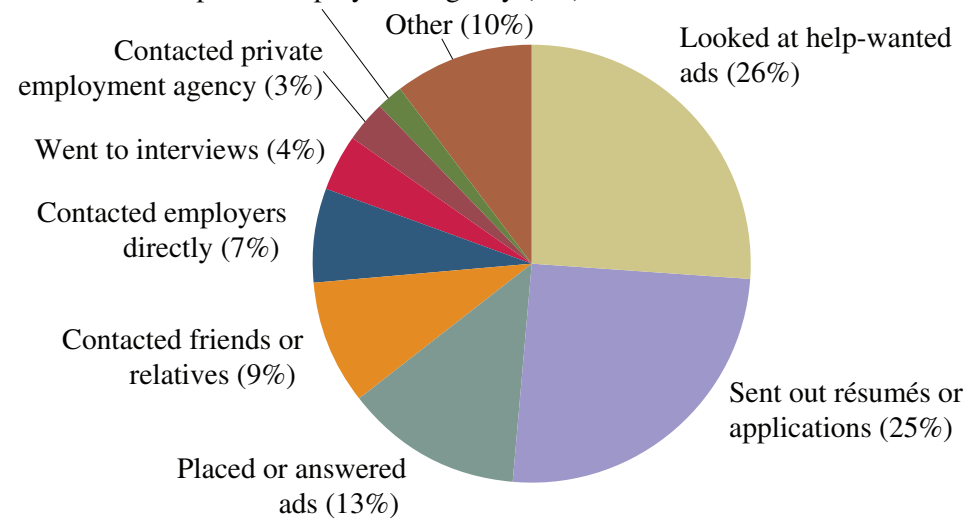

All interviews

Contacted public employment agency (3\%)

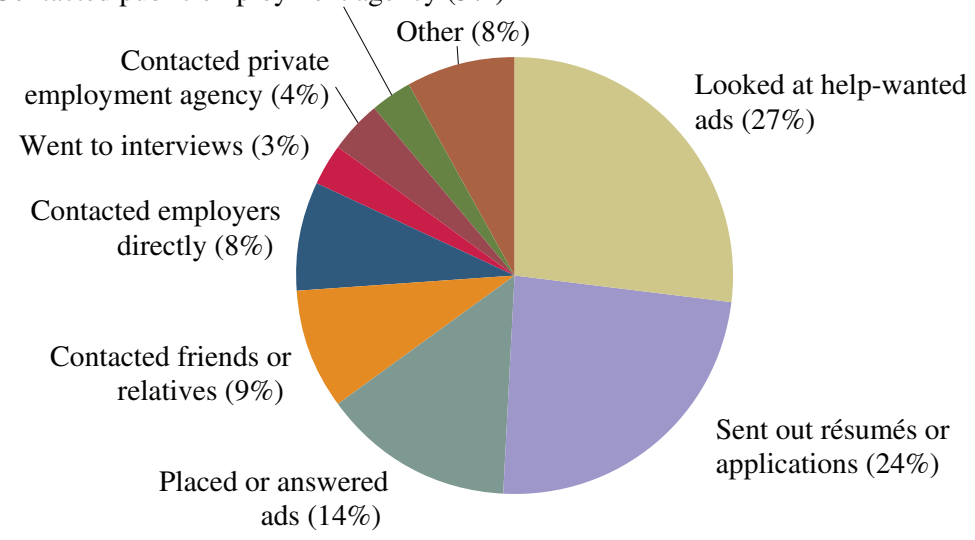

Source: Authors' calculations based on the survey data.

a. Percentages may not sum to 100 because of rounding.

\section{III.A. Job Search Methods}

The pie charts in figure 6 display the proportion of job search time in the past week spent on various methods as reported in the first weekly interview (top) and across all interviews (bottom). Almost two-thirds of job search time is spent looking at help-wanted ads, placing or answering ads, and sending out applications. Contacting friends and relatives, which has 
been found to be a highly effective job search method in past studies (for example, Holzer 1988, Granovetter 1974), accounts for 9 percent of search time. Only 3 percent of time is spent on job interviews.

Table 3 reports results of regressions in which the dependent variable is the amount of time devoted to a given search activity per day and the explanatory variables include the duration of unemployment and person fixed effects. (The model corresponds to that reported in the fourth column of the bottom panel of table 2.) With the exception of contacting a public employment agency, all the included search activities decline with the duration of unemployment. Interestingly, if one scales the coefficients by the average time devoted to the method, the activities decline roughly in proportion to their average time. Thus, the pie charts look fairly similar whether one uses the first week or the 12th week of the observed spell of unemployment.

\section{III.B. Duration, Calendar Time, and Cohort Effects}

We have implicitly discussed changes in job search behavior associated with changes in unemployment duration, for both individuals and cohorts, as if they were a result of duration itself. However, an alternative interpretation is that what appears to be a duration effect is actually the effect of calendar time, since for a given cohort indexed by time of job loss, increases in duration necessarily correspond to movements in calendar time. For example, because our survey began in October, it is possible that changing seasonal or business cycle conditions led to a decline in job search as we moved from October to November and November to December. If job search is weaker in November because of Thanksgiving, and weaker still in December because of Christmas, for instance, one might observe a pattern like those in figure 3.

Although one can never separately identify duration and calendar time effects for given cohorts, we think a range of evidence suggests that seasonal, holiday, and business cycle effects are not responsible for the observed decline in search time over the spell of unemployment in our data. First, when we drop the last two weeks of November and December to avoid the effects of holidays, the coefficient on duration in the model used in table 2, column 4, hardly changes. Second, in an effort to examine the effect of seasonal employment, we dropped construction workers, who tend to have highly seasonal employment in New Jersey, and found a similar slope. Third, we compared the gradients for men and married women, on the theory that married women have a greater opportunity cost of time around Thanksgiving and Christmas, and found that search time declined with duration for both groups at almost an equal rate. 
Table 3. Regressions Explaining Time Spent on Job Search in Last 7 Days with Unemployment Duration, by Job Search Method ${ }^{a}$

Dependent variable: time spent on job search (minutes per day)

\begin{tabular}{lcccc} 
& Total & $\begin{array}{c}\text { Contacted } \\
\text { employer } \\
\text { directly }\end{array}$ & $\begin{array}{c}\text { Contacted } \\
\text { public } \\
\text { employment } \\
\text { agency }\end{array}$ & $\begin{array}{c}\text { Contacted } \\
\text { private } \\
\text { employment } \\
\text { agency }\end{array}$ \\
\hline Independent variable: & -2.245 & -0.173 & 0.006 & -0.093 \\
$\quad$ unemployment duration (weeks) & $(0.288)^{* * *}$ & $(0.057)^{* * *}$ & $(0.038)$ & $(0.040)^{* *}$ \\
Mean of dependent variable & 97.6 & 7.6 & 3.3 & 3.6 \\
Minimum of dependent variable & 0 & 0 & 0 & 0 \\
Maximum of dependent variable & 685.7 & 385.7 & 300.0 & 257.1 \\
$N$ & 25,449 & 25,449 & 25,449 & 25,449 \\
$R^{2}$ & 0.765 & 0.56 & 0.62 & 0.64 \\
\hline
\end{tabular}

Source: Authors' regressions using the survey data and administrative data from LWD.

a. Survey weights are used in all regressions. All regressions include individual fixed effects. The sample for the regressions consists of respondents aged 20-65 who report not having yet accepted a job offer and who did not work in the survey week. Robust standard errors (clustered at the individual level) are in parentheses. Asterisks indicate statistical significance at the $* 0.1, * * 0.5$, and $* * * 0.01$ level.

Additional evidence that seasonal factors are not at work comes from the ATUS. We find that from 2003 to 2009, time spent in job search by the unemployed tended to rise from October to November, fall in December, and rise in January. So there is no evidence of a monotonically declining pattern over these months. Likewise, the BLS seasonal adjustment factor for the unemployment rate in New Jersey is similar in October, November, and December, which indicates relatively little seasonal shift in unemployment. Additionally, the unemployment rate was fairly stable in New Jersey in the last quarter of 2009 and the first quarter of 2010, suggesting that swings in the business cycle were not important.

Finally, and perhaps most important, Connie Wanberg and others (2011) report evidence of a downward-sloping pattern in job search over 15 weeks of unemployment for a longitudinal sample of unemployed workers in Minnesota who participated in an online survey from the end of January to the beginning of July of 2008. Wanberg and her coauthors surveyed 182 new UI recipients over 20 weeks of unemployment. Their weekly job search question was, "How many hours did you spend on your job search each day this week?" Participants reported the number of hours for each day of the week. Because these data covered a completely different period than ours, the downward-sloping search profile over the spell of unemployment does not appear to be unique to the time frame of our sample. 


\begin{tabular}{ccccccc}
$\begin{array}{c}\text { Contacted } \\
\text { friends or } \\
\text { relatives }\end{array}$ & $\begin{array}{c}\text { Placed or } \\
\text { answered ads }\end{array}$ & $\begin{array}{c}\text { Went to } \\
\text { interview }\end{array}$ & $\begin{array}{c}\text { Sent out } \\
\text { résumés or } \\
\text { applications }\end{array}$ & $\begin{array}{c}\text { Looked } \\
\text { at ads }\end{array}$ & Other & $\begin{array}{c}\text { Attended } \\
\text { job } \\
\text { training } \\
\text { program }\end{array}$ \\
\hline-0.182 & -0.352 & -0.056 & -0.714 & -0.378 & -0.303 & -0.101 \\
$(0.061)^{* * * *}$ & $(0.080)^{* * *}$ & $(0.043)$ & $(0.107)^{* * *}$ & $(0.099)^{* * *}$ & $(0.079)^{* * *}$ & $(0.082)$ \\
9.0 & 13.4 & 3.2 & 23.0 & 26.6 & 8.0 & 5.8 \\
0 & 0 & 0 & 0 & 0 & 0 & 0 \\
428.6 & 428.6 & 435.0 & 514.3 & 515.7 & 685.7 & 686 \\
25,449 & 25,449 & $(25,449)$ & 25,449 & 25,449 & 25,449 & 25,428 \\
0.56 & 0.60 & 0.46 & 0.70 & 0.65 & 0.55 & 0.59 \\
\hline
\end{tabular}

Although we find little evidence of temporal effects that would cause the downward-sloping search profiles in figure 3 , we do find some evidence that the cohorts that became displaced at different times have very different characteristics. Figure 7 plots, again for each cohort, average earnings in the base year, as well as other characteristics of respondents, against unemployment duration. ${ }^{13}$ Those UI recipients who had been laid off more recently, and hence had shorter durations, had significantly lower average earnings before displacement. For example, average earnings in the base year for those who had been unemployed 2 weeks or less at the start of our study were approximately $\$ 36,000$, compared with $\$ 38,000$ for those unemployed 10 to 12 weeks and $\$ 42,000$ for those unemployed 20 to 22 weeks. Moreover, the cohorts do not overlap in terms of earnings, or in terms of other characteristics such as industry of previous employment and educational attainment, when we compare groups with the same duration of unemployment at different calendar times. The cohorts based on duration of unemployment at a fixed calendar date are different because workers in different industries and skill groups were laid off at different times. Thus, at least in this period when unemployment had been rising rapidly for the preceding year and a half, comparing at a point in time workers who have been unemployed for

13. This figure is based on data from administrative records or from the first interview for all of the initial respondents, so attrition is not an issue. 
Figure 7. Selected Characteristics of Unemployed Workers, by Duration of Unemployment and by Cohort

Earnings in base year

Thousands of dollars

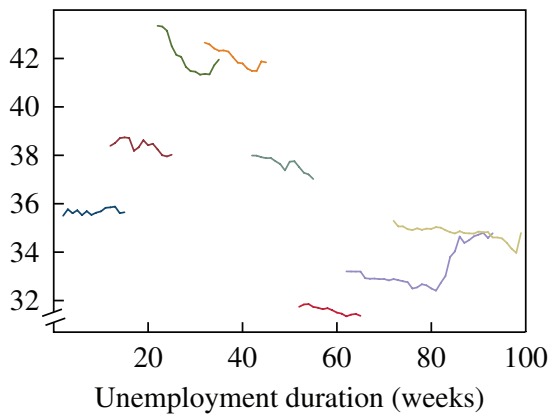

Share previously employed in education or health services

Percent

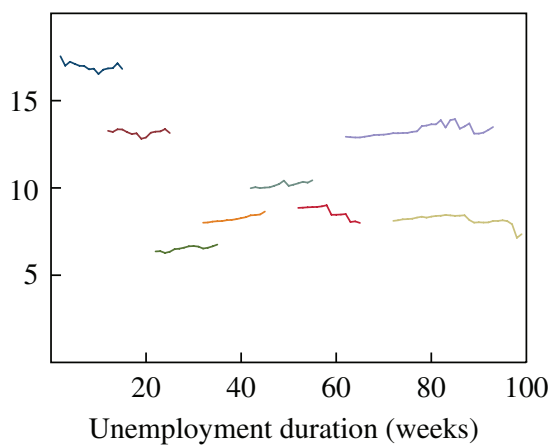

Share with high school diploma or less Percent

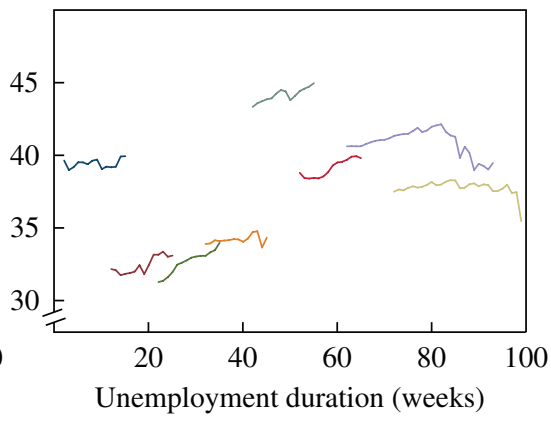

Share previously employed in manufacturing

Percent

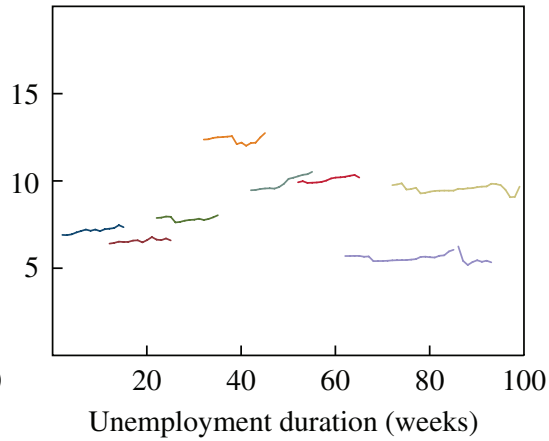

Source: Authors' calculations based on administrative data from LWD.

different lengths of time can be misleading because of differences in background characteristics across cohorts. The cohorts with lower earnings, for example, would be expected to search less, and this could partly explain why search time is not lower for the cohorts that had been unemployed longer at the beginning of our survey. Even after controlling for observed characteristics, however, we still find cohort differences in job search at the same duration of unemployment.

\section{III.C. Reporting Bias}

Another possible explanation for the decline in reported search time over the spell of unemployment is that it results from reporting bias rather than 
a real change in behavior. For example, it is possible that respondents exaggerated their search time in early interviews but grew more comfortable with truthfully reporting their job search time the longer they were interviewed, as they learned that there were no negative consequences of reporting truthfully. ${ }^{14}$ Indeed, some have conjectured that "rotation group bias" in the Current Population Survey (CPS), which causes the measured unemployment rate to be higher for those in their first and fifth months in the survey, may be a reflection of respondents becoming conditioned by repeated interviews or seeking to avoid answering contingent questions (see, for example, Bailar 1975, Solon 1986)..$^{15}$

The following four considerations are inconsistent with the interpretation that the patterns in figure 3 are entirely due to a reporting phenomenon, however. First, as mentioned, we find that both the probability of engaging in any search activity at all and the amount of time spent searching conditional on engaging in search decline with the duration of unemployment. If respondents were seeking to avoid answering subsequent questions or discovering that their UI benefits were not jeopardized if they reported no search activity, it is not clear why reported time spent searching would fall for those who reported devoting some time to job search. Second, responses to a time diary are more difficult to misreport than responses to a recall question, because the day has to be accounted for, yet we find virtually the same pace of decline in search time in the time diary data as in the weekly recall data. Third, a question on our survey asked individuals how many jobs they had applied for and to list the job titles of those positions (which adds another layer of difficulty for manipulation). The number of job applications that respondents submitted each week shows a downward pattern over the spell of unemployment.

Finally, when we reestimate the model in the fourth column of table 2 but include as an independent variable the number of interviews conducted so far, as well as the duration of unemployment, the former is statistically insignificant whereas the latter continues to be statistically significant and negative, although about one-third smaller in magnitude for the diary

14. One factor that may have tempered such a tendency in our study is that the letter inviting UI recipients to participate explicitly stated, "The researchers conducting the study will not share any information on specific individuals with the New Jersey Department of Labor and Workforce Development."

15. Since this pattern of rotation group bias is not monotonic, it is not consistent with our observed pattern of job search time. 
Table 4. Life Satisfaction of New Jersey UI Recipients and a Nationwide Sample of Employed Workers

Percent

\begin{tabular}{lcc}
\hline Reported satisfaction $^{\mathrm{a}}$ & New Jersey UI recipients $^{\mathrm{b}}$ & Nationwide employed $^{\mathrm{c}}$ \\
\hline Not at all satisfied & 12.1 & 1.4 \\
Not very satisfied & 45.0 & 7.7 \\
Satisfied & 37.1 & 45.5 \\
Very satisfied & 5.9 & 45.4
\end{tabular}

Sources: New Jersey UI survey and 2006 Princeton Affect and Time-Use Survey (PATS).

a. The question asked in both surveys was as follows: "Taking all things together, how satisfied are you with your life as a whole these days?" Weighted percentages are reported for samples aged 20-65.

b. Results are from the first weekly interview.

c. Sample size for the PATS is 1,961 .

data. ${ }^{16}$ Thus, duration of unemployment, rather than the number of interviews, appears to be the dominant determinant of the downward-sloping relationship between duration and job search. This regression, however, is identified only in a statistical sense because some respondents participated in the survey intermittently, and thus had the same increase in unemployment duration but a different number of interviews than other respondents. In future work, to separate out the effect of repeated interviews from that of the duration of unemployment, it would be useful to randomly vary the period between interviews for respondents and use the resulting data to test whether the duration of unemployment is related to job search conditional on the number of interviews completed so far.

\section{Subjective Well-Being over the Spell of Unemployment}

Several studies have found that the unemployed express low levels of satisfaction with their lives and report low levels on other measures of psychological well-being (Björklund 1985, Clark and Oswald 1994, Winkelmann and Winkelmann 1998, Mallar 2010). Table 4 reports results on reported life satisfaction for the New Jersey UI sample (using data from the first interview only) and for employed workers from a national telephone survey conducted in the spring of 2006. The differences are striking. Only 6 percent of the UI recipients say they are very satisfied with their lives, compared with 45 percent of the employed workers. The UI recipients may

16. In the weekly recall data, the coefficient on duration of unemployment is 10 percent larger. When we include the number of interviews in the model used in the fifth column of the table, the coefficient on duration of unemployment is -0.77 and insignificant in the time diary data, and -1.76 and significant at the 5 percent level in the weekly recall data (results available from the authors on request). 
have been particularly dissatisfied because they were searching for a job at a time of very high unemployment. Differences in the survey modes and the geographic representation of the samples may also have contributed to the differences in results.

A strength of our survey is that we can use it to examine trends in subjective well-being over time and during various activities. Table 5 indicates only modest movement over the course of unemployment in the fraction of UI recipients who say they are dissatisfied with their life, and there is some evidence of polarization: some of the unemployed are a bit more likely to say they are very satisfied, and some are more likely to say they are very dissatisfied, the longer they are unemployed. There is no change in the fraction who say they are satisfied or very satisfied with their lives as opposed to not satisfied or not at all satisfied.

By contrast, time spent in a self-reported bad mood appears to rise over the course of unemployment, while time spent in a very good mood tends to fall. This is clear from figure 8 , which depicts, for each cohort, the percentage of time that the unemployed report spending in a bad mood while at home each week (again removing person fixed effects), and from the regression results in table 6 . We find no effect on reported life satisfaction or mood from having benefits lapse or expire, but we do find significant (and contrasting) effects of the postextension dummy variable, which are more difficult to interpret.

\section{IV.A. Subjective Well-Being during Various Activities}

For three randomly selected episodes in the time diary component of our survey, respondents were asked to rate the extent to which they felt happy, sad, and stressed during the episode, on a 7-point scale with zero indicating "not at all" and a 6 indicating "very much." In addition, respondents were asked to rate these emotions during episodes of job search that occurred during the diary day. We use these data to compare self-reported emotional experience during different activities and over time. ${ }^{17}$ Of particular interest is whether respondents rate episodes involving job search as more or less pleasant the longer they are unemployed.

Table 7 summarizes respondents' self-reported emotions during various activities, with and without person fixed effects removed. (Job search was the

17. The emotion questions had a high item nonresponse rate because the instructions were vague. In the first interview, 28.5 percent of respondents failed to rate all three emotions. We subsequently redesigned the relevant web page to make it clearer that we sought a rating for all three emotions, and over the whole survey period the share of respondents who failed to answer all three questions fell to 14.1 percent. 


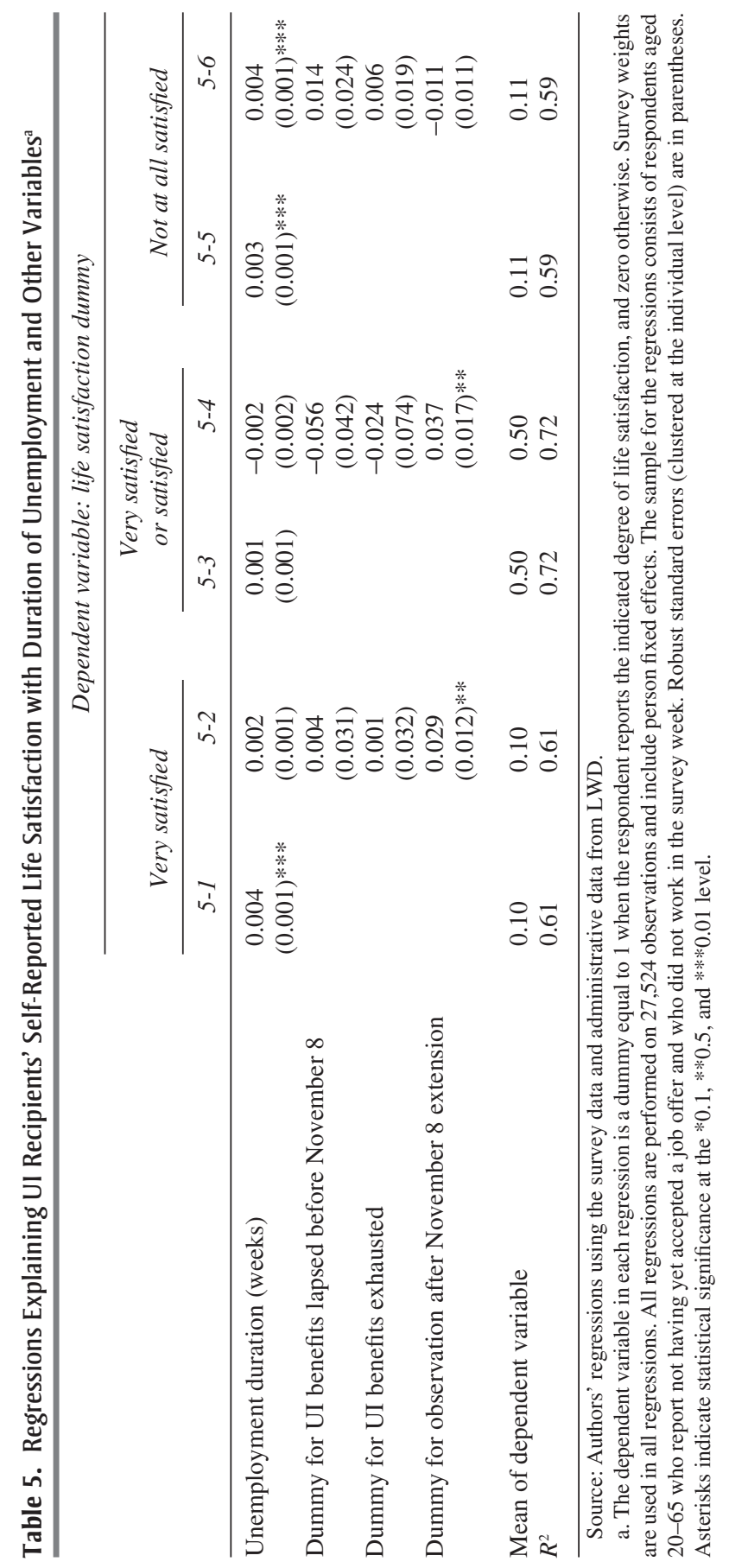


Figure 8. Share of Time Spent in a Bad Mood at Home, by Duration of Unemployment and by Cohort

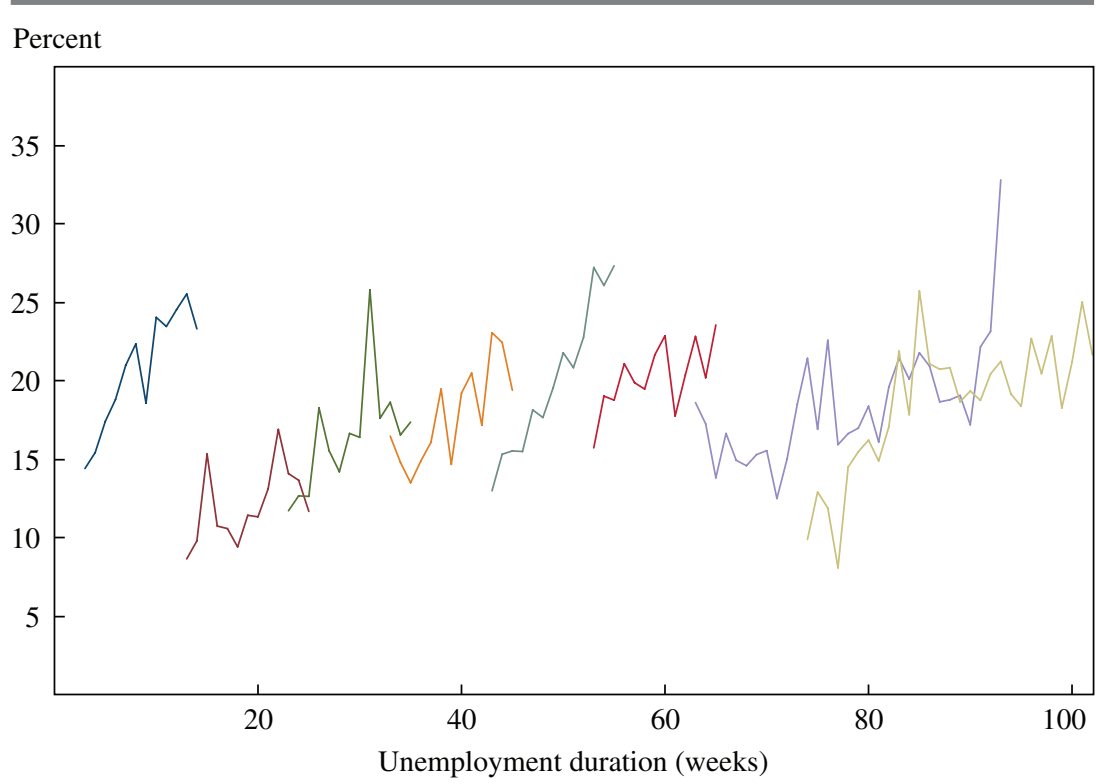

Source: Authors' calculations based on the survey data and on administrative data from LWD. a. Estimates remove person fixed effects.

omitted activity in the fixed effects regressions, so its ratings do not change.) Job search appears to be a particularly unpleasant activity: it has the highest average rating in terms of sadness and stress, and the lowest in terms of happiness. Time spent on job search is rated 0.3 and 0.4 standard deviation higher on feeling sad and feeling stressed, respectively, than the next highest rated activity, which is "using the computer, Internet, or e-mail."

The second page of the table divides job search into different categories. In the fixed effects specifications, which essentially compare the change in emotion as the same individual spends time in different search activities, looking at help-wanted ads is associated with the most unpleasant feelings. Going on a job interview seems to significantly raise respondents' happiness but does not significantly reduce their sadness or stress.

Table 8 pools together all of the episodes except for those involving job search and estimates fixed effects regressions to examine whether individuals become less happy and sadder and more stressed over the spell of unemployment. As the duration of unemployment increases, respondents tend to rate their episodes as more sad and less happy, but not more stressful. 


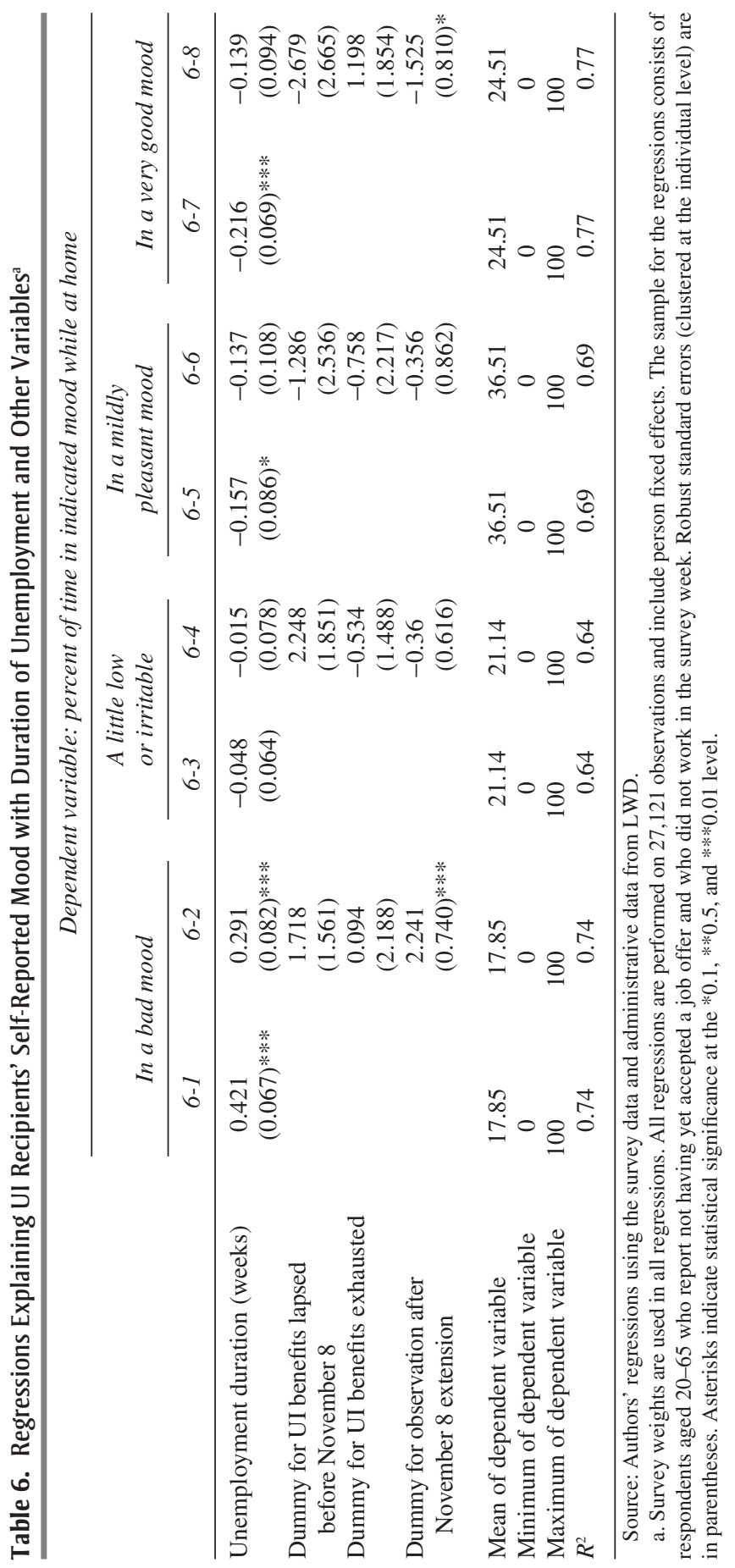




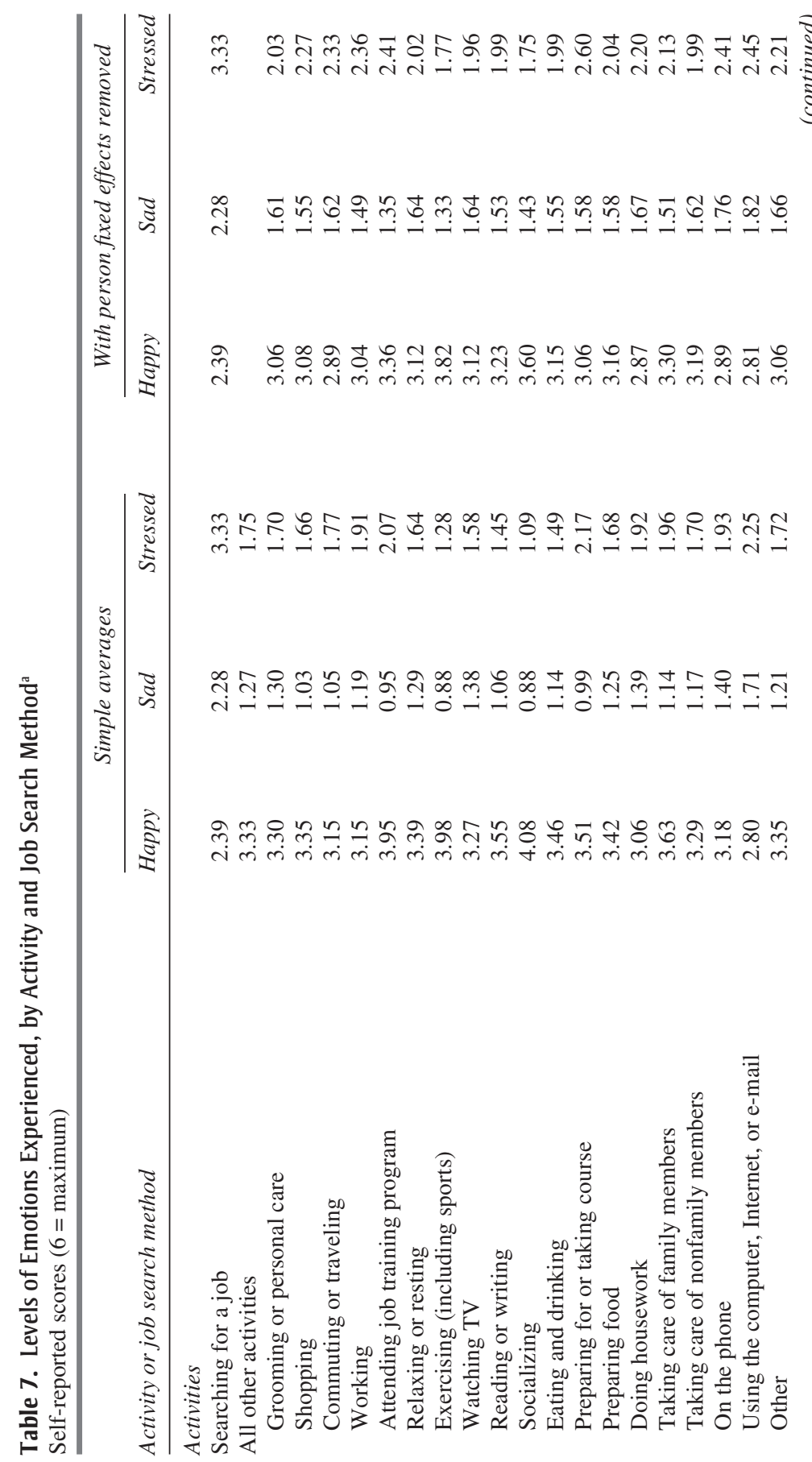




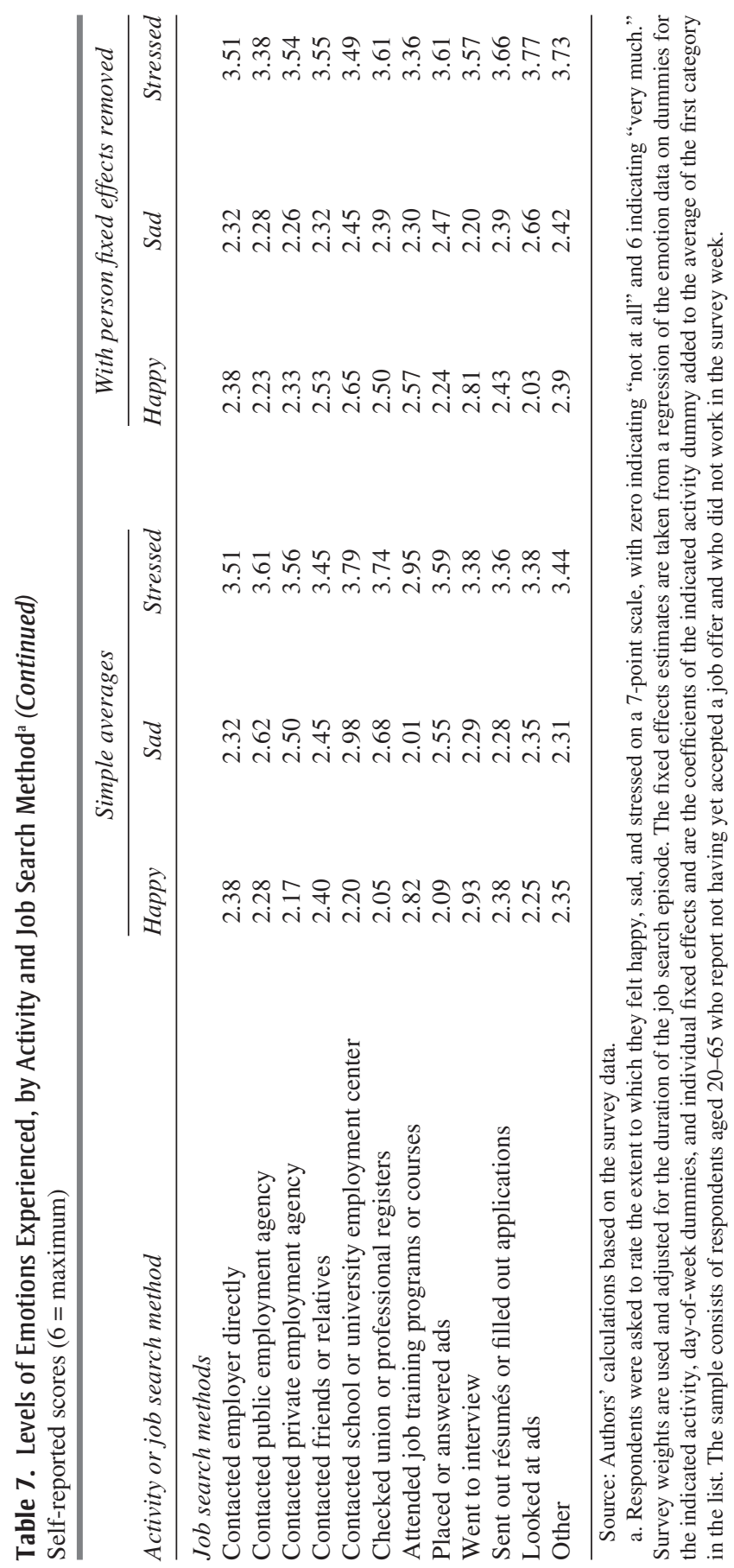




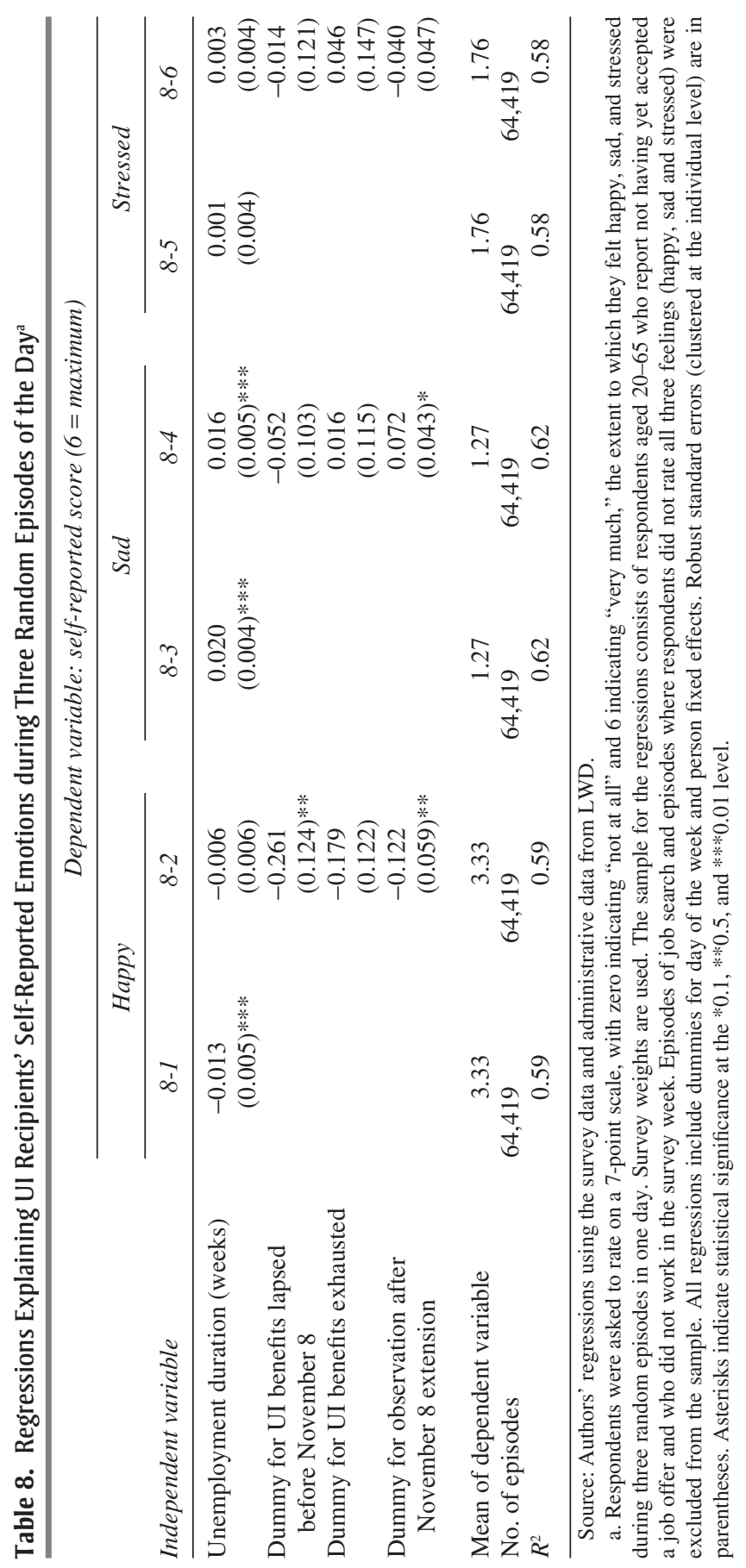


Figure 9. Sadness during Job Search Episodes, by Duration of Unemployment and by Cohort ${ }^{\mathrm{a}}$

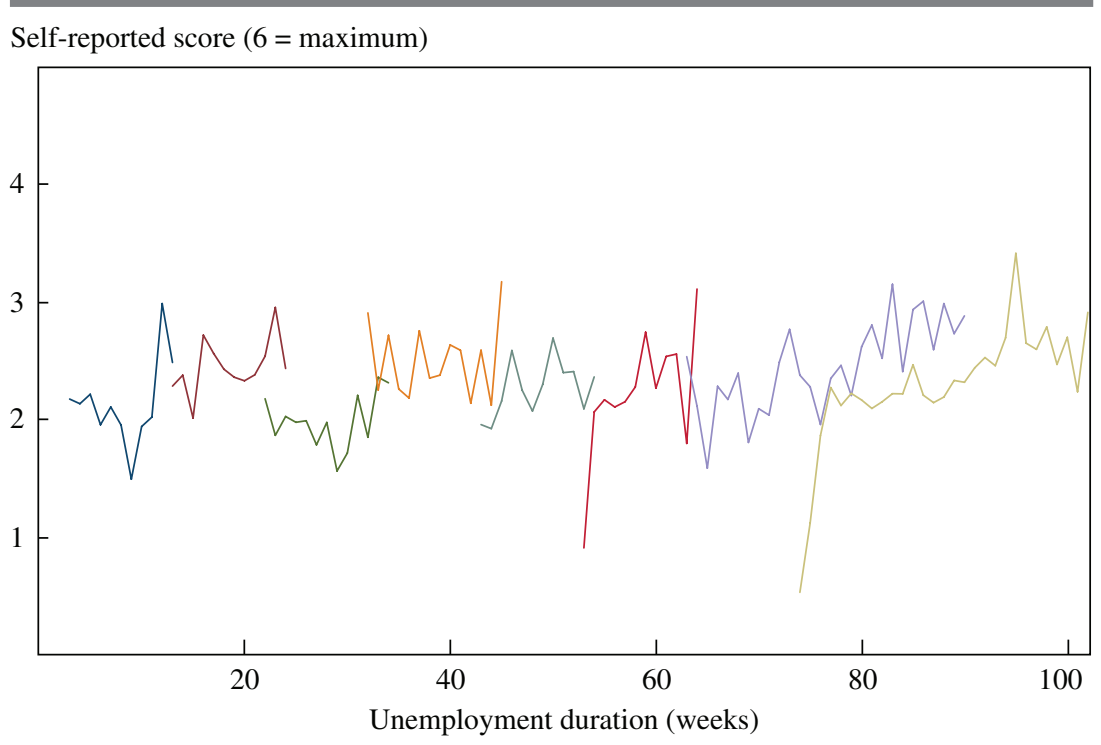

Source: Authors' calculations based on the survey data and on administrative data from LWD. a. Estimates remove person fixed effects.

An unemployed worker who searched for a job on a particular day was likely to rate his or her nonsearch activities as more stressful on that day, but not as less happy or more sad. Thus, there appears to be evidence of some spillover of the stress from job search to other activities during the same day.

Finally, we looked separately at episodes involving job search. Figure 9 shows the average rating of sadness over the spell of unemployment during job search (after removing person fixed effects). For most cohorts the graph displays an upward slope. Table 9 summarizes the results of regressions for the three emotions, restricting the sample to episodes involving job search. Sadness during job search rises with the duration of unemployment, but there is not a significant relationship with happiness or stress. A comparison of the coefficient on unemployment duration in tables 8 and 9 indicates that the feeling of sadness rises faster during periods of job search than during other activities. ${ }^{18}$ Thus, the emotional burden of job search seems

18. In a comparison of the models in the two middle columns of table 8 (nonsearch activities) with the corresponding columns in table 9 (search-related activities), the $p$ values for a test of the null hypothesis that the coefficient on unemployment duration is identical are 0.14 and 0.002 , respectively. 


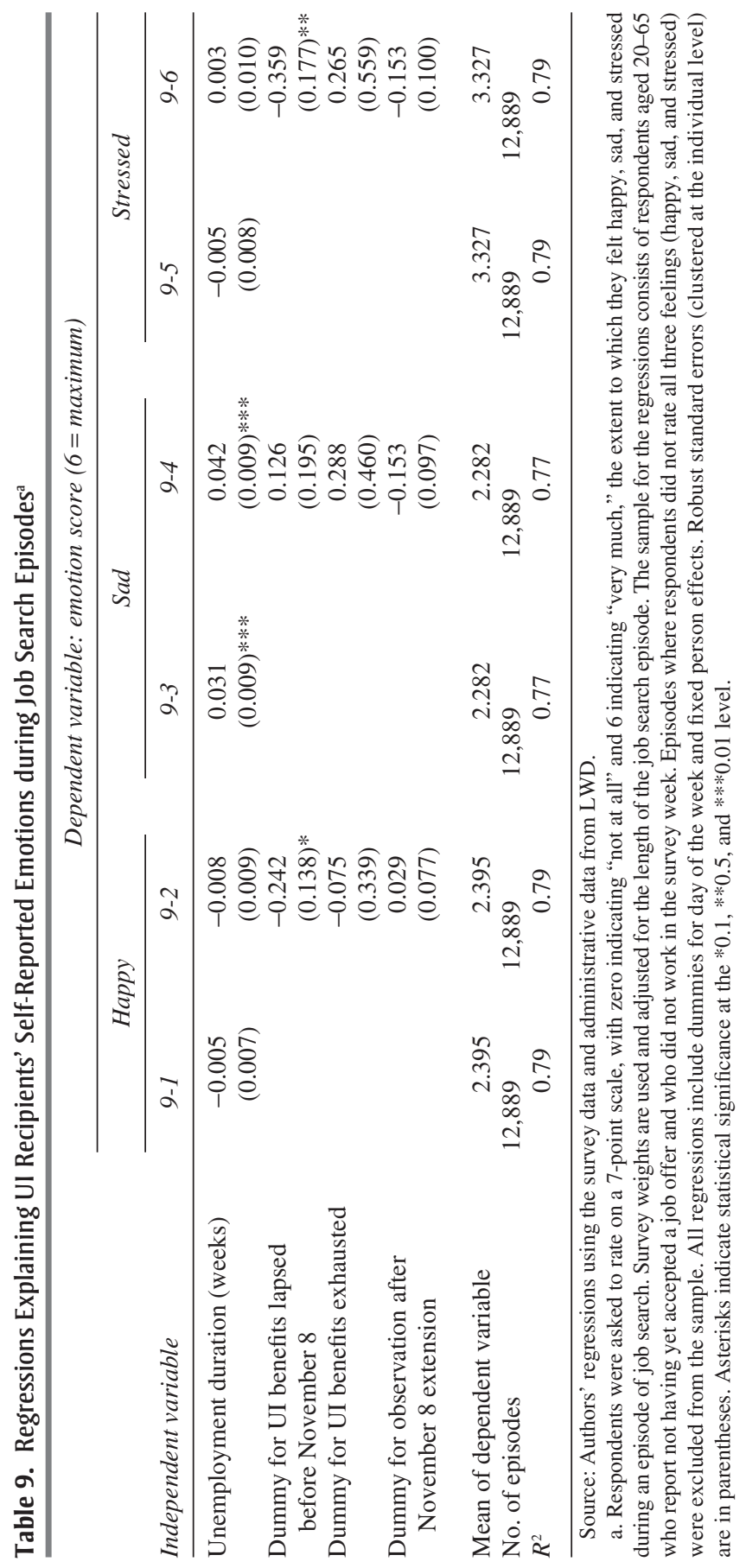


Table 10. Job Search Activity and Degree of Life Satisfaction

Percent

\begin{tabular}{lccc}
\hline & \multicolumn{3}{c}{ Search time on previous day } \\
\cline { 2 - 4 } Life satisfaction & None & 1-120 minutes & More than 120 minutes \\
\hline Very satisfied & 13.6 & 6.9 & 5.4 \\
Satisfied & 43.9 & 39.9 & 32.4 \\
Not satisfied & 33.5 & 44.4 & 47.1 \\
Not at all satisfied & 9.0 & 8.9 & 15.2
\end{tabular}

Source: Authors' tabulations based on the survey data.

to rise the longer one is unemployed. In regressions using the same model but breaking the sample down by duration of unemployment, the rise in sadness associated with additional weeks of unemployment is concentrated among the very long term unemployed, here defined as those unemployed for longer than 50 weeks.

\section{IV.B. Life Satisfaction and Job Search}

In view of the strong negative emotions apparently evoked by job search, we also examined the relationship between reported life satisfaction and the amount of time individuals devoted to job search. As table 10 indicates, we found a strong correlation. Workers who spent more time searching for a job on the previous day are less likely to report that they are satisfied with their life.

To probe this correlation further, we regressed a binary variable indicating whether the respondent reported being "very satisfied or satisfied" with his or her life, as opposed to "not satisfied or not at all satisfied," on the amount of time spent searching for a job on the previous day according to the time diary; the model also included person fixed effects. In this specification the effect of job search is identified by comparing days in which the same individual spent more or less time searching for a job. The effect of search time was negative and statistically significant at the 1 percent level. (Results are available from the authors upon request.) The coefficient on time spent searching implies that searching for an additional 5 hours reduces the likelihood for reporting oneself as "very satisfied or satisfied" with one's life by 9 percentage points, a large magnitude. When we added time spent searching in the previous week to the same fixed effects regression model, the coefficient on time spent searching yesterday was attenuated by only about 10 percent and was statistically significant at the 5 percent level, and the coefficient on time spent searching last week was negative 
and about half as large in magnitude as the coefficient on time spent searching yesterday.

Although one cannot draw causal inferences from such observational data, these results suggest that the experience of job search has a substantial and lingering effect on reported life satisfaction. Moreover, the fact that the life satisfaction question was the very first question on the weekly survey, and separated from the job search questions by a block of questions on consumption, suggests that job search has an unprompted negative effect on subjective well-being.

\section{IV.C. Subjective Well-Being and Reemployment}

Whereas unemployment is associated with lower life satisfaction and moment-to-moment feelings of despair, starting a new job has the opposite effect. In results available on request, we find that life satisfaction, mood at home, and feeling happy, sad, or stressed during the day all improve once a full-time job is accepted or when the respondent leaves UI before having exhausted benefits. Moreover, the beneficial effects of starting a new job or leaving UI early continue to be statistically significant when we control for person fixed effects and the mix of activities that people engage in during the diary day.

\section{IV.D. Summary}

Life self-evaluation and moment-to-moment emotional experience are distinct aspects of subjective well-being. The unemployed appear unsatisfied with their lives as a whole and spend much of their time in an unpleasant emotional state. Interestingly, however, only the moment-to-moment measures of feelings, or mood, seem to worsen over the spell of unemployment. Life satisfaction does not display a clear trend. Unemployed workers become increasingly sad while searching for a job the longer they are unemployed, which may raise the psychological cost of job search and account for some of the observed drop in job search time over the spell of unemployment. The finding that workers report lower life satisfaction following days that involved searching for a job is also consistent with there being a substantial psychological cost associated with job search. Because, as shown in the next section, most effort devoted to job search does not result in a job offer, the experience of searching for a job may conjure feelings of rejection that take a psychological toll on the unemployed worker. It is not surprising but nonetheless reassuring that all of our measures of subjective well-being improve markedly in the weeks after a worker accepts a full-time job or leaves UI without exhausting benefits. 
Table 11. Receipt of Job Offer by Type of Work Sought ${ }^{\mathrm{a}}$

Percent

\begin{tabular}{lccccc}
\hline Type of & Share of all & $\begin{array}{c}\text { Received } \\
\text { full-time } \\
\text { offer }\end{array}$ & $\begin{array}{c}\text { Received } \\
\text { part-time } \\
\text { offer }\end{array}$ & $\begin{array}{c}\text { Received } \\
\text { full- } \text { or } \\
\text { part-time } \\
\text { offer }\end{array}$ & $\begin{array}{c}\text { Left UI early } \\
\text { without } \\
\text { job offer } \\
\text { reported }\end{array}$ \\
\hline Full-time & 75.1 & 15.6 & 6.5 & 20.5 & 6.0 \\
Part-time & 4.3 & 10.1 & 15.9 & 20.9 & 12.9 \\
Doesn't matter & 16.7 & 14.0 & 10.0 & 20.0 & 4.9 \\
Not looking & 3.9 & 10.7 & 9.4 & 17.5 & 16.7 \\
$\quad$ for work & 100.0 & 14.9 & 7.6 & 20.3 & 6.6 \\
Total & & & & &
\end{tabular}

Source: Authors' tabulations based on the survey data.

a. The sample is restricted to respondents with at least two interviews in the baseline study.

b. As reported on the entry survey.

c. "Left UI early" is defined as those who left UI before they exhausted their UI benefits.

\section{Analysis of UI Exits and the Job Offer Generation Process}

We can use the New Jersey UI sample to explore the correlates of receiving a job offer and exiting UI. In the 39,201 weekly observations in our survey, there are 2,626 reports of job offers having been received. The same worker could receive a job offer in different weeks, or multiple offers in the same week. In total, 1,224 of the 6,025 respondents reported receiving at least one job offer in the period of study. ${ }^{19}$ Nearly a third of the job offers were for part-time jobs ( 32 hours or less per week).

Table 11 reports results on the likelihood of receiving a full- or a parttime job offer according to whether a full- or a part-time job was sought. Because individuals may have received an offer after they stopped responding to the survey, we also report the percent of individuals who left UI before exhausting benefits, even though we have no report of them having received a job offer. Among those who indicated in the entry survey that they were looking only for a part-time job, 15.9 percent received at least one part-time job offer, more than double the rate for those who indicated they

19. To increase the sample size, we do not impose an age restriction on the sample used in this section. In the survey, respondents could report job offers received in the last 7 days as well as job offers received since the last interview if they skipped one or more interviews. However, details about the job offer (wage, hours, and so forth) were asked only if the offer was received in the last 7 days or if the job offer was accepted. Moreover, if respondents indicated that they received more than one job offer in a given week, details were sought only about the "best" offer. Overall, we know the details of 2,036 job offers out of the total of 2,626. To avoid selection bias, in much of the analysis below we use information only on job offers received in the last 7 days. 
were looking only for a full-time job (6.5 percent). Among those who were looking only for a full-time job, full-time job offers were about 50 percent more likely to have been received (15.6 percent versus 10.1 percent). The average hourly wage offered was $\$ 19.50$ for full-time jobs, $\$ 16.50$ for parttime jobs, and $\$ 18.65$ overall. $^{20}$

In 24 percent of job offers, workers said they knew exactly what the job would pay when they first interviewed for it. ${ }^{21}$ Three-quarters of job offers were of the take-it-or-leave-it variety; the remainder entailed some bargaining over pay. For a sample hired during a more normal job market, Robert Hall and Krueger (2010) found that 82 percent of workers who did not have the option of keeping their previous job accepted a job with a take-it-or-leave-it offer; thus, the recession does not appear to have reduced the (already low) prevalence of bargaining among the unemployed who are offered jobs.

A significant share of the sample- 6.6 percent overall, about one-third as large as the share that reported job offers-left UI before exhausting benefits but did not report a job offer. We suspect that many of those who left UI early received job offers but did not report them in our survey because they stopped participating in the survey. For this reason we model the likelihood of leaving UI early as a function of past search activity as well as model the likelihood of receiving a job offer.

For members of each cohort, figure 10 displays the cumulative probability of having received at least one job offer by the specified date, treating those who stopped responding to the survey as censored. The tendency for the ogives to be concave with respect to the origin is an indication that the likelihood of receiving a job offer declines the longer a cohort remains unemployed. Moreover, the shorter vertical height of the ogives that are further from the origin is an indication that the cohorts that had been unemployed longer at the start of our study had a lower job offer rate in the ensuing 3 months. This finding is confirmed when we estimate hazard rate models for the likelihood of receiving a job offer each week.

Figure 11 shows the job offer hazard rate for those who have not accepted a job in the weeks leading up to and following the date that UI benefits are exhausted. We do not find any evidence of a spike in the job finding

20. These statistics cover only job offers in the last 7 days, because for other job offers made since the last interview, we know hours and wages only for offers that were accepted.

21. Another 32 percent said they had some idea about the pay, and 29 percent said they had very little idea; 15 percent of workers received a job offer without interviewing for it. The offered wage was above the respondent's reservation wage in 59 percent of full-time offers when workers knew the pay exactly at the time of the interview, and in only 32 percent of cases when they had very little idea. These results suggest that a subset of workers engage in directed search (that is, toward jobs paying above their reservation wage). 
Figure 10. Cumulative Probability of Receiving at Least One Job Offer, by Duration of Unemployment and by Cohort ${ }^{\mathrm{a}}$

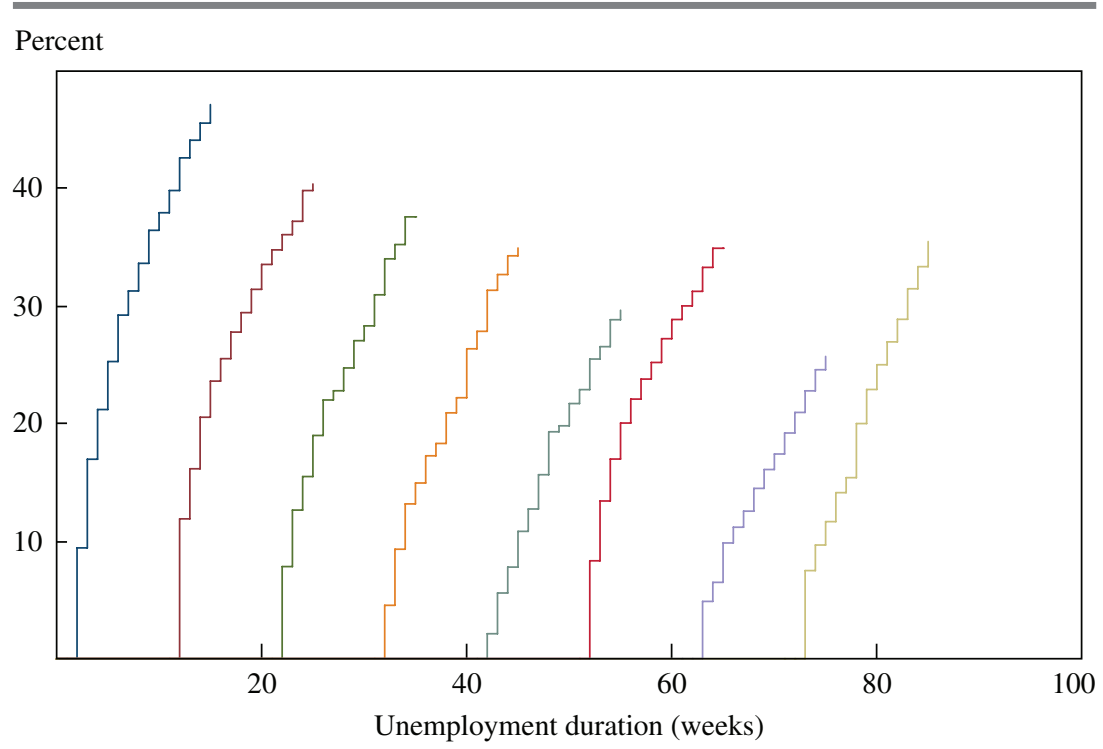

Source: Authors' calculations based on the survey data and on administrative data from LWD.

a. Curves are Kaplan-Meier failure estimates of the duration until the first job offer. If a respondent stopped participating in the survey, all weeks after the last interview are treated as censored. Respondents with fewer than two interviews are excluded. Only the first 12 weeks are shown for each cohort.

rate around the exhaustion date. Likewise, when we look at the job acceptance hazard rate (results not shown), we do not find a spike around UI benefit exhaustion. The absence of a spike in job finding around the benefit exhaustion date may be due to the weak job market and very long extension of UI benefits, rather than a general result. ${ }^{22}$

As mentioned, a limitation of our data is that we lack information on job offers received by workers who stopped responding to our survey. Nonetheless, workers who receive a job offer are more likely to exit UI early (that is, before their benefits are exhausted). Specifically, 34.7 percent of those who reported receiving a job offer at some point during our survey window exited UI early, compared with 8.2 percent of those who did not report receiving a job offer. ${ }^{23}$ For full-time job offers the difference was

22. Jurajda and Tannery (2003), however, find that there was still a substantial spike at benefit exhaustion in the early-1980s recessions in Pennsylvania, where benefits were extended up to 65 weeks.

23. These figures exclude those who exited UI at 51 or 52 weeks because, as explained previously, many of these exits did not involve finding a job. 
Figure 11. Probability of Receiving a Job Offer, by Weeks before or after the UI Benefit Exhaustion Date

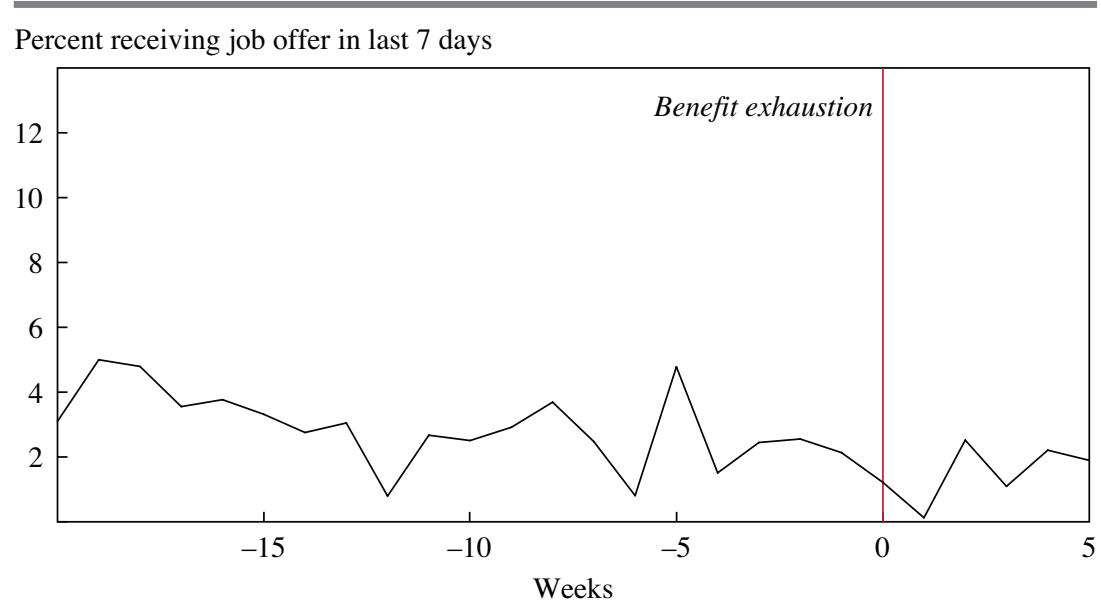

Source: Authors' calculations based on the survey data and on administrative data from LWD. a. The sample is restricted to respondents who report not having yet accepted a job offer.

even greater: 41.4 percent of those who received a full-time offer exited early versus 8.7 percent of those who did not. Some of those who received a full-time job offer did not exit UI early, either because they rejected the offer, or because they accepted the offer but subsequently became unemployed again and remained on the same benefit spell, or because their new job started after they had exhausted benefits.

In view of the missing data problems and the ambiguous and variable time lag between search activity and job offers, we took a simple approach to modeling job offers and UI exits. We treated the available data on job search and the reservation wage as having been sampled from the unemployment spell. Some workers search more than others, and we used the available data on search time during unemployment to represent the worker's average search intensity. Because search intensity falls with the duration of unemployment, we first regressed search time on individual dummy variables and dummies indicating the duration of unemployment for each cohort, using up to 12 weekly observations for each individual. The coefficients on the individual dummy variables (or fixed effects) from these regressions provide a measure of the workers' search intensity. We performed an analogous exercise for the reservation wage relative to the previous wage. 
We then estimated a probit model where the dependent variable is 1 if the individual left UI in the 24 weeks since we began interviewing without exhausting benefits, and zero otherwise, and the explanatory variables are the individual fixed effects from the regressions just described, along with other variables, such as whether recall was expected. We also estimated a parallel model where the dependent variable is 1 if a job offer was received at some point in our sample period, and zero otherwise. (The reservation wage ratio was not used as an explanatory variable in the job offer equation, because it should affect the likelihood of accepting a job offer, not of receiving one. We restricted the sample for this equation to those with two or more weekly observations.)

Table 12 summarizes various estimates for probit models predicting an early exit from UI (columns 12-1 to 12-3) and receipt of at least one job offer (columns 12-4 to 12-6). The results for exiting UI early accord with standard search theory: workers who devoted more time to searching for a job were more likely to exit UI early, as were those with a lower reservation wage relative to their past wage. The estimated coefficients imply that those who searched 20 hours per week more than the average unemployed worker were about 3.5 percentage points, or 20 percent, more likely to exit UI early. Having a 20 percent lower reservation wage is associated with a 1-percentage-point, or 6 percent, increase in the likelihood of exiting UI early. The magnitudes of the estimates are relatively small, but they are probably downwardly biased because of sampling error owing to the small number of weeks observed. ${ }^{24}$

When we divide the sample by education, we find that the reservation wage is a stronger predictor for those with less than a college degree, whereas search time is a stronger predictor for college graduates. Results for the other variables in column 12-3 indicate that workers with a definite recall date at the start of the survey are more likely to exit UI, as are workers with a college degree or higher and married workers.

The model does less well at predicting the receipt of a job offer than at predicting exit from UI. Surprisingly, receipt of a job offer is unrelated to job search time in our sample, and demographic characteristics are mostly insignificant predictors as well. When we disaggregate job search time into different activities, the only one that predicts the receipt of a job offer is time

24. Attenuation bias due to sampling variability is likely small for the reservation wage, however, because it is very stable over time. See Jones (1988) for cross-sectional evidence on how the reservation wage relates to unemployment duration for a sample of 854 unemployed British workers. 


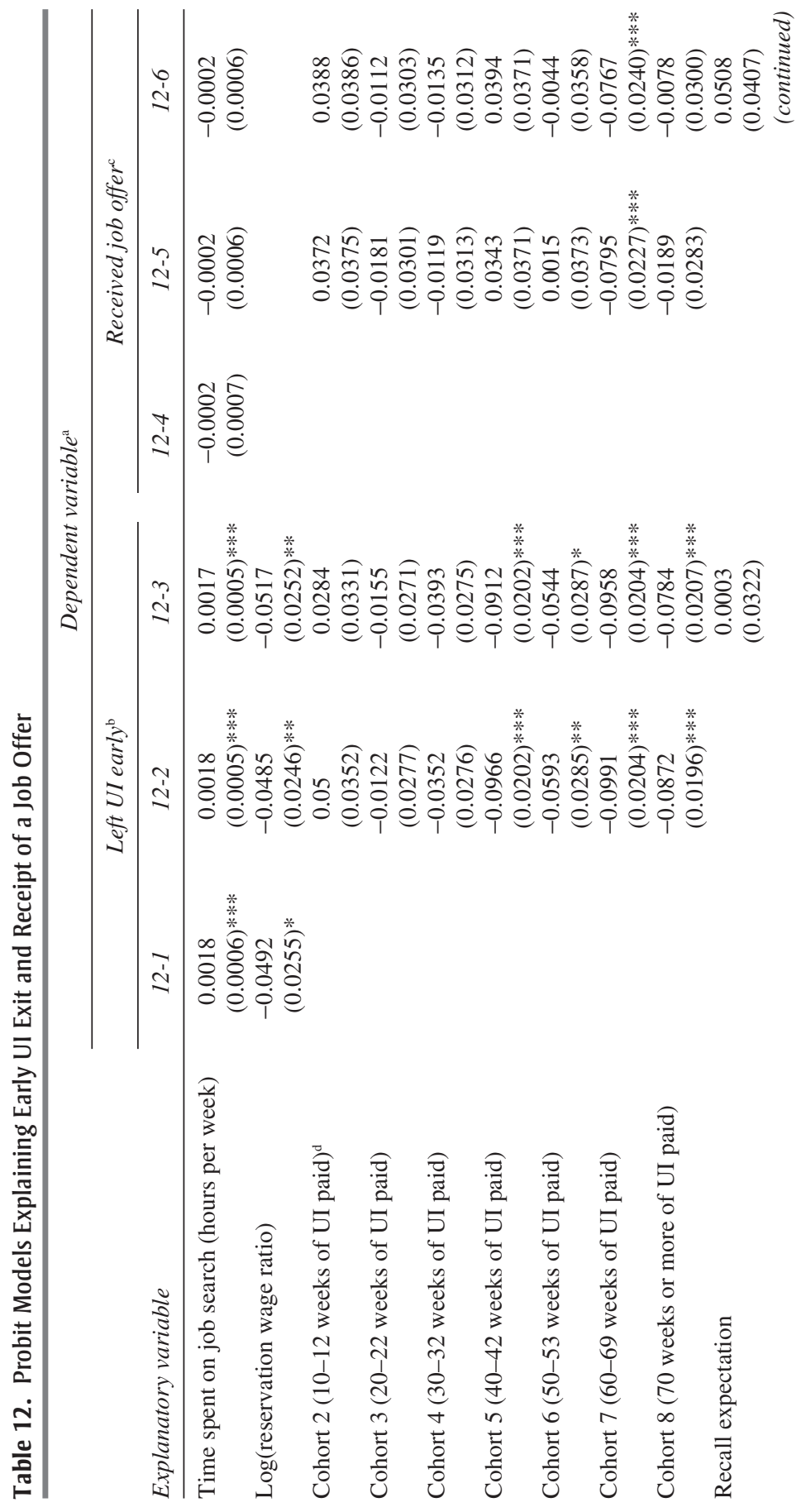




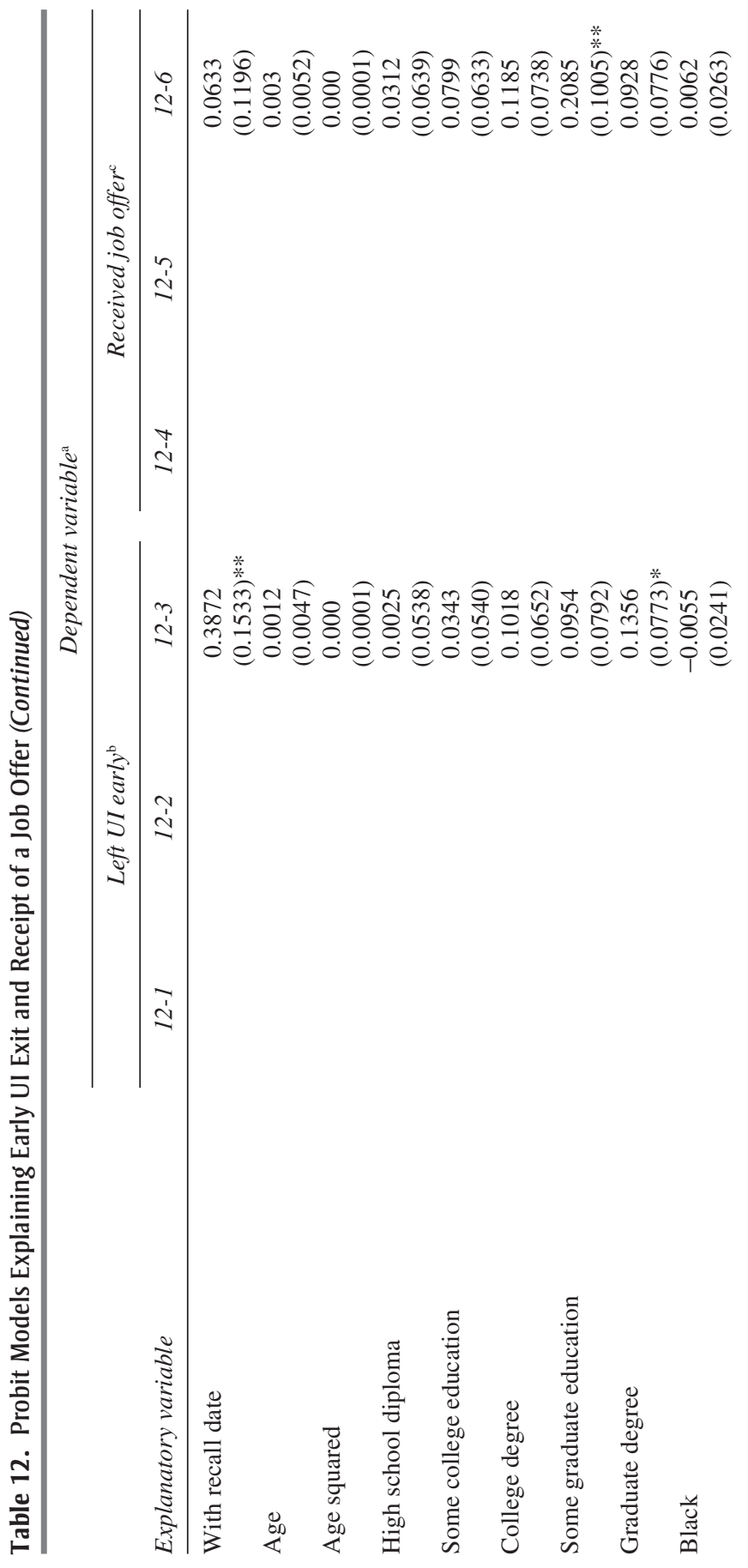




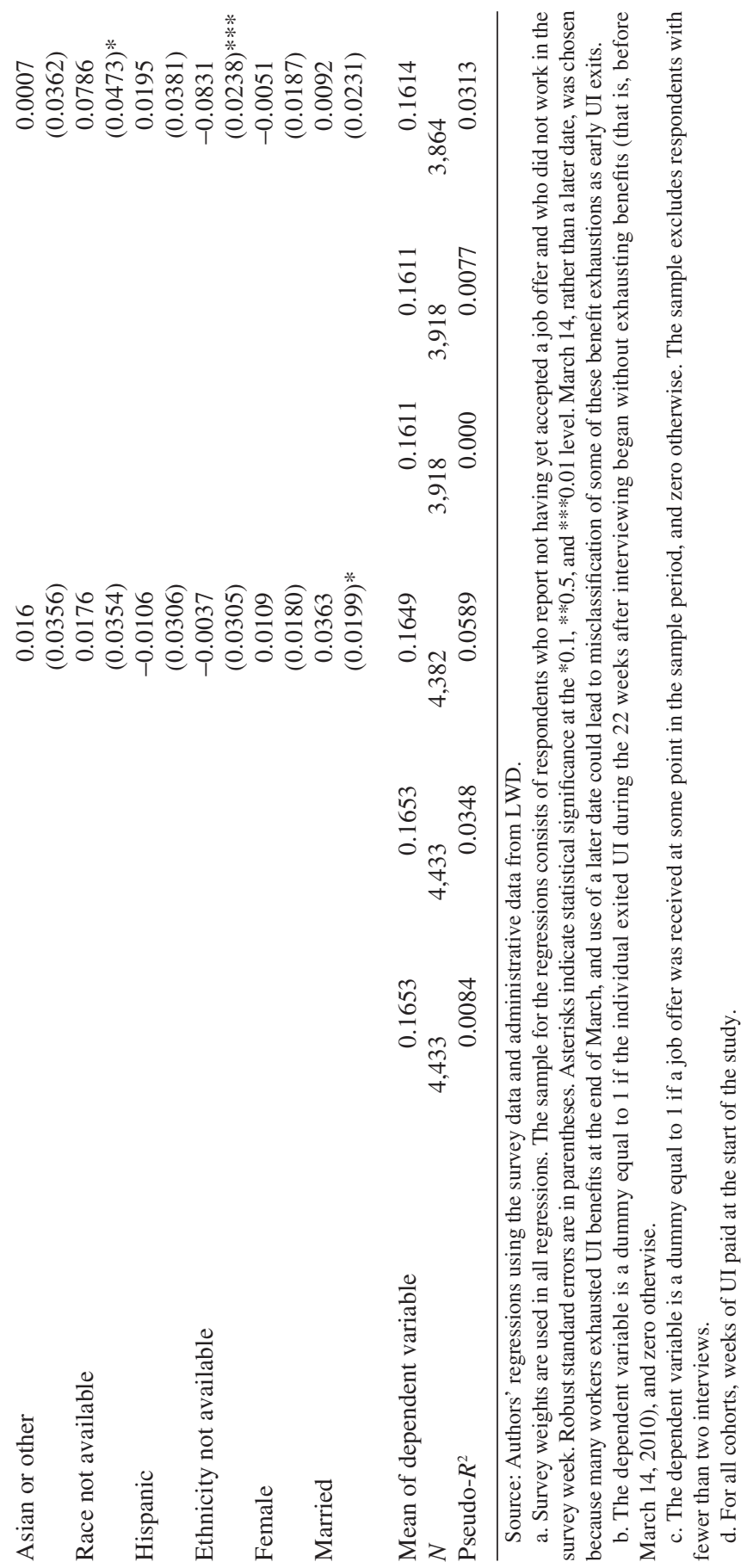


spent on job interviews. As mentioned above, we omitted the reservation wage ratio from the regressions reported in columns 12-4 to 12-6. However, when we include the logarithm of the reservation wage ratio in this model, the estimated coefficient is negative, significant, and similar in size to those in the regressions in columns 12-1 to 12-3. One possible explanation for this finding is that potential employers have some knowledge of the worker's reservation wage and are less likely to make a job offer if they perceive the reservation wage to be high. ${ }^{25}$

\section{Conclusion}

Several findings in this paper shed light on job search behavior in a depressed job market. In contrast to the prediction of sequential, stationary job search models (such as that of Mortensen 1977), we find that the amount of time devoted to job search declines sharply over the spell of unemployment. Because temporal factors (for example, seasonality or benefit extensions) could have distorted job search in our sample, a priority for future research is to determine whether this pattern can be replicated using longitudinal data for other time periods. Assuming that the declining search profile is robust, there are three likely explanations for this phenomenon. First, workers may exhaust the stock of suitable jobs to apply for the longer they are unemployed, and then wait for more jobs to become available rather than continue to spend time searching. Second, search efficiency may rise with time spent searching. Third, workers may become discouraged the longer they are unemployed, and this may prevent them from applying for available jobs. These factors are not mutually exclusive; each may occur to various degrees.

Some of our findings suggest that many workers become discouraged the longer they are unemployed. In particular, the unemployed report feeling more sad the longer they are unemployed, and their sadness rises more quickly with unemployment duration during episodes of job search. In addition, reported life satisfaction is lower for the same individual following days in which comparatively more time was devoted to job search, although we do not see a clear trend in life satisfaction over the spell of unemployment (perhaps because the declining amount of time spent searching for a job counteracts an otherwise declining trend in life satisfaction). These findings suggest that the psychological cost of job search rises the longer one is

25. We thank our discussant Steven Davis for this suggestion. 
unemployed, a feature that is not reflected in models that specify the cost of job search as the opportunity cost of time. The growing psychological cost of job search could lead many of the unemployed to become discouraged from searching vigorously for a job after an extended period of unemployment. If this is the case, the economy may be at risk of hysteresis and prolonged joblessness after the job market improves.

One possible reason why past studies have found job search assistance to consistently speed individuals' return to work is that it helps the unemployed to overcome feelings of anxiety and sadness that are associated with job search. ${ }^{26}$ Interventions that keep the long-term unemployed engaged in job search despite the high psychological cost may be particularly valuable in the current environment, with the average duration of unemployment at a record high level.

We find mixed results concerning extended unemployment benefits. On the one hand, workers do not appear to search more intensively in periods when their UI benefits have lapsed or have been exhausted, suggesting that EUC did not provide a serious disincentive to finding a job. In addition, we do not observe an increase in job finding once benefits are exhausted. On the other hand, we find that average search time was lower for workers as a whole after the maximum duration of benefits was extended from 79 to 99 weeks. However, this finding is sensitive to the functional form of the unemployment duration variable and the particular measure of job search and may be confounded by other temporal factors, such as seasonality. ${ }^{27}$ In future work we plan to examine the effect of EUC on consumption and reported reservation wages.

Lastly, the findings that the reservation wage and job search time predict early exit from UI highlight the importance for public policy of understanding these variables. Interventions that encourage more search effort and more moderate reservation wages could help to speed the return to work. However, the effect of the reservation wage on exiting UI is relatively small in our analysis because receipt of job offers is relatively rare in our sample.

26. See Meyer (1995) for a review of evidence regarding the effectiveness of job search assistance.

27. Also, it is worth noting that because we analyze search behavior of UI recipients at the individual worker level, the general equilibrium effects on job finding and employment are likely to be smaller than reflected in our data, as a reduction in search effort by some workers may increase the job-finding probability for other workers. See, for example, Levine (1993) for an analysis of spillover effects between the insured and uninsured unemployed. 
APPENDIX

\section{Description of the Survey and Data Coding}

On October 1, 2009, the Princeton University Survey Research Center (PSRC) obtained a complete list of the roughly 360,000 individuals receiving UI benefits in New Jersey as of September 28, 2009. The data were subjected to a stratified random sampling procedure to obtain a sample of $63,813 \mathrm{UI}$ recipients. This appendix provides a detailed description of the sampling and survey procedures.

\section{Stratified Random Sampling Procedure}

Almost half of UI recipients in New Jersey provided their e-mail address to the New Jersey Department of Labor and Workforce Development (LWD) when filing their claim. (Providing an e-mail address is a requirement for filing an online claim in New Jersey.) We selected workers both with and without e-mail addresses to participate in the study. So that we could follow relatively homogeneous groups over the course of the study, we sampled eight cohorts, defined by the number of weeks of UI benefits paid on current UI claims as of September 2009: zero to 2 weeks, 10 to 12 weeks, 20 to 22 weeks, 30 to 32 weeks, 40 to 42 weeks, 50 to 53 weeks, 60 to 63 weeks, and 72 to 77 weeks. Our initial design was to draw a random sample of 7,000 unemployed workers for each of the first seven cohorts (5,000 with e-mail addresses on file and 2,000 without), and 14,000 for the last cohort. This sampling procedure deliberately oversampled the long-term unemployed. Unfortunately, the number of unemployed workers in the seventh and eighth cohorts with e-mail addresses was smaller than our target, so we also sampled those with 64 to 71 weeks and more than 77 weeks of benefits, but in both cases we restricted the oversample to those with e-mail addresses on file.

The sampling strata thus consist of 18 groups, based on the initial duration of unemployment and the availability of an e-mail address. In total, the sample included 45,813 unemployed workers with e-mail addresses and 18,000 without.

\section{Invitation and Reminder E-Mails}

The LWD sent out an initial e-mail or letter a few days before the start of the survey to inform the selected sample members about the study and to encourage them to participate. The letter also made clear that participation in the study was voluntary and that the PSRC would not share any information on specific individuals with the LWD. 
The initial e-mail invitations, which contained a link to the web questionnaire, were sent out on October 13, 2009. An important component of the questionnaire was a time-use diary, which asked hour by hour how the respondent spent the previous day. To ensure that the number of time-use diaries was more or less evenly distributed across weekdays, the sample was divided into five groups, the first of which was sent an invitation e-mail on Tuesday morning, the second on Wednesday morning, and so on through Saturday morning. Participants were asked to complete the survey within 2 days of receiving the invitation e-mail.

Physical letters were mailed to those without e-mail addresses during the week of October 13. The letter provided the URL of the web page with the questionnaire and a 9-digit survey identification number, which the individual needed to log into the survey. The letters were staggered over 5 days in the same manner as the e-mail invitations. Survey participants from the letter strata were required to enter a valid e-mail address in order for them to receive e-mail invitations for the follow-up weekly interviews. If a respondent did not have an e-mail address, he or she could nevertheless participate in the weekly interviews by logging into the same access web page with the same 9-digit survey identification number as in the invitation letter.

Between October 19 and October 23, the PSRC made nearly 10,000 phone calls to encourage those who had not responded to the initial invitation to participate in the survey. In addition, 3 days and 7 days after the initial invitation was sent out, e-mails were sent to nonrespondents who had an e-mail address on file, encouraging them to participate. We closed the survey for entry on November 3 , when the average number of new participants had dropped to below 20 a day. Overall, 6,025 unemployed workers participated in the survey, 5,680 of whom entered within the first 2 weeks.

Invitations to complete the follow-up weekly interviews were sent out by e-mail 7 days after the most recent online interview was completed, but not on Sundays or Mondays, because we wanted the time-use diary to pertain to weekdays. ${ }^{28}$ If a participant did not complete a weekly interview within 3 days of receipt of an invitation, we sent a reminder e-mail. Further reminder e-mails were sent 7,14,21, 28, and 35 days after the last interview was completed. We encouraged people to respond to the survey even if they had already found a job.

Initially, individuals who were selected for the study were invited to participate for 12 consecutive weeks. In early January 2010, however,

28. Thus, if a respondent completed an interview on a Sunday, he or she would receive the invitation to the next interview on Tuesday of the following week, 9 days later. 
individuals with 60 weeks or more of UI benefits paid at the start of the study were invited to participate in an extended study for an additional 12 weeks. Some 1,148 individuals (out of 2,022 eligible) completed at least one interview of the extended study. The e-mail invitation and reminder system for the longer-term survey was exactly the same as for the initial 12 weeks of the study.

\section{Online Survey Instrument}

The online survey instrument was developed in collaboration with the Survey Research Institute (SRI) at Cornell University and consisted of two parts, the entry survey and the weekly questionnaire. The entry survey contained questions that were asked only once, the first time the individual completed the online survey. These questions related to the respondent's previous employment, job search, mortgage, and asset holdings and the employment status of the respondent's spouse. The weekly questionnaire was administered every time the participants completed the survey, and the questions related to the participant's life satisfaction, weekly food consumption, job search efforts over the previous week, reservation wage, and job offers. It also contained a time-use diary about activities in the previous day. In the first online interview the weekly questions were shortened, because the respondents also had to complete the entry part of the survey. Moreover, some questions in the weekly questionnaire were asked at a monthly frequency to reduce the burden on the respondent.

The time-use diary covered the previous day from 7 a.m. to 11 p.m. For each hour in the time diary, respondents could select up to 2 activities from a list of 21. The activities were chosen to represent the time-use codes most frequently used in other time-use surveys, such as the ATUS, and specifically included job search as an activity.

The average time to complete the weekly online survey was 15 minutes, and the median time was 12 minutes. The entry questionnaire was shorter and took on average 11 minutes to complete, with a median of 9 minutes. ${ }^{29}$

\section{Incentives}

At the end of the first online interview, participants were given two choices of payment: a \$20 VISA gift card to be sent to the participant within a few days, or a $\$ 40$ gift card to be sent at the end of the 12-week

29. We have only the start and the end time of each online interview. Some participants started the survey and then decided to return to it later in the day. We excluded from the calculation of average completion time all interviews where the start and end times were more than 2.5 hours apart. 
study period. ${ }^{30}$ The motivation for offering this choice was to elicit information on participants' time preferences. The online survey instrument stressed that if the participant chose the second option, we would send the $\$ 40$ gift card regardless of whether or not he or she completed the follow-up weekly interviews. Almost 54 percent of respondents opted to take the immediate $\$ 20$ payment over the delayed $\$ 40$ payment. The implicit discount rate consistent with choosing the $\$ 20$ payment exceeds 1,500 percent. In a probit analysis, we found that older workers, more highly educated workers, whites, and workers with credit cards (perhaps indicating greater access to credit) were significantly more likely to select the delayed $\$ 40$ payment over the immediate $\$ 20$ payment.

Subjects invited to participate in the extended survey of the long-term unemployed (see the subsection "Invitation and Reminder E-Mails") were promised a $\$ 40$ gift card at the end of the 12 -week period.

A total of $\$ 220,000$ in incentive payments was made.

\section{Nonresponse and Weighting}

The response rate for the entry survey was 9.7 percent. ${ }^{31}$ The response rate was higher among those contacted by e-mail (10.7 percent) than among those contacted by regular mail ( 6.9 percent). The number of follow-up interviews completed by each cohort was relatively similar. After the initial interview, the average respondent completed 4.1 follow-up interviews out of a maximum of 11 (excluding the longer-term follow-up), so participants in the initial survey responded to almost 40 percent of the potential follow-up interviews.

Thus, the response rate for the survey was low, as is typical of Internet surveys, but we were fortunate also to have restricted access to administrative data from the LWD. The administrative data encompass a large set of variables, including demographic information, the weekly UI benefit, earnings in the base year, weeks worked in the base year, number of employers in the base year, industry and occupation on the last job, the date of claim, the number of weeks of UI benefits paid, and the remaining balance on the UI claim. We also obtained updated UI data at the end of the study period on the weeks of UI benefits paid, the date of the most recent UI payment on

30. The decision to offer a one-time payment for participation rather than an ongoing payment for each interview completed was made to minimize recordkeeping and associated costs.

31. The calculation of the response rate excluded from the denominator 1,972 cases for which the address could not be certified by the Coding Accuracy Support System of the U.S. Postal Service and therefore no letter was generated, or where the letter was sent but returned as nondeliverable. 
the claim, and whether the respondent had filed a new UI claim since the start of the study.

Table 1 in the text shows descriptive statistics for the universe of unemployed, the sample frame, and the respondents. The statistics for the sample frame are relatively similar to those for the universe, except for the weeks of UI benefits paid, because the stratified sample intentionally oversampled those with longer durations. There are some noticeable differences between the sample frame and the respondents, however. The respondents tended to have higher base-year earnings and higher benefit amounts and were more likely to be female, white, and non-Hispanic and to have attained a college degree.

To adjust our estimates for different sampling probabilities and response rates, we created survey weights based on the administrative data. Specifically, for the initial interview we estimated a logit regression where the dependent variable was a dummy variable indicating whether the unemployed worker had responded to the survey or not, and the independent variables were demographic measures, including education, age, sex, race, and ethnicity. (The bottom panel of table 1 contains the full list of demographic variables included in the models.) Our logit model also included dummy variables for each stratum used in our sampling procedure ( 0 to 9 weeks of UI benefits paid, 10 to 19 weeks, and so forth up to 70 or more weeks, each interacted with a dummy for whether the person had an e-mail address on file or not).

Entry-wave survey weights were computed as the inverse of the predicted value of the logit regression; these weights adjust for different response rates as well as different sampling probabilities due to our stratified random sampling procedure. As one would expect, the weights are greater, on average, for men, Hispanics, blacks, those with a high school diploma or less, and those whose strata were undersampled (that is, those with lower durations and those without an e-mail on file). The weights were rescaled to sum to the total number of individuals in the universe. We label these weights "person weights," as they adjust for different response rates for the first interview of the survey and do not vary with the weeks of the survey.

To derive weights for differential response rates over the 12 weeks of the survey (or 24 weeks, for those who participated in the extended study), we created an analogous set of weights, labeled "current week weights," for each week of the survey. To obtain these weights we estimated the same logit model described above for each week of the survey and rescaled the weights to sum to the number of cases in the universe.

Finally, we created "strata weights" for the sample frame, which simply reflect the different sampling probabilities due to our stratified random 
sampling procedure but do not adjust for differential response across demographic groups. These weights are used to compare the stratified sample frame with the universe or with the weighted sample of respondents (weighted with the person weights or the current week weights).

The last two columns of table 1 report weighted descriptive statistics for the sample frame and the respondents. Comparing the universe and the weighted sample frame with the weighted statistics of the respondents in the last column, one finds that the demographics are very similar for these three samples. In particular, the share of college graduates falls from 40.7 percent for the unweighted respondents to 18.7 percent for the weighted respondents, which is very close to the percentages for the universe and the weighted sample frame (both 19.0 percent). This is not surprising as education dummies and other demographic data were used to create the survey weights. As an out-of-sample test, we compared the weighted statistics of variables that were not used in the creation of the survey weights. Most important, weighted earnings of respondents during the base year $(\$ 37,960)$ are reasonably close to earnings in the base year in the universe $(\$ 35,335)$. The industry composition of the weighted respondents is also relatively similar to that for the universe, although construction workers are underrepresented among the respondents. Finally, weeks of UI benefits paid are slightly lower for the weighted respondents than for the universe. The reason is that the universe includes workers of all durations, whereas the stratified sample frame includes only workers with durations of 0 to 2 weeks, 10 to 12 weeks, and so forth. When the stratified sample frame is compared with the respondents, weighted and unweighted, the weeks of UI benefits paid are very similar, suggesting that response rates were similar across unemployed workers with different durations.

\section{Data Coding and Trimming}

BASE-YEAR EARNINGS ABOVE THE TOP CODE. Annual earnings are top-coded at $\$ 99,999$ in the administrative data. Some 3.8 percent of observations had earnings above the top code. We follow the procedure outlined by Feenberg and Poterba (1993) to impute earnings above the top code. We assume that earnings above a certain percentile follow a Pareto distribution and estimate the two parameters of the Pareto distribution with earnings for the part of the distribution that is not top-coded. More precisely, the cumulative distribution function of the Pareto distribution is $F(e)=1-(k / e)^{\alpha}$, and we estimate the parameters $k$ and $\alpha$ with base earnings at the 90th percentile, where $F\left(e_{p 90}\right)=0.9$ and $e_{p 90}=68,866$, and with base earnings at the top 
code, where $F\left(e_{t c}\right)=0.9663$ and $e_{t c}=99,999.99$. The estimated parameter values are $k=31,266$ and $\alpha=2.916$, and the implied mean above the top code is:

$$
E\left(e \mid e>e_{t c}\right)=\frac{1}{1-F\left(e_{t c}\right)} \int_{e_{t c}} e f(e ; k, \alpha) d e=152,190.5
$$

where $f(e ; k, \alpha)=\alpha k^{\alpha} e^{-(\alpha+1)}$ is the density of the Pareto distribution.

To eliminate some apparent mistakes, in our analysis sample we trimmed a small number of observations (1.3 percent) whose ratio of weekly benefits to weekly earnings exceeded 2.0.

IMPUTING HOURS ON PREVIOUS JOB WHEN HOURS "VARIED" OR ARE MISSING. Around 18 percent of the respondents reported "hours varied" on their previous main job (question e1) or on their previous other jobs (question e3). We imputed hours for this group and for those few cases with missing hours data using the following procedure. First, we estimated separate regressions for men and women, in which the dependent variable was hours and explanatory variables were age, race, ethnicity, education, marital status, presence of children, and a dummy for whether the person had more than one job. Then we computed the fitted value of this regression to impute hours for those who had indicated "hours varied" or had missing hours. If hours varied only for the other jobs (e3), we added the coefficient estimate for the dummy "had more than one job" to the hours reported for the main job (e1).

WEEKLY AND HOURLY PREVIOUS WAGES. We computed the weekly previous wage by dividing the base earnings by the number of weeks worked in the base year (the "base weeks"), and the hourly previous wage by dividing the weekly previous wage by the hours reported in the survey. We trimmed observations with previous weekly earnings greater than $\$ 8,000$ or less than $\$ 100$ and with previous hourly wages greater than $\$ 100$ or less than $\$ 5$.

RESERVATION WAGES. Our reservation wage question was almost identical to that from the 1976 Current Population Survey analyzed by Feldstein and Poterba. We trimmed 2,234 out of 36,514 observations with reservation wage ratios greater than 3 or less than $1 / 3$, following the same procedure as Feldstein and Poterba (1984). We defined the reservation wage ratio as the weekly reservation wage divided by the weekly previous wage (based on administrative data), because by using weekly wage data we avoided using imputed hours for those who had indicated that hours varied on their last job. We also trimmed observations with weekly reservation wages greater than $\$ 8,000$ or less than $\$ 100$, and with hourly reservation wages greater 
than $\$ 100$ or less than $\$ 5$. This caused us to exclude an additional 458 observations.

TIME SPENT ON JOB SEARCH. In our analysis of the time spent on job search yesterday, we used only observations where at least 14 out of 16 episodes in the time diary were filled in and where the respondents indicated at least four different activities over the course of the day. Around 7.8 percent of the diaries did not meet these quality criteria and were excluded from our analysis. Respondents could check two activities in each 1-hour interval. If two activities were reported, we assigned 30 minutes to each activity.

We computed the total amount of time spent on job search in the past week as the sum of time spent on the different job search methods. If a respondent indicated that she or he did not search over the last 7 days (question q9a), the total amount of time was set to zero. We trimmed observations where the total amount of time spent on job search exceeded 80 hours a week. We also trimmed observations if time spent on a job search method was missing. Overall, 1.3 percent of the interviews were excluded from our analysis of time spent on job search in the last 7 days because of trimming.

ACKNOWLED G MENTS We thank Ed Freeland for invaluable assistance in designing and implementing our survey, Yasamin Miller and her team for implementing the web survey, Doug Mills for computer programming assistance, and the Princeton University Industrial Relations Section, the Woodrow Wilson School of Public and International Affairs, and the National Institute of Aging (Roybal Grant P30AG024928) for financial support. We thank Orley Ashenfelter, David Card, Bob Hall, Larry Katz, and Rob Shimer for helpful comments. This research was conducted under the terms of a memorandum of understanding with the New Jersey Department of Labor and Workforce Development, and we are grateful for their assistance and cooperation. The authors are solely responsible for all views expressed in the paper and for any errors. Alan Krueger was assistant Treasury secretary for economic policy from 2009-10, during periods when UI benefits were extended. The authors report no relevant potential conflicts of interest. 


\section{References}

Bailar, Barbara A. 1975. "The Effects of Rotation Group Bias on Estimates from Panel Surveys." Journal of the American Statistical Association 70, no. 349: 23-30.

Barron, John M., and Wesley Mellow. 1979. "Search Effort in the Labor Market." Journal of Human Resources 14, no. 3: 389-404.

Björklund, Anders. 1985. "Unemployment and Mental Health: Some Evidence from Panel Data." Journal of Human Resources 20, no. 4: 469-83.

Clark, Andrew E., and Andrew J. Oswald. 1994. "Unhappiness and Unemployment." Economic Journal 104, no. 424: 648-59.

Devine, Theresa J., and Nicholas M. Kiefer. 1991. Empirical Labor Economics. New York: Oxford University Press.

Elsby, Michael W. L., Bart Hobijn, and Ayşegül Şahin. 2010. "The Labor Market in the Great Recession." BPEA, no. 1: 1-48.

Feenberg, Daniel R., and James M. Poterba. 1992. "Income Inequality and the Incomes of Very High Income Taxpayers: Evidence from Tax Returns." In Tax Policy and the Economy, vol. 7, edited by James M. Poterba. MIT Press.

Feldstein, Martin, and James Poterba. 1984. "Unemployment Insurance and Reservation Wages." Journal of Public Economics 23, no. 1-2: 141-67.

Granovetter, Mark S. 1974. Getting a Job: A Study of Contacts and Careers. Harvard University Press.

Hall, Robert E., and Alan B. Krueger. 2010. "Evidence on the Determinants of the Choice between Wage Posting and Wage Bargaining." Working Paper no. 16033. Cambridge, Mass.: National Bureau of Economic Research.

Holzer, Harry J. 1988. "Search Method Use by Unemployed Youth." Journal of Labor Economics 6, no. 1: 1-20.

Jones, Stephen R. G. 1988. "The Relationship between Unemployment Spells and Reservation Wages as a Test of Search Theory." Quarterly Journal of Economics 103, no. 4: 741-65.

Jurajda, Stepan, and Frederick J. Tannery. 2003. "Unemployment Durations and Extended Unemployment Benefits in Local Labor Markets." Industrial and Labor Relations Review 56, no. 2: 324-48."

Kaitz, Hyman B. 1970. "Analyzing the Length of Spells of Unemployment." Monthly Labor Review 93 (November): 11-20.

Katz, Lawrence F., and Bruce D. Meyer. 1990. "Unemployment Insurance, Recall Expectations, and Unemployment Outcomes." Quarterly Journal of Economics 105, no. 4: 973-1002.

Krueger, Alan B., and Andreas Mueller. 2010. "Job Search and Unemployment Insurance: New Evidence from Time Use Data." Journal of Public Economics 94, no. 3-4: 298-307.

Levine, Phillip B. 1993. "Spillover Effects between the Insured and Uninsured Unemployed." Industrial and Labor Relations Review 47, no. 1: 73-86. 
Marlar, Jenny. 2010. "Worry, Sadness, Stress Increase with Length of Unemployment." Washington: Gallup. www.gallup.com/poll/139604/worry-sadness-stressincrease-length-unemployment.aspx.

Meyer, Bruce D. 1990. "Unemployment Insurance and Unemployment Spells." Econometrica 58, no. 4: 757-82.

1995. "Lessons from the U.S. Unemployment Insurance Experiments." Journal of Economic Literature 33, no. 1: 91-131.

Moffitt, Robert. 1985. "Unemployment Insurance and the Distribution of Unemployment Spells." Journal of Econometrics 28, no. 1: 85-101.

Mortensen, Dale T. 1977. "Unemployment Insurance and Job Search Decisions." Industrial and Labor Relations Review 30, no. 4: 505-17.

Solon, Gary. 1986. "Effects of Rotation Group Bias on Estimation of Unemployment." Journal of Business and Economic Statistics 4, no. 1: 105-09.

Van den Berg, Gerard J., and Jan C. van Ours. 1994. "Unemployment Dynamics and Duration Dependence in France, the Netherlands and the United Kingdom." Economic Journal 104, no. 423: 432-43.

Wanberg, Connie R., Jing Zhu, Ruth Kanfer, and Zhen Zhang. Forthcoming. "After the Pink Slip: Applying Dynamic Motivation Frameworks to the Job Search Experience." Academy of Management Journal.

Winkelmann, Liliana, and Rainer Winkelmann. 1998. "Why Are the Unemployed So Unhappy? Evidence from Panel Data.” Economica 65, no. 257: 1-15. 


\section{Comments and Discussion}

\section{COMMENT BY}

STEVEN J. DAVIS Alan Krueger and Andreas Mueller present new evidence on job search activity, job finding, life satisfaction, mood, and reservation wages among unemployed workers. Notably, they exploit highfrequency longitudinal data to estimate how individual search time responds to unemployment spell duration (measured as weeks receiving unemployment benefits). Another noteworthy aspect of the Krueger-Mueller study is the setting: a period of high unemployment and historically low job-finding rates.

The authors' survey instrument yields two measures of search time. On average, unemployed workers devote 65 minutes per day to job search activity according to time diary data and 98 minutes per day according to weekly recall data. Over three decades ago, John Barron and Wesley Mellow (1979) reported that unemployed persons spend on average about 7 hours per week searching for a job, remarkably similar to what Krueger and Mueller find in their time diary data.

Krueger and Mueller find large negative effects of unemployment spell duration on job search time. In a regression specification that controls for individual fixed effects, they estimate that 10 additional weeks of unemployment reduces search time by 27 minutes per day in the time diary data and by 22 minutes per day in the weekly recall data (their table 2). This estimated effect drops to about 16 minutes when they add controls for whether an individual's benefits lapsed or ended and a dummy for observations after November 8, 2009, when the federal government extended the maximum benefit duration from 79 weeks to 99 weeks. Given the wide variation in spell duration, its estimated effect is very large relative to mean search time.

This finding is important for at least two reasons. First, standard theoretical models of job-seeking behavior imply that search intensity is constant or increasing with respect to unemployment spell duration. This implication 
is at odds with the Krueger-Mueller evidence, assuming that search time serves as a reasonable proxy for search intensity. Second, the large theoretical and empirical literatures that use matching functions to explain labor market flows, job-finding rates, and Beveridge curve behavior routinely assume that average search intensity per unemployed worker is stable over time. As I explain below, the Krueger-Mueller evidence challenges this assumption. Some of my recent work with Jason Faberman and John Haltiwanger (Davis, Faberman, and Haltiwanger 2010) challenges the analogous assumption of stable recruiting intensity per vacancy on the employer side of the market.

My remarks below treat three issues related to Krueger and Mueller's finding that search time falls with spell duration. First, do reporting errors impart a bias to this estimated relationship? Second, why might search time fall with the duration of unemployment? Third, does the estimated effect of spell duration on search time have important macroeconomic implications? In particular, can it shed light on the cyclical behavior of average job-finding rates among the unemployed? Although the paper has many other interesting aspects, I confine my remarks to these issues.

DO REPORTING ERRORS BIAS THE ESTIMATED EFFECT OF SPELL DURATION ON SEARCH TIME? The authors' weekly survey instrument triggers several additional questions if the respondent reports searching for a job. These additional questions seek to elicit information about time spent in specific search activities, self-assessed mood during various search activities, the types of jobs to which the respondent applied, the farthest distance traveled to look for a job, and whether and how the respondent used the Internet to search for a job. Thus, the respondent can lessen the inconvenience of completing the questionnaire by reporting that he or she did not search for a job. A given respondent completes the questionnaire up to 24 times. So there is ample opportunity to learn that affirmative responses to questions about job search trigger additional questions. If respondents become more likely to falsely report no job search as they gain familiarity with the questionnaire, they also become more likely to falsely report zero search time as spell duration increases. This pattern of reporting errors imparts a negative bias to the estimated effect of spell duration in search-time regressions fit to longitudinal data.

Two aspects of the empirical results reported suggest that this source of bias is at work. First, across cohorts defined by the timing of job loss in the authors' figure 3, reported search time in the first application of the survey instrument does not fall with spell duration-despite a range of more than 70 weeks in the initial spell duration. Krueger and Mueller refer 
to this phenomenon as a "curious" pattern of parallel search-time profiles across cohorts. They argue, persuasively in my view, that calendar time effects do not explain this curious pattern. They also argue that differences in average characteristics across cohorts influence the levels of the cohortspecific search-time profiles. However, they do not quantify whether and to what extent these differences help reconcile their preferred estimates for the spell duration effect with the cross-cohort pattern of search-time profiles. I suspect that differences in average cohort characteristics do not go very far in this direction. In short, it appears that neither calendar time effects nor cohort effects explain the curious pattern in figure 3. Reporting errors that vary with the number of previous interviews provide an alternative explanation.

Second, the top panel of the authors' figure 4 shows that reported participation in job search activity declines sharply with spell duration for each cohort. This graph also exhibits the same curious pattern as figure 3 . These two aspects are consistent with the reporting error story described above. However, the bottom panel of the figure shows that reported search time falls with spell duration among those who report job search activity on the previous day. This graph also exhibits the same curious pattern of roughly parallel search-time profiles across cohorts. The reporting error story described above does not imply these patterns in the bottom panel.

In practice, the number of previously completed interviews does not advance in lockstep with spell duration because respondents skip many of the weekly interviews. This makes it possible to estimate the effect of spell duration conditional on the number of previous interviews. Krueger and Mueller kindly supplied me with search-time regression results for specifications that include controls for the number of previous interviews. My table 1 reports the estimated effect of spell duration on search time with and without these controls. The first column reproduces results from the authors' table 2. The second column allows for a reporting error effect that is linear in the number of previous interviews, and the third relaxes the linearity restriction. ${ }^{1}$

Adding a linear control attenuates the estimated spell duration effect in the time diary data but not in the weekly recall data. Adding a vector

1. Specifically, the third column adds to the regression in the first column a vector of dummy variables for $1,2,3,4,5$, and 6 or more previous interviews. This specification adequately controls for the reporting error effect discussed in the text if there are no material differences in conditional mean reporting errors by cohort and by number of previous interviews greater than 6. 
Table 1. Regressions Explaining Job Search Time with Unemployment Spell Duration and the Number of Survey Interviews ${ }^{\mathrm{a}}$

\begin{tabular}{|c|c|c|c|}
\hline \multirow[b]{2}{*}{ Regression specification } & \multicolumn{3}{|c|}{ Additional controls } \\
\hline & None $e^{\mathrm{b}}$ & $\begin{array}{l}\text { No. of previous } \\
\text { interviews }\end{array}$ & $\begin{array}{c}\text { Vector of controls } \\
\text { for previous } \\
\text { interviews }\end{array}$ \\
\hline \multicolumn{4}{|c|}{ Dependent variable: time spent on job search yesterday (minutes per day) } \\
\hline $\begin{array}{l}\text { Krueger and Mueller, } \\
\text { table } 2 \text {, fourth column }\end{array}$ & $\begin{array}{l}-2.73 \\
(0.25)\end{array}$ & $\begin{array}{l}-1.83 \\
(0.75)\end{array}$ & $\begin{array}{r}-0.44 \\
(0.32)\end{array}$ \\
\hline $\begin{array}{l}\text { Krueger and Mueller, } \\
\text { table } 2 \text {, fifth column }\end{array}$ & $\begin{array}{l}-1.62 \\
(0.31)\end{array}$ & $\begin{array}{l}-0.77 \\
(0.74)\end{array}$ & $\begin{array}{l}-0.45 \\
(0.36)\end{array}$ \\
\hline \multicolumn{4}{|c|}{ Dependent variable: time spent on job search in last 7 days (minutes per day) } \\
\hline $\begin{array}{l}\text { Krueger and Mueller, } \\
\text { table } 2 \text {, fourth column }\end{array}$ & $\begin{array}{l}-2.25 \\
(0.29)\end{array}$ & $\begin{array}{l}-2.45 \\
(0.85)\end{array}$ & $\begin{array}{l}-0.96 \\
(0.39)\end{array}$ \\
\hline $\begin{array}{l}\text { Krueger and Mueller, } \\
\text { table } 2, \text { fifth column }\end{array}$ & $\begin{array}{l}-1.54 \\
(0.33)\end{array}$ & $\begin{array}{l}-1.76 \\
(0.84)\end{array}$ & $\begin{array}{l}-0.90 \\
(0.40)\end{array}$ \\
\hline \multicolumn{4}{|c|}{$\begin{array}{l}\text { Source: Krueger and Mueller, this volume, and regressions conducted by Krueger and Mueller not } \\
\text { eported in the paper. } \\
\text { a. Table reports estimated coefficients on the unemployment spell duration variable in the indicated } \\
\text { egression specification. Standard errors are in parentheses. } \\
\text { b. As reported in Krueger and Mueller, this volume, table } 2 \text {. } \\
\text { c. Vector consists of dummy variables for } 1,2,3,4,5 \text {, and } 6 \text { or more previous interviews. }\end{array}$} \\
\hline
\end{tabular}

of controls for number of previous interviews has a much stronger impact on the character of the results. As the third column of table 1 shows, the estimated spell duration effect is now modest and statistically insignificant in the time diary data. It remains negative and statistically significant in the weekly recall data, but the point estimate is much smaller than in the first column.

I read table 1 and my observations about the authors' figures 3 and 4 as strong indications that the estimates reported in the rightmost three columns of their table 2 overstate the true effect of spell duration on search time. My table 1 suggests that the bias results from reporting errors that become more severe with repeated applications of the survey instrument. However, these results and my remarks about figure 4 indicate that reporting errors do not fully explain the decline in search time as an individual's unemployment spell lengthens. In other words, the overall weight of the evidence supports the claim that search time declines with spell duration. As I remarked at the outset, I see this result as an important finding.

There is a need for additional research into the relationship between spell duration and search time. As Krueger and Mueller point out, it would be useful to randomly vary the time interval between interviews to deal more 
conclusively with the effects of reporting errors that vary with the number of interviews.

WHY MIGHT SEARCH TIME FALL WITH UNEMPLOYMENT SPELL DURATION? One possibility is that individuals become more efficient searchers with practice: for example, they may become faster at scanning help-wanted advertisements and assessing which ones offer suitable matches. If search efficiency improves in this sense, optimal search time per period declines with spell duration under mild assumptions about the costs and benefits of job search. ${ }^{2}$ A second possibility is that job search activity becomes increasingly painful psychologically as an unemployment spell lengthens. Psychological effects of this sort could raise the marginal cost of searching and reduce individually optimal search time. Yet another possibility is that lack of success in job hunting leads to negative revisions in the worker's assessment of his or her own skills and capabilities. Revisions of this sort imply inward shifts in the schedule describing the perceived marginal benefit of search time. As a result, individually optimal search time falls. A fourth possibility is that persons negatively revise their judgments about the availability of suitable job opportunities as an unemployment spell lengthens. This possibility involves revisions to perceived market opportunities rather than one's own skills, but it, too, produces an inward shift in the perceived rewards to search activity. All four of these possibilities warrant attention in future research.

Krueger and Mueller interpret some of their findings as evidence that the psychological costs of job search may rise with spell duration, and that such costs could discourage job search after an extended period of unemployment. I am sympathetic to this concern, but the relationship between subjective well-being and search intensity is likely to be complex. Even if deteriorations in mood or life satisfaction raise the psychological costs of job search, the overall effect on search intensity is unclear because of a countervailing effect on the psychological reward to finding a job.

Previous research suggests that this countervailing effect is empirically relevant and large. Using British data, Andrew Clark (2003) finds that persons who experience larger drops in subjective well-being on becoming unemployed are more likely to search actively for a new job if still unemployed 1 year later. Using German data, Anne Gielen and Jan van Ours (2010) find much higher job-finding rates for persons who experience

2. Marginal costs that rise with search time in the period and marginal benefits that fall with efficiency units of search are sufficient conditions at an interior optimum. 
Figure 1. Mean Unemployment Spell Duration, January 2001-February 2011

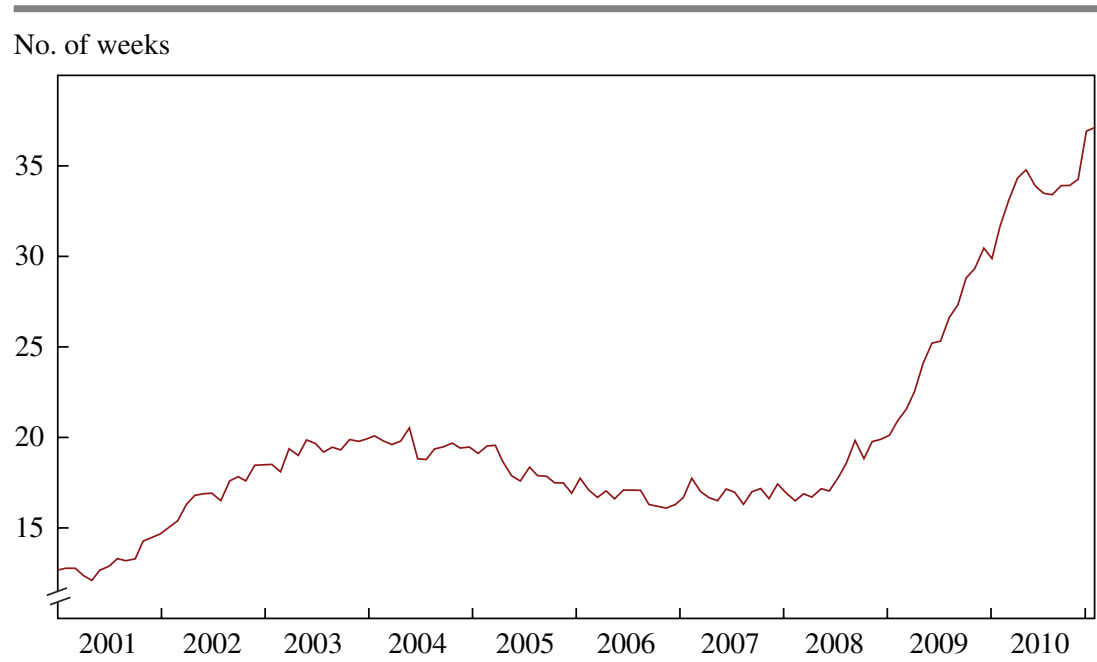

Source: Current Population Survey data.

a. Data are for persons 16 years and older and are seasonally adjusted.

larger drops in life satisfaction on becoming unemployed. They also find that postunemployment wages are unrelated to the drop in life satisfaction, which suggests that higher job-finding rates result from greater search intensity, not from lower reservation wages.

Evaluating the impact of psychological effects on job search activity and, more generally, investigating why spell duration negatively affects search time are important topics for future research. Krueger and Mueller's study adds to the impetus for additional research in this area.

IMPLICATIONS FOR THE CYCLICALITY OF AVERAGE JOB-FINDING RATES My figure 1 plots the mean unemployment spell duration in the United States from January 2001 to February 2011. The figure shows a dramatic rise in mean duration from 17 weeks in July 2008 to 34 weeks in May 2010 and 37 weeks in January 2011. If one applies the spell duration effect estimated by Krueger and Mueller to this 20 -week rise in mean spell duration, it implies that average search time per unemployed worker fell by 31 to 55 minutes per day over this period. ${ }^{3}$ That is a very large drop relative to

3. These search-time responses reflect the estimated coefficients on spell duration in the last two columns of Krueger and Mueller's table 2, reproduced in the first column of my table 1 . 
Figure 2. Empirical Job-Finding Rate and Rate Implied by a Standard Job-Matching Function, January 2001-February 2011

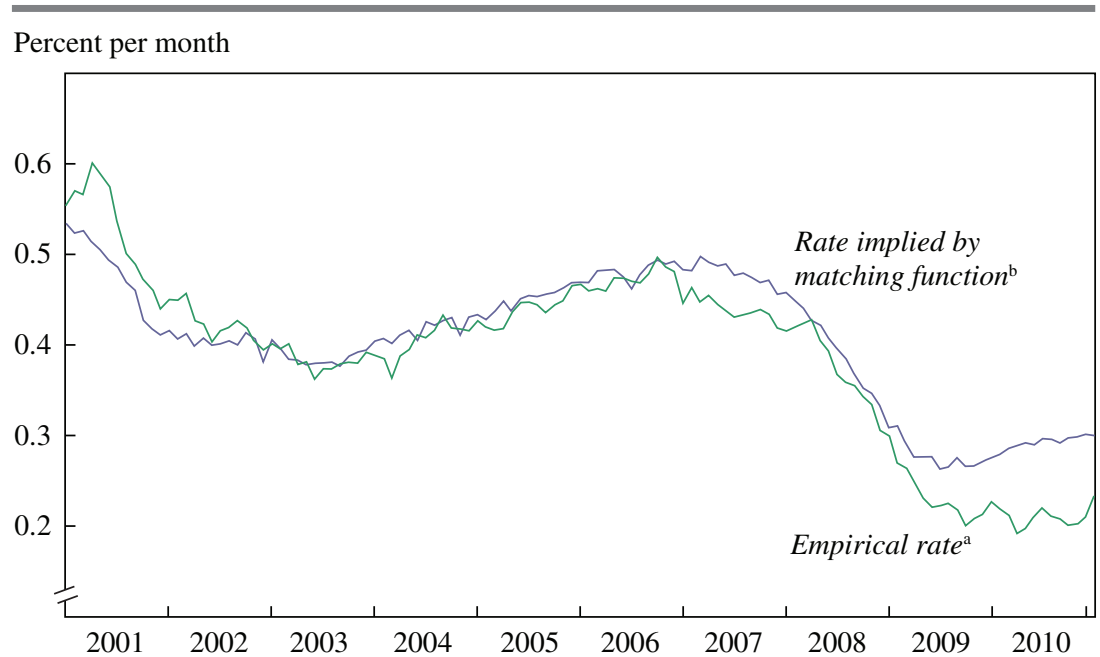

Source: Author's calculations using data from the Current Population Survey (CPS) and the Job Openings and Labor Turnover Survey (JOLTS).

a. Unemployment exit rate calculated using CPS data on unemployment by duration. See, for example, section II.B in Davis, Faberman, and Haltiwanger (2010) for a description of the calculation.

b. Calculated by substituting CPS data on unemployment and JOLTS data on job vacancies into the matching function $H=\mu U^{\alpha} V^{1-\alpha}$, where $\mu$ is chosen to equate the means of the empirical and implied job-finding rates from 2001 to 2007 and $\alpha=0.6$.

the mean search time of 60 to 100 minutes per day reported by Krueger and Mueller and by Barron and Mellow (1979), and large enough to have important macroeconomic consequences.

To appreciate this point, consider the cyclical behavior of job-finding rates for unemployed workers, an object of intensive research efforts in recent years (for example, Hall 2005 and Shimer 2005). My figure 2 compares a standard empirical measure of the job-finding rate since 2001 with the rate implied by a standard Cobb-Douglas matching function for aggregate hires, $H=\mu U^{\alpha} V^{1-\alpha}$. In computing the implied job-finding rate, I set $\alpha=0.6$. This value lies in the middle of the range of elasticity estimates produced by matching function studies that use unemployment outflows as the dependent variable (Petrongolo and Pissarides 2001).

As figure 2 shows, the actual and implied job-finding rates track each closely over most of the sample period, but there is a large and persistent divergence in recent years. The nature of the divergence is interesting: the empirical job-finding rate declines more sharply than implied by the standard 
matching function beginning in 2007. Moreover, it has yet to recover to levels implied by the standard matching function.

The standard matching function includes no role for variations in average search intensity per unemployed worker. The evolution of the gap between empirical and implied job-finding rates in figure 2 and its rough similarity to the path of mean spell duration in figure 1 suggest that the standard matching function breaks down because it neglects the role of cyclical movements in search intensity. Davis, Faberman, and Haltiwanger (2010) present an analogous comparison for the job-filling rate of vacant job positions. They obtain a pattern very similar to that in figure 2 : the empirical and implied job-filling rates track each other closely until the end of 2007, after which a large and persistent divergence arises. Thus, it is unlikely that the path of the residual gap in figure 2 reflects some deficiency in the empirical measure of the job-finding rate. Instead, the deficiency more likely lies in the specification of the matching function.

The evidence presented by Krueger and Mueller, taken together with figure 1, suggests that one deficiency is the omission of movements in average search intensity per unemployed worker. Davis, Faberman, and Haltiwanger (2010) develop evidence that another deficiency is the omission of movements in recruiting intensity per vacancy. Following the approach in my work with Faberman and Haltiwanger, I now generalize the standard matching function to encompass these two intensity margins. I will use the generalized function to provide a first-pass quantification of what the Krueger-Mueller evidence implies for the cyclical behavior of jobfinding rates.

To draw out the implications of the Krueger-Mueller evidence, I must take a partial stand on what drives the estimated effect of spell duration on search time. I treat search time as a measure of effective search units supplied by an individual unemployed worker. This approach is a natural one and consistent with standard extensions of Mortensen-Pissarides models to incorporate variable search intensity (see, for example, chapter 5 in Pissarides 2000). However, my approach here is not suitable if individual search efficiency per unit of search time varies substantially with individual spell duration.

Consider a generalized matching function for new hires in period $t$ given by

$$
H_{t}=\mu\left[s_{t} U_{t}\right]^{\alpha}\left[q_{t} V_{t}\right]^{1-\alpha}
$$

where $U$ and $V$ are the numbers of unemployed workers and vacant jobs, $s$ is average search intensity per unemployed worker, $q$ is average recruiting intensity per vacancy, and the elasticity parameter $\alpha$ lies between 
0 and 1 . This matching function yields the following expression for the job-finding rate:

$$
J F_{t}=\mu\left[s_{t}\right]^{\alpha}\left[q_{t}\left(V_{t} / U_{t}\right)\right]^{1-\alpha} .
$$

To operationalize this expression, I need measures for vacancies, unemployment, the two intensity indexes, and the elasticity parameter. I obtain data on vacancies and unemployment from the Bureau of Labor Statistics' Job Openings and Labor Turnover Survey and the Current Population Survey (CPS), respectively. I set the elasticity parameter $\alpha=0.6$, as before. The recruiting intensity index I borrow from Davis, Faberman, and Haltiwanger (2010).

To construct a search intensity index, I combine the Krueger-Mueller estimation results with CPS data on mean unemployment spell duration. Specifically, I treat search intensity per unemployed worker as a linear function of search time per unemployed worker:

$$
s_{t}=A-\beta(\text { weeks })_{t},
$$

where weeks is the mean spell duration of unemployed workers and $\beta$ is the marginal effect of spell duration on search time. From the last column of Krueger and Mueller's table 2 (bottom panel), I set $\beta=1.54$. I set $A=$ $97.6+1.54(27.4)$, where 97.6 is mean search time in minutes per week in the Krueger-Mueller sample and 27.4 is mean spell duration in weeks at the sample start. Substituting these values into the search intensity index and feeding through the aggregate time series for mean spell duration yields a time series for $s$. In light of my earlier remarks about bias in the KruegerMueller estimates, I repeat the construction of the search intensity index using $\beta=0.90$ from the third column of my table $1 .{ }^{4}$

Figure 3 plots the resulting index of search intensity alongside the index of recruiting intensity. Both intensity measures fall sharply in recent years, which depresses the job-finding rate at any given vacancyunemployment ratio. The recent behavior of the two indexes also differs in important respects. The recruiting intensity index falls by about 20 percent over 2007 and 2008, then stabilizes and recovers slightly. The search intensity index holds steady until the middle of 2008 but then falls nearly 25 percent by the middle of 2010 . The big swings in these two indexes suggest that attention to search and recruiting intensity can improve our

4. In this case I should also adjust the mean search time in the Krueger-Mueller sample for measurement error. For simplicity, I ignore this issue in my calculations. 
Figure 3. Indexes of Search Intensity per Unemployed Worker and Recruiting Intensity per Vacancy, January 2001-February 2011

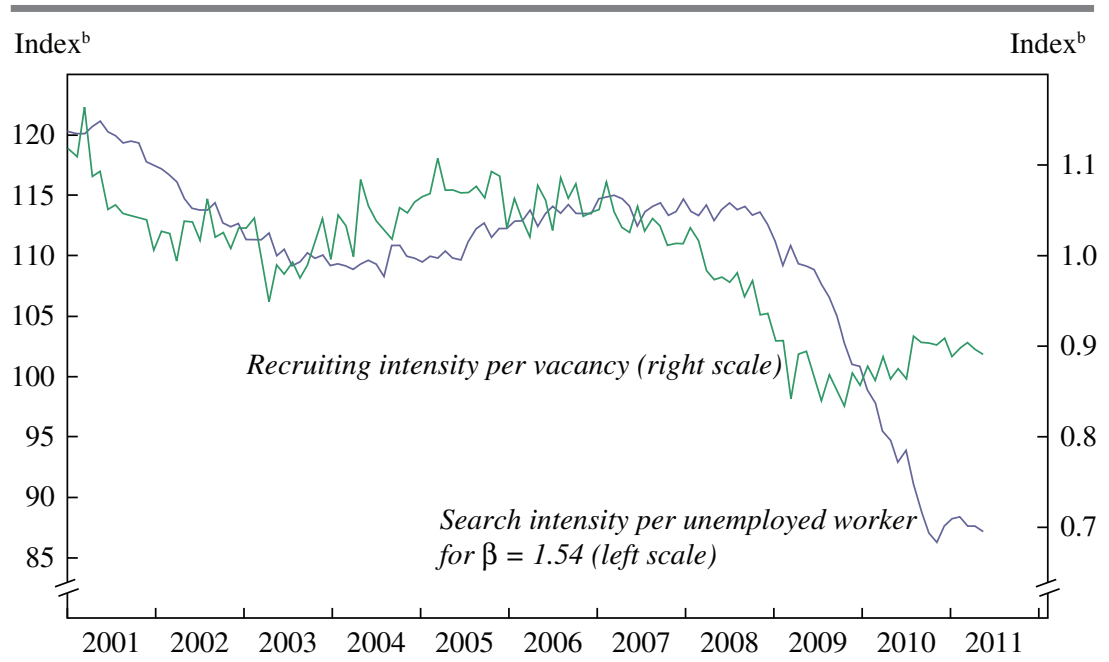

Source: Author's calculations and Davis, Faberman, and Haltiwanger (2010).

a. Based on seasonally adjusted data.

b. Index values are normalized to have a mean of 100 (search intensity index) or 1 (recruiting intensity index) over the sample period.

understanding of fluctuations in job-finding rates, job-filling rates, and related phenomena.

Table 2 reports the results of a simple exercise along these lines: a decomposition of the change in the job-finding rate from 2006 to 2010. As reported in the first row, the empirical job-finding rate fell by $81 \log$ points over this period, an enormous drop. As the next row shows, the standard matching function predicts a drop of only $50 \mathrm{log}$ points. In other words, the fall in the vacancy-unemployment ratio from 2006 to 2010 accounts for only 62 percent of the drop in the observed job-finding rate. This calculation confirms the visual impression given by the path of the residual gap in figure 2 .

The second and third panels in table 2 report the log change in the jobfinding rate implied by the generalized matching function. In constructing the search intensity index, in the second panel I draw on Krueger and Mueller's table 2 to obtain the effect of spell duration on search time. The third panel draws on the estimated spell duration effect in the specification that includes a vector of controls for number of previous interviews. I use estimates based on the weekly recall data in both cases, because they are more robust to the treatment of the reporting error effect. 


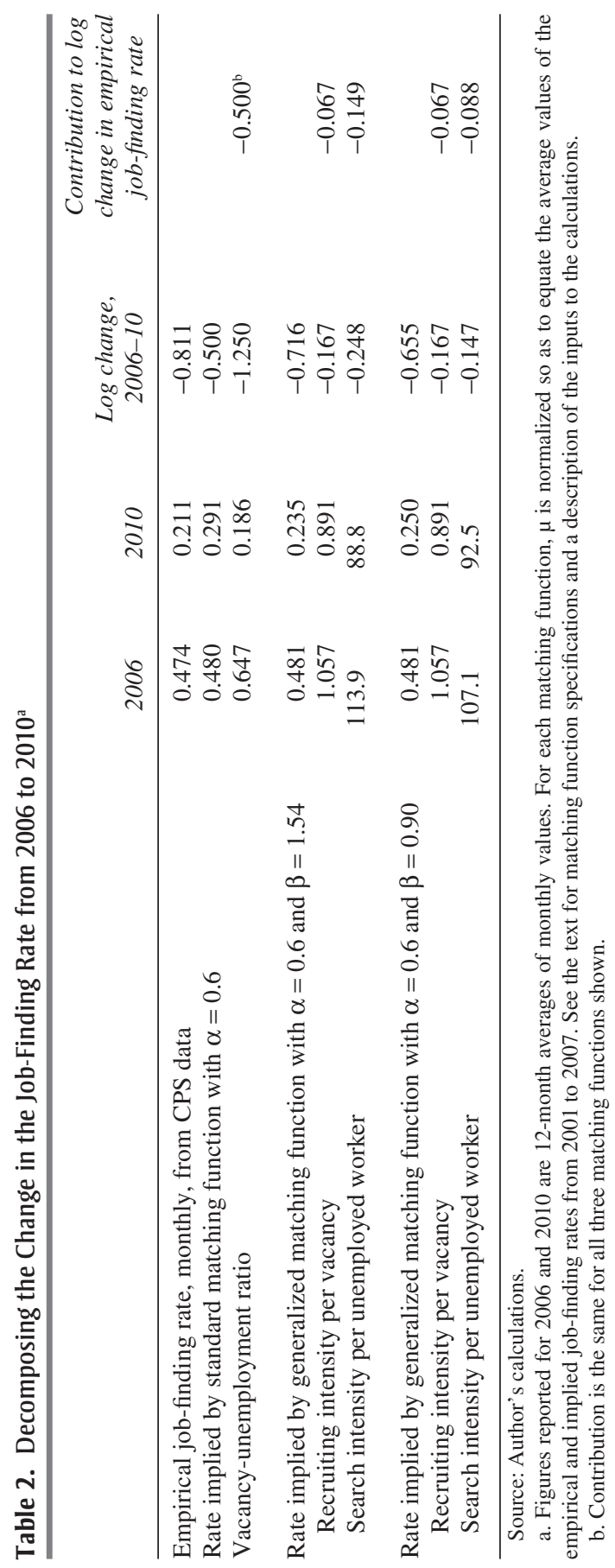


The generalized matching function performs much better in explaining the observed drop in the job-finding rate from 2006 to 2010. Using the higher value of $\beta=1.54$ and comparing the first and fourth rows of table 2, I find that the generalized matching function accounts for 88 percent of the log change in the observed job-finding rate. The last two rows in the second panel show that the recruiting intensity margin accounts for a decline in the job-finding rate of $6.7 \mathrm{log}$ points over this period, and the search intensity margin for a decline of $14.9 \log$ points. Taken together, the two intensity margins erase 70 percent of the residual gap between the observed and the implied job-finding rates that emerges over this period (figure 2). The contribution of the search intensity margin is smaller when the generalized matching function is constructed using $\beta=0.90$ (bottom panel), but the contribution of the intensity margins remains sizable.

To sum up, the results in table 2 point to important roles for variation in search intensity per unemployed worker and recruiting intensity per vacancy in the recent behavior of U.S. job-finding rates. As a corollary, the intensity margins also have important effects on the rate at which employers fill vacant job positions, the evolution of the unemployment rate, and the behavior of the Beveridge curve. I conclude that Krueger and Mueller's estimated effect of spell duration on individual search time has important macroeconomic implications. There is high value to additional research that seeks to more precisely pin down the size of the spell duration effect and to identify the factors that influence its magnitude and possible variation over time. There is also high value to research that explicitly incorporates search and recruiting intensity margins into macroeconomic models of fluctuations in the labor market.

\section{REFERENCES FOR THE DAVIS COMMENT}

Barron, John M., and Wesley Mellow. 1979. "Search Effort in the Labor Market." Journal of Human Resources 14, no. 3: 389-404.

Clark, Andrew E. 2003. "Unemployment as a Social Norm: Psychological Evidence from Panel Data." Journal of Labor Economics 21, no. 2 (April): $323-51$.

Davis, Steven J., R. Jason Faberman, and John C. Haltiwanger. 2010. "The Establishment-Level Behavior of Vacancies and Hiring." Working Paper no. 16265. Cambridge, Mass.: National Bureau of Economic Research.

Davis, Steven J., R. Jason Faberman, John Haltiwanger, Ron Jarmin, and Javier Miranda. 2010. "Business Volatility, Job Destruction, and Unemployment." American Economic Journal: Macroeconomics 2, no. 2 (April): 259-87. 
Gielen, Anne C., and Jan C. van Ours. 2010. "Unhappiness and Job Finding Rates." Institute for the Study of Labor, Bonn, Germany, and Tilburg University, the Netherlands. espe.conference-services.net/resources/321/2017/pdf/ESPE2010_ 0168_paper.pdf.

Hall, Robert E. 2006. "Job Loss, Job Finding, and Unemployment in the U.S. Economy over the Past Fifty Years." NBER Macroeconomics Annual 101-37.

Petrongolo, Barbara, and Christopher A. Pissarides, 2001. "Looking into the Black Box: A Survey of the Matching Function." Journal of Economic Literature 39, no. 2: 390-431.

Pissarides, Christopher A. 2000. Equilibrium Unemployment Theory, 2nd ed. MIT Press.

Shimer, Robert. 2005. "The Cyclical Behavior of Equilibrium Unemployment and Vacancies." American Economic Review 95, no. 1: 25-49.

\section{COMMENT BY}

AYŞEGÜL ŞAHIN In this paper Alan Krueger and Andreas Mueller study job search behavior and the emotional well-being of unemployed workers in New Jersey during the period from fall 2009 to winter 2009-10. The authors designed and conducted a survey of unemployment insurance (UI) claimants in New Jersey, collecting high-frequency longitudinal data on search activity. More than 6,000 unemployed workers were interviewed every week for up to 24 weeks. The strength of the paper is its use of longitudinal data that track search intensity for the same individuals over the course of their unemployment spell. Since workers with different durations of unemployment can be quite different in their characteristics, this type of analysis is superior to examining cross-sectional patterns of job search across those with different durations.

The authors' analysis of their survey findings reveals some interesting patterns regarding job search and emotional well-being among these unemployed workers. Perhaps the most striking finding is that job search time declines sharply over the spell of unemployment: average daily search time falls by 30 minutes over a 12 -week period, about a third of the average search time at the start of an unemployment spell. The study also finds that an unemployment spell is a stressful period for workers. Unemployed workers express dissatisfaction and unhappiness with their lives, and their unhappiness rises the longer they are unemployed.

These and other findings make this a very interesting and timely paper. With more than 13 million workers still unemployed, unemployment remains a major issue for the U.S. labor market. How unemployed workers search for employment opportunities, how their behavior changes depending on 
unemployment insurance (UI) policy, and their emotional state during the spell of unemployment are all important issues that need to be better understood. Krueger and Mueller report some striking facts about unemployment and job search. It will probably take a long time before the patterns they have uncovered in their carefully designed survey are fully understood. Nevertheless, I will attempt to interpret their findings in light of well-known labor market models.

JOB SEARCH BEHAVIOR The first part of the paper focuses mostly on the job search behavior of UI claimants. What should one expect to see in light of existing job search models? Krueger and Mueller mostly focus on the implications of Dale Mortensen's 1977 study. Mortensen's model implies that the amount of time devoted to searching for a job should be constant or rising over the spell of unemployment. The intuition is clear: as the unemployment spell progresses, an unemployed worker's savings become depleted and the expiration of UI benefits gets closer, leading the unemployed worker to search harder. However, various other forces, absent in the standard model, can affect job search time in the opposite direction over the unemployment spell. Human capital depreciation is one of these. As modeled by Lars Ljungqvist and Thomas Sargent (1998), skill depreciation during unemployment could cause a decline in reemployment wages. Consequently, the value of a job to the unemployed worker falls, inducing a decline in job search effort as unemployment duration gets longer. Another possible rationale for declining search effort can be found in stock-flow matching models of the labor market. In that class of models, newly unemployed workers face a pool of job vacancies for which they can apply. Those who exhaust this initial stock of job openings without finding a job then start to monitor the flow of new openings. This stock-flow nature of matching causes a decline in job search time. A third possibility is "learning by searching." Unemployed workers may become more efficient in job search as they gain experience in monitoring, identifying, and applying for job openings. Depending on the quantitative importance of all these factors, search effort could go down or up over the spell of unemployment.

Using their unique survey of UI claimants, Krueger and Mueller provide estimates of job search time over the spell of unemployment. Their figure 4 reveals two striking patterns. First, search effort falls as the unemployment spell progresses. Second, the search time profiles of cohorts of workers who enter the survey at different times in their unemployment spell are approximately parallel lines, with the exception of the very long term unemployed. The question is what might explain these patterns. Are they at odds with what one would expect? I will discuss three potential 
explanations: calendar time effects, stock-flow matching, and the use of a sequential search strategy. In doing so, I will make use of Help Wanted OnLine (HWOL) data from the Conference Board, which are targeted to cover the full universe of all online advertised vacancies posted directly on Internet job boards or through newspaper online ads. ${ }^{1}$ The reason for focusing on job openings is that, as Krueger and Mueller show in their figure 6, almost two-thirds of job search time is spent looking at job advertisements, placing or answering advertisements, and sending out applications. Consequently, the number of job openings is likely to be an important determinant of search time. The HWOL data are ideal for examining the link between job openings and job search time, since they provide information about the location, occupation, required education level, and other aspects of each job listing.

CALENDAR TIME EFFECTS Before discussing calendar time effects, it will be worth recalling a few details about the timing and the administration of the authors' survey. Individuals selected for the study were invited to participate for 12 consecutive weeks. Most of the interviews took place between September 2009 and January 2010. In early January 2010, individuals with 60 weeks or more of UI paid at the start of the study were invited to participate in an extended study. Consequently, two cohorts (the two rightmost cohorts in the authors' figure 4) were interviewed for an additional 12 weeks from January to April 2010. If unemployed workers are spending a great deal of their search time reviewing job listings, the time series of the number of job openings in New Jersey during that period should be an important determinant of job search time. In particular, if there was a decline in the number of job listings, it could explain the declining search time profiles observed in the survey.

To investigate this issue, my figure 1 shows the number of job openings in New Jersey from the HWOL data between September 2009 and May 2010, the period during which all the interviews were conducted. Job openings did decline during the first wave of the survey but recovered after January 2010. The decline is likely to have affected all cohorts, possibly having a calendar time effect on search time profiles. Moreover, for the long-term unemployed who were interviewed for the additional 12 weeks, search time profiles flatten during that period. Such a flattening is consistent with the pickup in job listings that took place in New Jersey in the first 5 months of

1. The HWOL data provide monthly measures of advertised vacancies at the national, regional, state, and metropolitan area levels since July 2005. For more details see www. conferenceboard.org/data/helpwantedonline.cfm. 
Figure 1. Online Job Vacancies, New Jersey, September 2009-May 2010

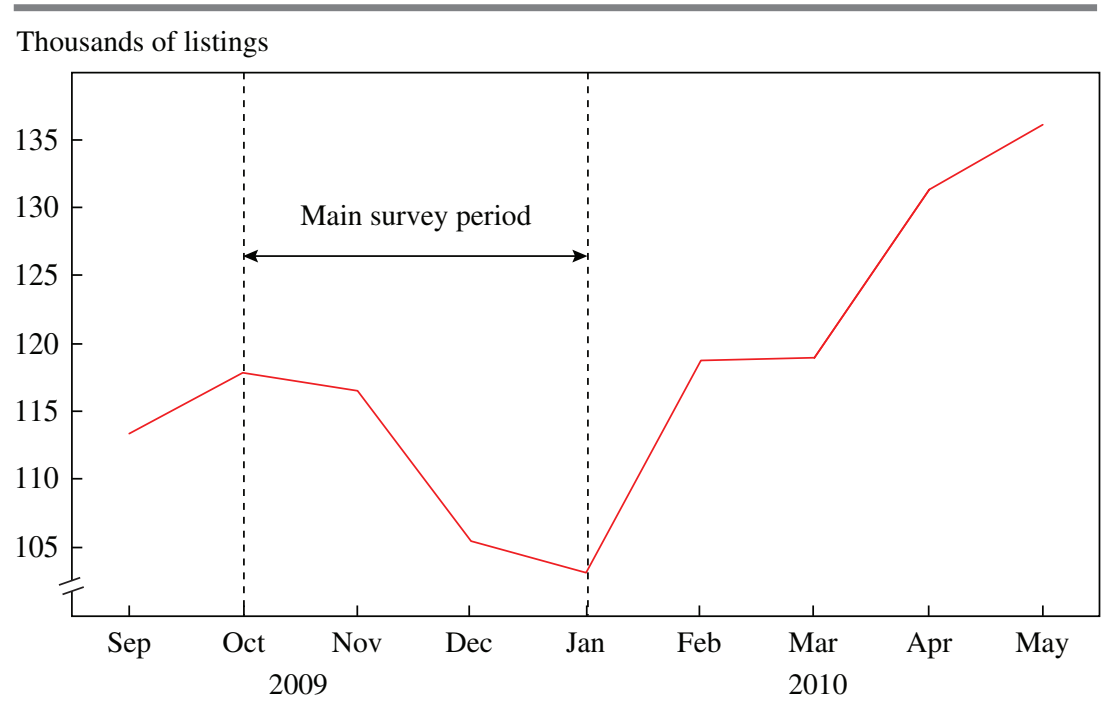

Source: The Conference Board Help Wanted OnLine Data Series.

2010. I argue therefore that calendar time effects are potentially important in affecting the observed job search behavior, since there is pronounced time variation in job openings.

STOCK-FLOW MATCHING Another potential explanation for the decline in job search time is stock-flow matching, which can be described as follows. ${ }^{2}$ Imagine a worker who has recently lost her job. She first observes the current stock of vacancies in the market in which she is searching and applies for a set of jobs drawn from this initial stock. If she finds a suitable vacancy, she can quickly leave unemployment. If not, she must wait for the inflow of new vacancies coming onto the market. Since the stock of job listings generally exceeds the flow, this phenomenon of stock-flow matching is consistent with workers spending more time searching in the early part of the unemployment spell, then reducing their search effort after they exhaust this stock and can only monitor the inflow of new vacancies.

Using the HWOL data, one can examine the stock and the flow of vacancies at a monthly frequency. Before doing so, however, it is important to try to define the labor markets within which individuals are searching, since

2. See Coles and Smith (1998), Coles and Petrongolo (2008), and Ebrahimy and Shimer (2010) for a detailed discussion of stock-flow matching models. 
Figure 2. Total and New Job Listings in Median Occupational Categories, New Jersey, September 2009-May 2010
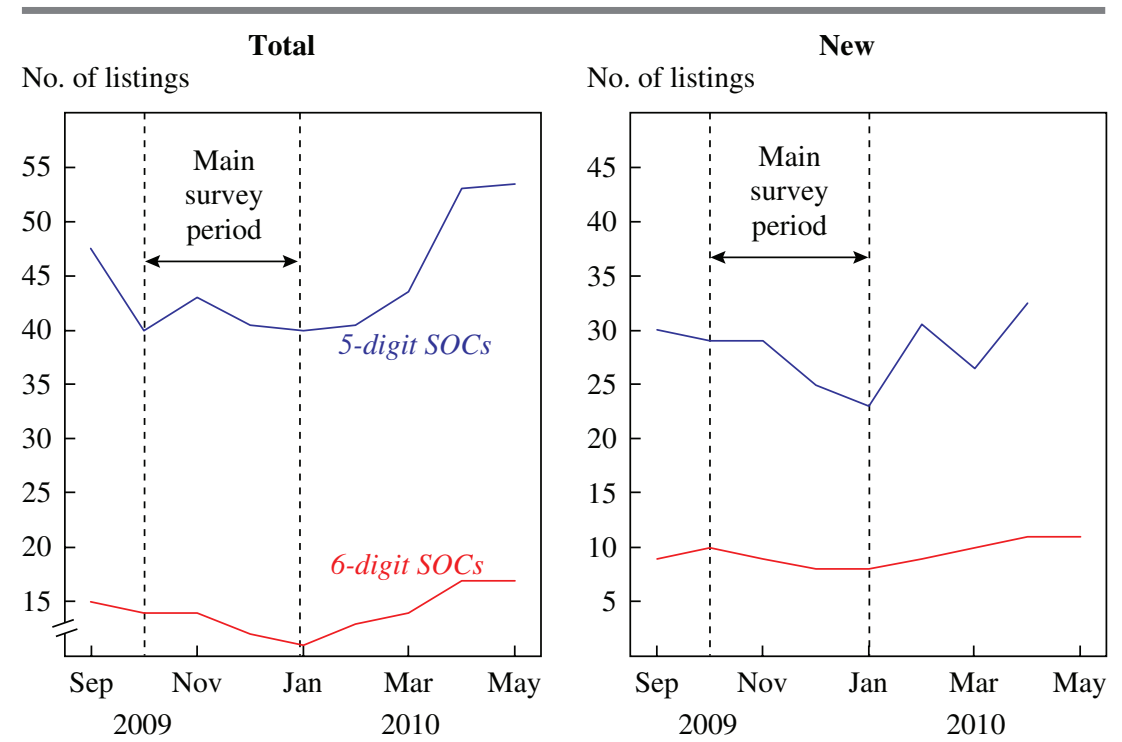

Source: The Conference Board Help Wanted OnLine Data Series.

workers care only about job listings that are potentially relevant for them. Unemployed workers most likely limit their search to a certain geographic area and a particular occupation category. The HWOL data report the occupations of vacancies using the Standard Occupational Classification (SOC) coding system, which at the 5- or 6-digit level defines a reasonable market for job searchers. (For example, at the 5-digit level, the code 21101 stands for counselors, and at the 6-digit level, the code 211013 stands for marriage and family therapists.) Assuming that unemployed workers limit their search to a single 5- or 6-digit occupation classification in their home state, I will therefore examine the stock and flow of vacancies in New Jersey at the 5- and 6-digit SOC levels.

The left panel of my figure 2 shows the stock of job listings for the median 5- and 6-digit SOC codes during the authors' survey period in New Jersey. The stock of job openings for the median 5-digit occupation was around 40 to 50 , implying that for the median unemployed worker there were 40 to 50 relevant job listings. The right panel shows that the flow of vacancies for the median 5-digit occupation is around 25 to 30 : every month there are about 25 to 30 suitable new job listings. This difference between the stock and the flow of vacancies may help explain Krueger and Mueller's finding 
Figure 3. Distribution of Total Listings for 5-Digit SOCs, New Jersey, September 2009-May 2010

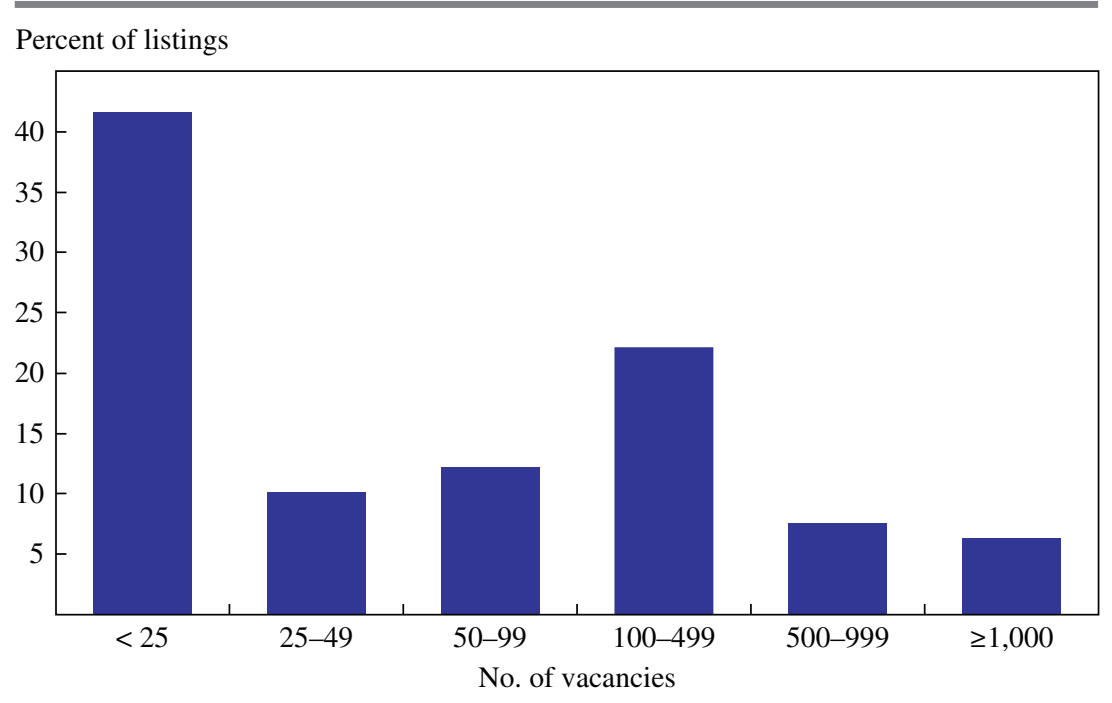

Source: The Conference Board Help Wanted OnLine Data Series.

of a drop in search time from 65 minutes per day to 35 minutes per day over a 12-week period.

SEQUENTIAL JOB SEARCH STRATEGY Both calendar time effects and stockflow matching are consistent with declining search time profiles. However, they do not explain why the search time profiles approximate parallel lines for different cohorts, with the exception of the very long-term unemployed. This feature of the data seems rather puzzling. One possibility is that the different cohorts differ in their characteristics, and Krueger and Mueller show that this is indeed the case. Their figure 7 shows that, possibly because of differences in the timing of layoffs in different industries, cohorts differ markedly in earnings and other characteristics such as industry and education. I expect that unemployed workers with different characteristics will have different average job search times simply because of differences in the number of suitable job vacancies. For example, as my figure 3 shows, from September 2009 to May 2010, 52 percent of 5-digit occupations had fewer than 50 job listings, 12 percent had between 50 and 99 listings, 22 percent had 100 to 499 listings, and 14 percent had 500 listings or more. This wide dispersion in the distribution of vacancies suggests that if different cohorts vary in their characteristics and thus in their suitability for 
jobs in different occupations, this could generate differences in job search time that are independent of the duration of unemployment.

If this is so, then another potential explanation for the parallel lines for different cohorts is one that combines stock-flow matching with the idea that unemployed workers pursue a sequential job search strategy: they search first within the stock of job listings in their preferred labor market in terms of occupation and location; if unsuccessful, they continue to monitor the flow of new listings in the preferred labor market. At some point they also start searching in a less preferred labor market, again looking first at the existing stock of vacancies, and then monitoring new listings in both the preferred market and the new market. The very long term unemployed, finding that all stocks related to their occupations of interest have been depleted, will simply monitor the new listings in various occupations. This sequential strategy would thus lead to a flat search time profile over time.

UNEMPLOYMENT AND HAPPINESS Another important contribution of Krueger and Mueller's survey is their examination of trends in the wellbeing and happiness of unemployed workers over time and during various activities. They find that only a small fraction of UI recipients say they are very satisfied with their lives, compared with almost half of employed workers. Moreover, unemployed workers grow increasingly unhappy the longer they are unemployed. ${ }^{3}$ These findings are consistent with those of a growing literature that links economic conditions and happiness and finds that high unemployment lowers happiness and life satisfaction (see, for example, Di Tella, MacCulloch, and Oswald 2003, Wolfers 2003, and Stevenson and Wolfers 2008). However, in standard macroeconomic models where unemployment is modeled as a temporary loss of wage income, unemployment does not appear to be very costly for the individuals in the model (as discussed by Mukoyama 2010). The reason is that the median unemployment duration in the United States is generally less than 3 months, so that individuals can maintain their consumption during a typical unemployment spell by using their savings. But what are the costs of unemployment that go beyond temporary loss of income? And what is the link between the perceived cost of unemployment and the cost of unemployment implied by economic models?

3. Krueger and Mueller's survey was conducted during the most depressed labor market conditions in the postwar era. The unemployment rate was around 10 percent, and approximately 40 percent of the unemployed had been unemployed for more than 6 months. It is likely that these adverse labor market conditions aggravated the pain of unemployment, with the unemployed becoming increasingly pessimistic about their job-finding prospects as they observed the dismal aggregate labor market conditions. 
An abundance of evidence indicates that displaced workers who had previously enjoyed long job tenure experience large and enduring earnings losses upon reemployment (see Couch and Placzek 2010, Jacobson, LaLonde, and Sullivan 1993, Neal 1995, and Farber 2005). Workers losing jobs in a depressed labor market experience especially large losses (Jacobson, LaLonde, and Sullivan 1993). Unemployment also has longlasting effects on young workers. The evidence surveyed by Till von Wachter (2010) suggests that the consequences of entering the labor market in a recession are severe in both the short and the long run. In the short run, labor market entrants and young workers suffer more from larger increases in unemployment and layoffs than the average worker. According to Philip Oreopoulos, von Wachter, and Andrew Heisz (2008), part of the decline in earnings arises because young workers entering the labor market in a recession accept jobs that they otherwise would reject. Lisa Kahn (2010) finds in addition that cohorts who graduate from college during poor economic conditions tend to find work in occupations that pay lower wages than the occupations they would otherwise enter, which suggests that these workers find it difficult to shift into better jobs after the economy picks up. As a result, some individuals never recover from the initial shock and experience persistent negative effects. In addition to these earnings losses, Daniel Sullivan and von Wachter (2009) find major health consequences for displaced workers: high-seniority male workers who were displaced in Pennsylvania in the 1970s and 1980s had 10 to 15 percent higher mortality rates than would otherwise have been expected, even 20 years after displacement. Models of unemployment that abstract from these long-lasting earnings or health consequences are naturally likely to underestimate the costs of unemployment.

It is important to emphasize that the costs of unemployment go beyond economic costs. Loss of a job is often associated with loss of one's identity, self-esteem, self-confidence, and sense of security. Unemployment can also cause stress in the household by causing a shift in the allocation of household responsibilities. As discussed by Krueger and Mueller, job search assistance might be helpful for the unemployed in overcoming feelings of anxiety and sadness associated with job search.

To conclude, Krueger and Mueller's paper uncovers new information about the job search behavior of the unemployed. Their unique dataset can be useful in improving our understanding of unemployment and potentially devising ways of helping unemployed workers in their job search. For example, one potential intervention that could be very beneficial in improving the job search and matching process would be to link UI records 
with the HWOL data. The UI records provide an estimate of the number and characteristics of unemployed workers searching for jobs, whereas the HWOL data give an estimate of the composition and number of job listings. Providing the unemployed with an estimate of their job finding prospects in a particular location and occupation would help them direct their search. Moreover, using the HWOL data in combination with the UI records could help in directing training into particular fast-growing occupations.

\section{REFERENCES FOR THE ŞAHIN COMMENT}

Coles, Melvyn, and Barbara Petrongolo. 2008. "A Test between Stock-Flow Matching and the Random Matching Function Approach." International Economic Review 49, no. 4: 1113-41.

Coles, Melvyn G., and Eric Smith. 1998. "Marketplaces and Matching." International Economic Review 39, no. 1: 239-55.

Couch, Kenneth A., and Dana W. Placzek. 2010. "Earnings Losses of Displaced Workers Revisited." American Economic Review 100: 572-89.

Di Tella, Rafael, Robert J. MacCulloch, and Andrew J. Oswald. 2003. "The Macroeconomics of Happiness." Review of Economics and Statistics 85, no. 4: 809-27.

Ebrahimy, Ehsan, and Robert Shimer. 2010. "Stock-Flow Matching." Journal of Economic Theory 145, no. 4: 1325-53.

Farber, Henry S. 2005. "What Do We Know about Job Loss in the United States? Evidence from the Displaced Workers Survey, 1984-2004." Economic Perspectives (Spring): 13-28.

Jacobson, Louis S., Robert J. LaLonde, and Daniel G. Sullivan. 1993. "Earnings Losses of Displaced Workers." American Economic Review 83, no. 4: 685-709.

Kahn, Lisa B. 2010. "The Long-Term Labor Market Consequences of Graduating from College in a Bad Economy." Labour Economics 17, no. 2: 303-16.

Ljungqvist, Lars, and Thomas J. Sargent. 1998. "The European Unemployment Dilemma." Journal of Political Economy 106, no. 3: 514-50.

Mortensen, Dale T. 1977. "Unemployment Insurance and Job Search Decisions." Industrial and Labor Relations Review 30, no. 4: 505-17.

Mukoyama, Toshihiko. 2010. "Understanding the Welfare Effects of Unemployment Insurance Policy in General Equilibrium." University of Virginia.

Neal, Derek. 1995. "Industry-Specific Human Capital: Evidence from Displaced Workers." Journal of Labor Economics 13, no. 4: 653-77.

Oreopoulos, Philip, Till von Wachter, and Andrew Heisz. 2008. "The Short- and Long-Term Career Effects of Graduating in a Recession: Hysteresis and Heterogeneity in the Market for College Graduates." IZA Discussion Paper no. 3578. Bonn: Institute for the Study of Labor.

Stevenson, Betsey, and Justin Wolfers. 2008. "Economic Growth and Happiness: Reassessing the Easterlin Paradox." BPEA, no. 1: 1-87. 
Sullivan, Daniel, and Till von Wachter. 2009. "Job Displacement and Mortality: An Analysis Using Administrative Data." Quarterly Journal of Economics 124, no. 3: $1265-1306$.

Von Wachter, Till. 2010. "Avoiding a Lost Generation: How to Minimize the Impact of the Great Recession on Young Workers." Presented at a hearing of the Joint Economic Committee of the U.S. Congress, May 26.

Wolfers, Justin. 2003. "Is Business Cycle Volatility Costly? Evidence from Surveys of Subjective Well-Being." International Finance 6, no. 1: 1-26.

GENERAL DISCUSSION Jennifer Hunt found it interesting that the authors observed no spike in job search, and no spike in receipt of offers, at exhaustion of benefits. She questioned nevertheless whether the existence of a spike in acceptance of job offers at that point could be excluded. It might be that the typical worker receives offers periodically and rejects them if they are unsatisfactory, but when benefit exhaustion looms and desperation sets in, the worker might accept almost any offer received; this could occur even without an increase in searching or an increase in the number of offers coming in.

Justin Wolfers congratulated the authors for compiling a valuable new set of data but highlighted what he saw as a puzzle in the data. The authors found that happiness declines through the duration of unemployment. Given that recessions generally cause unhappiness, and that the most recent recession was one in which long-term unemployment was very high, happiness should therefore have fallen more in this recession than in previous ones. Yet the only high-frequency happiness data available, from the Behavior Risk Factor Survey, do not show any indication of such a "happiness recession."

David Romer observed from the authors' figures 3 and 4 that reported time spent on job search and the probability of reporting spending time on job search the previous day depend, to a first approximation, on time since the respondent began participating in the survey. He saw three possible explanations. It could in principle be due to the calendar timeline, but the effects were enormous and the authors had done a good job of ruling this out. The cohorts could also be extremely different from each other. Or, finally, there could be substantial reporting error. The last of these stood out as the natural explanation, and rejecting it would require documenting very large differences across cohorts. The job-finding rate showed a similar phenomenon: respondents had a high likelihood of finding a job in the first week of participation in the survey regardless of how long they had been 
unemployed. That, too, pointed to selection or reporting error, rather than to differences across cohorts, as an important driver of the results.

Given Romer's observation, Steven Davis found it reassuring that an effect of spell duration remains even when one includes an extensive set of controls for number of interviews previously completed by the respondent. Davis went on to note that the paper drew attention to some truly enormous differences in reported measures of subjective well-being between employed and unemployed workers-not a surprising finding but important nonetheless. If this was not simply an income effect, its explanation could have implications for policies serving unemployed workers. For example, if people derive self-esteem from engaging in productive activity for compensation, then the unemployed might be better off if required to perform public service in return for UI benefits, or at least given the option. Davis was also interested in seeing a careful treatment of response rates, search time, and search effectiveness and how these varied with reported measures of subjective well-being. It seemed to him likely that a worker who is depressed would find it hard to get motivated about searching for a job. In that case, research linking these measures of subjective well-being to outcomes in both the labor market and the macroeconomy could be worthwhile.

Michael Klein noted that the recent recession and its aftermath have been unique in that more workers were threatened with an imminent loss of housing than in past recessions; this would have been especially true during the period when the authors' survey was conducted. There may also have been some stratification by income: lower-income workers might not have faced as high a threat of housing loss as those with higher incomes, who were more likely to have been able to buy a home and later find themselves underwater. The added worry of possibly losing one's home would surely raise a respondent's stress level significantly.

Matthew Weinzierl found it interesting that the things that made respondents happy included some that one would expect, such as exercising and socializing, but at least one that was surprising, namely, attending a job training program. He wondered what this might indicate about the impact of loneliness on happiness during a period of unemployment.

Robert Hall drew attention to a paper by the same authors that showed two things about reservation wages: they tend to be close to the previous wage earned, and they do not decline with duration of unemployment. The paper also showed that the number of offers received by the average job seeker is small, because some get a few offers and most get zero. Also, most offers received are accepted. Thus, the typical experience is to go for 
a long time without getting any offers, and then get an offer and accept it. As a consequence, most job seekers do not get enough offers during an unemployment spell to learn anything from them. That put a somewhat different perspective on the question of how much adjustment can occurmost of the typical spell consists in waiting for an offer.

John Haltiwanger noted that when one analyzes closely related administrative data, such as UI wage records data, it becomes clear that what matters for the change in wages following a separation is the duration of joblessness. Displacement, although emphasized in some of the earlier literature, is not so critical, but it, too, matters. The workers who take the biggest wage cuts tend to be those who have had longer spells of joblessness. 